Supporting Information for:

\title{
A Multifunctional Reagent Designed for the Site-Selective Amination of Pyridines
}

Patrick S. Fier, * Suhong Kim, and Ryan D. Cohen 


\section{General experimental details}

Reagents and common substrates were purchased from commercial suppliers and used as received. Noncommercially available substrates were procured from Merck's building block collection and used as received. Anhydrous dioxane was purchased from Sigma-Aldrich and used as received. All reactions were carried out on the benchtop without special precautions towards air or moisture. NMR chemical shifts are reported in ppm and referenced to residual solvent peaks. Coupling constants are reported in hertz. All 2D NMR data were recorded using a $600 \mathrm{MHz}$ Bruker AVANCE III HD spectrometer equipped with a 5-mm liquid helium-cooled, triple resonance (HCN) cryoprobe. ${ }^{1} \mathrm{H} /{ }^{13} \mathrm{C} \mathrm{HMBC},{ }^{1} \mathrm{H} /{ }^{15} \mathrm{~N} \mathrm{HMBC}$, and ${ }^{1} \mathrm{H} /{ }^{13} \mathrm{C}$ LRHSQMBC NMR spectra were acquired with J-optimizations of $8 \mathrm{~Hz}, 5 \mathrm{~Hz}$ and $3 \mathrm{~Hz}$, respectively. A mixing time of 500 ms was employed for the NOESY spectral acquisition.

\section{General procedure for the $\mathbf{C}-\mathbf{2}$ functionalization of pyridines}

To a screw-cap vial with a magnetic stirbar was added pyridine substrate (3, 1.0 equiv), N,Obis(trimethylsilyl)acetamide (3.0 equiv), and anhydrous dioxane ( $4 \mathrm{~mL}$ per mmol of $3 ; 0.25 \mathrm{M}$ ). To the resulting mixture was added solid 2 (1.5 equiv), then the vial was sealed and heated at $80{ }^{\circ} \mathrm{C}$ for $3 \mathrm{~h}$. The reaction mixture was cooled to ambient temperature, diluted with glacial $\mathrm{AcOH}(4 \mathrm{~mL}$ per mmol of 3 , equal volume as dioxane), and $\mathrm{Zn}$ powder (5.0 equiv) was added at once (note: a mild exotherm was observed on $5 \mathrm{mmol}$ scale). The resulting slurry was stirred vigorously for $3 \mathrm{~h}$ at ambient temperature. The mixture was concentrated to dryness, and the product was purified on silica gel.

For cases where assay yields of the products were determined, the entire reaction mixture was diluted in a volumetric flask with $3: 1 \mathrm{MeCN}: 0.1 \%$ aqueous $\mathrm{H}_{3} \mathrm{PO}_{4}$ and the resulting solution was analyzed on an UPLC instrument calibrated to the product using the method shown below.

\begin{tabular}{|l|l|}
\hline Column: & $\begin{array}{l}\text { Waters Acquity UPLC BEH C18 }(100 \mathrm{~mm} \times 2.1 \mathrm{~mm} \times 1.7 \mu \mathrm{m} \\
\text { Part Number } 186002352\end{array}$ \\
\hline Mobile Phase: & $\mathrm{A}=0.1 \% \mathrm{H}_{3} \mathrm{PO}_{4}(\mathrm{aq})$ \\
& $\mathrm{B}=$ Acetonitrile \\
\hline Gradient: & $10-95 \% \mathrm{~B}$ in 4 min and hold at $95 \% \mathrm{~B}$ for 1 minute \\
\hline Flow rate: & $0.5 \mathrm{~mL} / \mathrm{min}$ \\
\hline Run Time: & 5 minutes (2.5 minute re-equilibration) \\
\hline Temperature: & $40^{\circ} \mathrm{C}$ \\
\hline Injection Volume: & $1-2 \mu \mathrm{L}$ \\
\hline Wavelength: & $210 \mathrm{~nm}$ \\
\hline
\end{tabular}




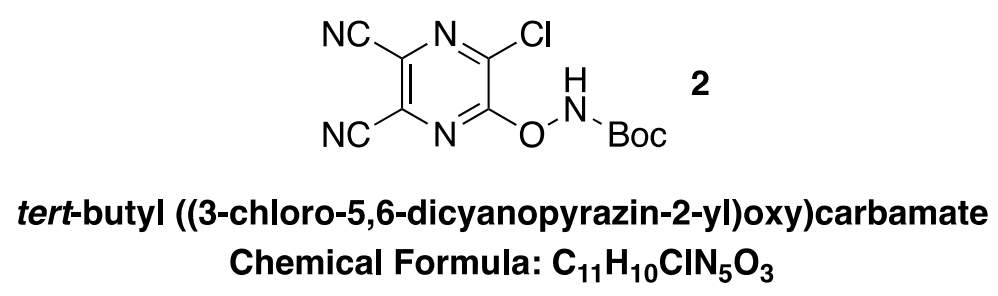

Exact Mass: 295.0472

Into a $10 \mathrm{~L}$ 4-necked round-bottom flask was added 5,6-dichloropyrazine-2,3-dicarbonitrile (400.00 g, $2010.2 \mathrm{mmol}, 1.00$ equiv), BocNHOH (294.41 g, $2211.2 \mathrm{mmol}, 1.10$ equiv), and THF (4.0 L). The mixture was cooled to $-20^{\circ} \mathrm{C}$ and $\mathrm{Et}_{3} \mathrm{~N}(223.75 \mathrm{~g}, 2211.2 \mathrm{mmol}, 1.10$ equiv) was added dropwise over $30 \mathrm{~min}$. The resulting solution was stirred for $10 \mathrm{~min}$ at $-20^{\circ} \mathrm{C}$, the solids were filtered off, and the filtrate concentrated. The residue was purified on silica gel, eluting with ethyl acetate in hexanes (0-20\%). The crude product was then dissolved in DCM $(3 \mathrm{~mL} / \mathrm{g})$, and hexanes $(12 \mathrm{~mL} / \mathrm{g})$ was slowly added as anti-solvent to form crystalline 2 . The solid was collected, washed with hexanes, and dried under vacuum with a nitrogen stream to afford 2 (205 g, 35\%) as a white solid

${ }^{1} \mathrm{H}$ NMR $\left(600 \mathrm{MHz}, 1,4-\right.$ Dioxane- $\left.d_{8}\right) \delta 10.24(\mathrm{~s}, 1 \mathrm{H}), 1.48$ (s, 9H).

${ }^{13} \mathrm{C}$ NMR $\left(151 \mathrm{MHz}, 1,4-\right.$ Dioxane- $\left.d_{8}\right) \delta 158.4,155.6,140.9,129.8,127.5,113.4,113.2,84.1,28.3$.

ESI MS (negative detection): $294.10(\mathrm{M}-\mathrm{H})$ 


\section{Physical Safety Assessment of 2}

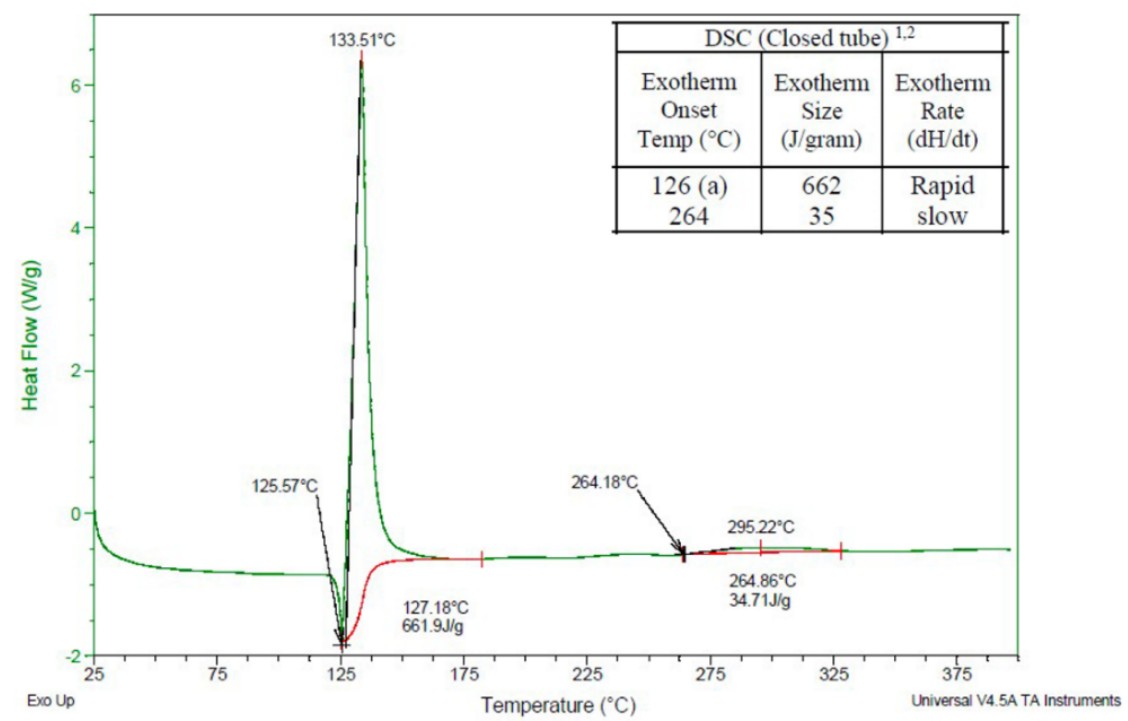

1. A Potential Thermal Hazard identified by DSC is a $>50 \mathrm{~J} / \mathrm{g}$ exotherm within $60^{\circ} \mathrm{C}$ of the larger of (max operating temp. including adiabatic temp. rise from desired process, or max jacket temp.) or a $>400 \mathrm{~J} / \mathrm{g}$ exotherm at any temp 2. Standard run parameters for DSC: $5^{\circ} \mathrm{C} / \mathrm{min}$ up to $350^{\circ} \mathrm{C}$ (Gold plated high pressure bomb).

Yoshida Correlation

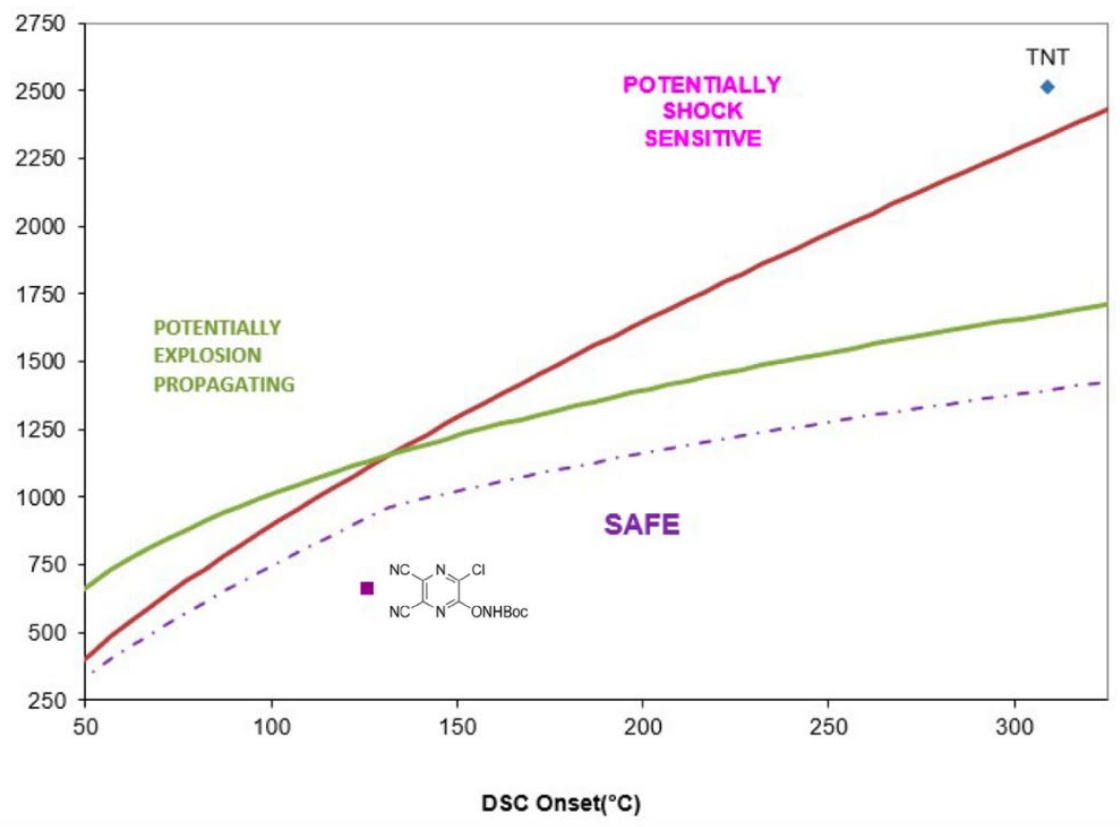

We recommend that typial safety precautions should be taken with the use of $\mathbf{2}$. While no exothermic events were observed in the use of 2 in the C-2 amination reactions, as with all reactions, we recommend that safety tests be conducted with specific substrates of interest if $\mathbf{2}$ is intended to be used on large-scale. 


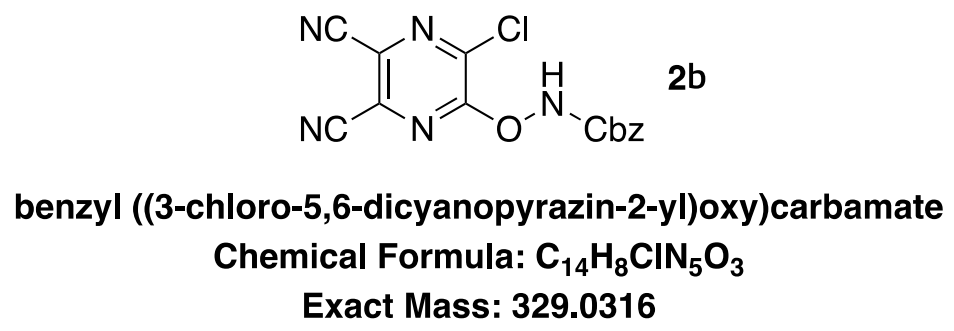

To a $100 \mathrm{~mL}$ round-bottom flask was added 5,6-dichloropyrazine-2,3-dicarbonitrile (3.00 g, $15.1 \mathrm{mmol}, 1.00$ eq.), $\mathrm{CbzNHOH}(2.77 \mathrm{~g}, 16.6 \mathrm{mmol}, 1.10$ eq.), and THF (30 mL). The mixture was cooled in an ice bath and triethylamine $(1.68 \mathrm{~g}, 16.6 \mathrm{mmol}, 1.10 \mathrm{eq}$.) was added dropwise over 3 minutes. The resulting solution was stirred for $10 \mathrm{~min}$ at $0-5{ }^{\circ} \mathrm{C}$. The solids were filtered off, and the filtrate concentrated. The residue was purified on silica gel, eluting with ethyl acetate in hexanes (0-20\%) to afford $\mathbf{2 b}(2.05 \mathrm{~g}, 41 \%)$ as a white solid

${ }^{1} \mathrm{H}$ NMR (500 MHz, CD $\left.3 \mathrm{CN}\right) \delta 9.71(\mathrm{~s}, 1 \mathrm{H}), 7.39(\mathrm{~m}, 5 \mathrm{H}), 5.24(\mathrm{~s}, 3 \mathrm{H})$.

${ }^{13} \mathrm{C}$ NMR $\left(126 \mathrm{MHz}, \mathrm{CD}_{3} \mathrm{CN}\right) \delta 158.6,156.9,141.5,136.6,130.0,129.65,129.50,129.0,127.7,113.57$, 113.53, 69.2 .

\author{
$\overbrace{\mathrm{N}^{-}}^{\mathrm{NC}}{ }_{\mathrm{N}_{T S}}^{\mathrm{Cl}} 2 \mathrm{C}$ \\ $\mathrm{N}$-((3-chloro-5,6-dicyanopyrazin-2-yl)oxy)-4-methylbenzenesulfonamide \\ Chemical Formula: $\mathrm{C}_{13} \mathrm{H}_{8} \mathrm{CIN}_{5} \mathrm{O}_{3} \mathrm{~S}$ \\ Exact Mass: 349.0036
}

To a $100 \mathrm{~mL}$ round-bottom flask was added 5,6-dichloropyrazine-2,3-dicarbonitrile $(1.79 \mathrm{~g}, 9.00 \mathrm{mmol}, 1.00$ eq.), TsNHOH (1.85 g, $9.90 \mathrm{mmol}, 1.10$ eq.), and THF (20 mL). The mixture was cooled in an ice bath and triethylamine $(1.00 \mathrm{~g}, 9.90 \mathrm{mmol}, 1.10 \mathrm{eq}$.) was added dropwise over 3 minutes. The resulting solution was stirred for $10 \mathrm{~min}$ at $0-5^{\circ} \mathrm{C}$. The solids were filtered off, and the filtrate concentrated. The residue was purified on silica gel, eluting with ethyl acetate in hexanes $(0-70 \%)$ to afford $2 \mathrm{c}(1.13 \mathrm{~g}, 36 \%)$ as a white solid

${ }^{1} \mathrm{H}$ NMR $\left(500 \mathrm{MHz}, \mathrm{CD}_{3} \mathrm{CN}\right) \delta 9.70(\mathrm{~s}, 1 \mathrm{H}), 7.90(\mathrm{~d}, J=8.4 \mathrm{~Hz}, 2 \mathrm{H}), 7.50(\mathrm{~d}, J=8.1 \mathrm{~Hz}, 2 \mathrm{H}), 2.48(\mathrm{~s}, 3 \mathrm{H})$.

${ }^{13} \mathrm{C}$ NMR $\left(126 \mathrm{MHz}, \mathrm{CD}_{3} \mathrm{CN}\right) \delta 157.9,147.6,141.5,133.6,131.1,130.0,129.8,127.7,113.46,113.43$, 21.7. 


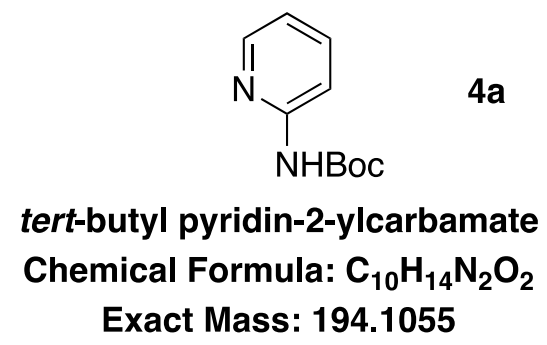

The compound was prepared using the standard procedure on $0.5 \mathrm{mmol}$ scale. The assay yield was determined by UPLC to be $93 \%$ based on calibration with an authentic standard. NMR data for in-situ characterization at the end of reaction in 1:1 1,4-Dioxane- $d_{8} / \mathrm{CD}_{3} \mathrm{COOD}$ is provided below.

${ }^{1} \mathrm{H}$ NMR $\left(600 \mathrm{MHz}, 1: 1\right.$ 1,4-Dioxane- $\left.d_{8} / \mathrm{CD}_{3} \mathrm{COOD}\right) \delta 8.28$ (ddd, $J=5.6,1.9,0.8 \mathrm{~Hz}, 1 \mathrm{H}$ ), 7.94 (ddd, $J=$ 9.0, 7.4, 1.9 Hz, 1H), 7.67 (d, $J=8.6 \mathrm{~Hz}, 1 \mathrm{H}), 7.19$ (ddd, $J=7.0,5.6,1.1 \mathrm{~Hz}, 1 \mathrm{H}), 1.45(\mathrm{~s}, 9 \mathrm{H})$.

${ }^{13} \mathrm{C}$ NMR (151 MHz, 1:1 1,4-Dioxane- $\left.d_{8} / \mathrm{CD}_{3} \mathrm{COOD}\right) \delta$ 154.6, 152.2, 145.3, 143.5, 120.2, 115.8, 84.3, 28.4 .

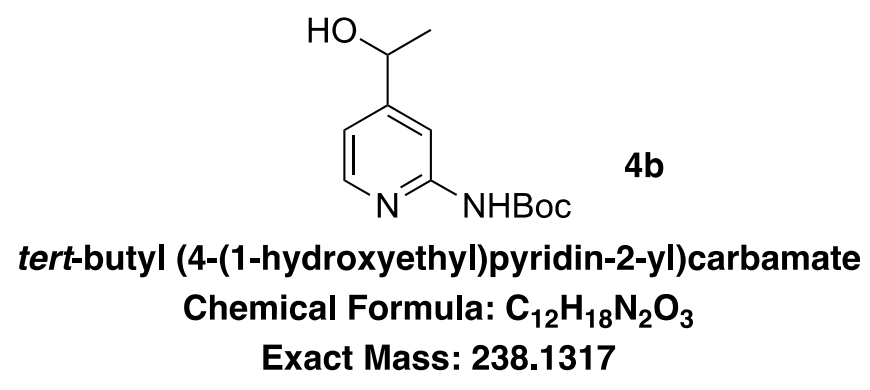

The compound was prepared using the standard procedure on $0.5 \mathrm{mmol}$ scale. The product was purified on silica gel with a gradient of $0-10 \% \mathrm{MeOH}$ in $\mathrm{DCM}$, and obtained as a colorless liquid in $71 \%$ yield.

${ }^{1} \mathrm{H}$ NMR $\left(500 \mathrm{MHz}, \mathrm{CD}_{3} \mathrm{CN}\right) \delta 8.18(\mathrm{~s}, 1 \mathrm{H}), 8.16(\mathrm{~d}, J=5.3 \mathrm{~Hz}, 1 \mathrm{H}), 7.90(\mathrm{~d}, J=1.6 \mathrm{~Hz}, 1 \mathrm{H}), 6.98(\mathrm{dd}, J=$ $5.2,1.6 \mathrm{~Hz}, 1 \mathrm{H}), 4.79(\mathrm{q}, J=6.6 \mathrm{~Hz}, 1 \mathrm{H}), 3.40(\mathrm{~s}, 1 \mathrm{H}), 1.51(\mathrm{~s}, 9 \mathrm{H}), 1.37(\mathrm{~d}, J=6.6 \mathrm{~Hz}, 3 \mathrm{H})$.

${ }^{13} \mathrm{C}$ NMR $\left(126 \mathrm{MHz}, \mathrm{CD}_{3} \mathrm{CN}\right) \delta 159.2,153.5,148.6,116.4,109.4,81.2,69.1,28.4,25.4$.

ESI MS: $239.2(\mathrm{M}+\mathrm{H})$ 


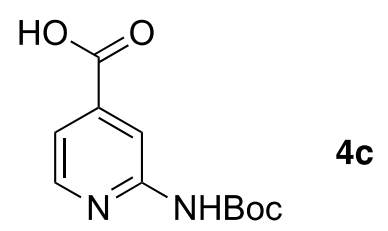

\section{2-((tert-butoxycarbonyl)amino)isonicotinic acid}

Chemical Formula: $\mathrm{C}_{11} \mathrm{H}_{14} \mathrm{~N}_{2} \mathrm{O}_{4}$

Exact Mass: 238.0954

The compound was prepared using the standard procedure on $0.5 \mathrm{mmol}$ scale. The product was purified on silica gel with a gradient of $0-10 \% \mathrm{MeOH}$ in $\mathrm{DCM}$, and obtained as a white solid in $85 \%$ yield.

${ }^{1} \mathrm{H}$ NMR $\left(500 \mathrm{MHz}, \mathrm{DMSO}-\mathrm{d}_{6}\right) \delta 13.57(\mathrm{~s}, 1 \mathrm{H}), 10.02(\mathrm{~s}, 1 \mathrm{H}), 8.39(\mathrm{dd}, J=5.1,0.8 \mathrm{~Hz}, 1 \mathrm{H}), 8.30(\mathrm{t}, J=1.2$ $\mathrm{Hz}, 1 \mathrm{H}), 7.42(\mathrm{dd}, J=5.0,1.4 \mathrm{~Hz}, 1 \mathrm{H}), 1.48(\mathrm{~s}, 9 \mathrm{H})$.

${ }^{13} \mathrm{C}$ NMR $\left(126 \mathrm{MHz}, \mathrm{DMSO}-d_{6}\right) \delta$ 166.2, 153.4, 152.7, 148.8, 140.0, 117.2, 111.6, 79.9, 28.0.

ESI MS: $239.1(\mathrm{M}+\mathrm{H})$

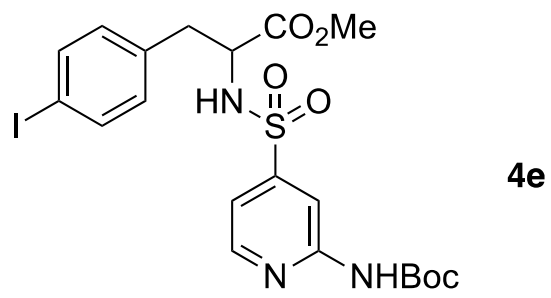

methyl 2-((2-((tert-butoxycarbonyl)amino)pyridine)-4-sulfonamido)-3-(4-iodophenyl)propanoate Chemical Formula: $\mathrm{C}_{20} \mathrm{H}_{24} \mathrm{IN}_{3} \mathrm{O}_{6} \mathrm{~S}$

Exact Mass: 561.0430

The compound was prepared using the standard procedure on $0.5 \mathrm{mmol}$ scale. The product was purified on silica gel with a gradient of $0-100 \%$ EtOAc in hexanes, and obtained as a white solid in $40 \%$ yield.

${ }^{1} \mathrm{H}$ NMR (500 MHz, DMSO- $\left.d_{6}\right) \delta 10.27(\mathrm{~s}, 1 \mathrm{H}), 8.55(\mathrm{~d}, J=9.1 \mathrm{~Hz}, 1 \mathrm{H}), 8.40(\mathrm{~d}, J=2.4 \mathrm{~Hz}, 1 \mathrm{H}), 7.84(\mathrm{~d}, J$ $=8.9 \mathrm{~Hz}, 1 \mathrm{H}), 7.78(\mathrm{dd}, J=8.9,2.4 \mathrm{~Hz}, 1 \mathrm{H}), 7.54-7.49(\mathrm{~m}, 2 \mathrm{H}), 6.97-6.91(\mathrm{~m}, 2 \mathrm{H}), 4.03(\mathrm{td}, J=9.4,5.6$ $\mathrm{Hz}, 1 \mathrm{H}), 3.44(\mathrm{~s}, 3 \mathrm{H}), 2.91$ (dd, $J=13.8,5.5 \mathrm{~Hz}, 1 \mathrm{H}), 2.71$ (dd, $J=13.8,9.5 \mathrm{~Hz}, 1 \mathrm{H}), 1.49(\mathrm{~s}, 9 \mathrm{H})$.

${ }^{13} \mathrm{C}$ NMR $\left(126 \mathrm{MHz}\right.$, DMSO- $\left.d_{6}\right) \delta 171.1,155.0,152.4,146.1,136.84,136.19,136.00,131.6,130.8,111.4$, 92.5, 80.3, 56.9, 52.0, 36.9, 28.0.

ESI MS: $562.1(\mathrm{M}+\mathrm{H})$ 


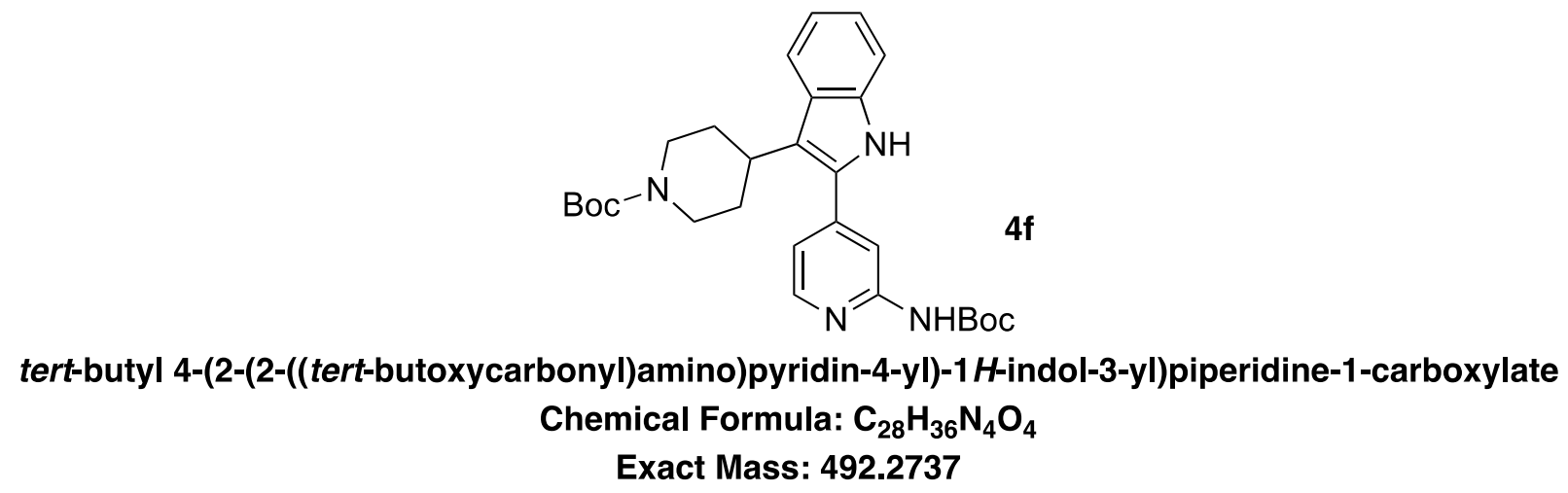

The compound was prepared using the standard procedure on $0.5 \mathrm{mmol}$ scale. The product was purified on silica gel with a gradient of $0-100 \%$ EtOAc in hexanes, and obtained as a pale yellow solid in $64 \%$ yield.

${ }^{1} \mathrm{H}$ NMR (500 MHz, DMSO-d6) $\delta 11.33(\mathrm{~s}, 1 \mathrm{H}), 9.89(\mathrm{~s}, 1 \mathrm{H}), 8.34(\mathrm{~d}, J=5.2 \mathrm{~Hz}, 1 \mathrm{H}), 8.03(\mathrm{~s}, 1 \mathrm{H}), 7.64(\mathrm{~d}$, $J=8.1 \mathrm{~Hz}, 1 \mathrm{H}), 7.40(\mathrm{~d}, J=8.1 \mathrm{~Hz}, 1 \mathrm{H}), 7.18(\mathrm{dd}, J=5.2,1.5 \mathrm{~Hz}, 1 \mathrm{H}), 7.13(\mathrm{t}, J=7.3 \mathrm{~Hz}, 1 \mathrm{H}), 7.03-6.96$ $(\mathrm{m}, 1 \mathrm{H}), 4.09(\mathrm{~d}, J=12.9 \mathrm{~Hz}, 2 \mathrm{H}), 3.21(\mathrm{dd}, J=14.1,10.4 \mathrm{~Hz}, 1 \mathrm{H}), 2.82(\mathrm{~s}, 2 \mathrm{H}), 2.09(\mathrm{qd}, J=12.7,4.1 \mathrm{~Hz}$, $2 \mathrm{H}), 1.73(\mathrm{~d}, \mathrm{~J}=13.0 \mathrm{~Hz}, 2 \mathrm{H}), 1.49(\mathrm{~s}, 9 \mathrm{H}), 1.45(\mathrm{~s}, 9 \mathrm{H})$.

${ }^{13} \mathrm{C}$ NMR $\left(126 \mathrm{MHz}\right.$, DMSO-d $\left.d_{6}\right) \delta 154.1,152.93,152.81,148.2,141.8,136.8,131.6,126.5,122.0,120.4$, $118.8,117.50,117.37,111.91,111.45,79.7,78.5,34.1,31.6,28.13,28.01$.

ESI MS: $493.4(\mathrm{M}+\mathrm{H})$

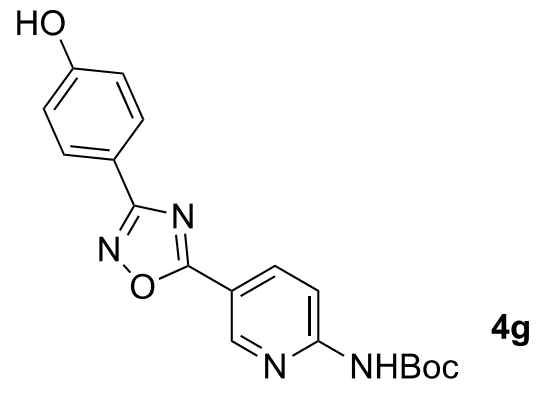

tert-butyl (5-(3-(4-hydroxyphenyl)-1,2,4-oxadiazol-5-yl)pyridin-2-yl)carbamate

Chemical Formula: $\mathrm{C}_{18} \mathrm{H}_{18} \mathrm{~N}_{4} \mathrm{O}_{4}$

Exact Mass: 354.1328

The compound was prepared using the standard procedure on $0.5 \mathrm{mmol}$ scale. The product was purified on silica gel with a gradient of $0-100 \%$ EtOAc in hexanes, and obtained as a light yellow oil in $46 \%$ yield.

${ }^{1} \mathrm{H}$ NMR (500 MHz, DMSO-d6) $\delta 10.42(\mathrm{~s}, 1 \mathrm{H}), 10.16(\mathrm{~s}, 1 \mathrm{H}), 9.00(\mathrm{~d}, J=2.0 \mathrm{~Hz}, 1 \mathrm{H}), 8.45$ (dd, $J=8.9,2.4$ $\mathrm{Hz}, 1 \mathrm{H}), 8.07(\mathrm{~d}, J=8.9 \mathrm{~Hz}, 1 \mathrm{H}), 7.92(\mathrm{~d}, J=8.7 \mathrm{~Hz}, 2 \mathrm{H}), 6.95(\mathrm{~d}, J=8.7 \mathrm{~Hz}, 2 \mathrm{H}), 1.50(\mathrm{~s}, 9 \mathrm{H})$.

${ }^{13} \mathrm{C}$ NMR $(126 \mathrm{MHz}$, DMSO-d $) \delta 173.3,168.0,160.4,155.7,152.5,147.8,137.5,128.9,116.7,116.0$, $114.4,112.0,80.4,27.9$.

ESI MS: $355.2(\mathrm{M}+\mathrm{H})$ 


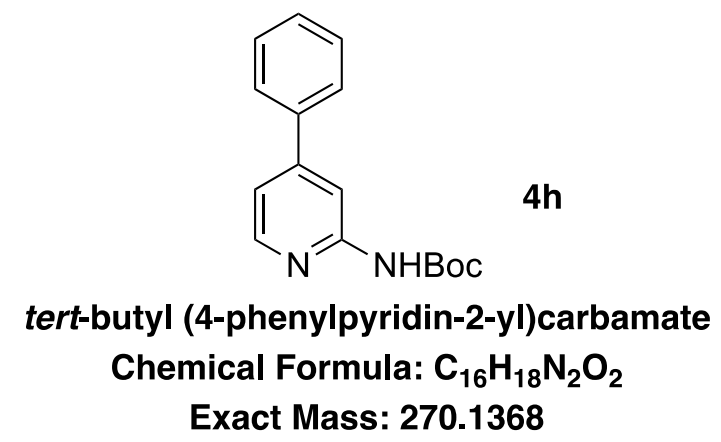

The compound was prepared using the standard procedure on $5.0 \mathrm{mmol}$ scale. The product was purified on silica gel with a gradient of $0-60 \%$ EtOAc in hexanes, and obtained as a white solid in $83 \%$ yield.

${ }^{1} \mathrm{H}$ NMR (500 MHz, DMSO-d6) $\delta 9.83(\mathrm{~s}, 1 \mathrm{H}), 8.30(\mathrm{~d}, J=5.2 \mathrm{~Hz}, 1 \mathrm{H}), 8.09(\mathrm{~d}, J=1.6 \mathrm{~Hz}, 1 \mathrm{H}), 7.74-7.68$ $(\mathrm{m}, 2 \mathrm{H}), 7.53$ (t, $J=7.4 \mathrm{~Hz}, 2 \mathrm{H}), 7.50-7.44(\mathrm{~m}, 1 \mathrm{H}), 7.33$ (dd, $J=5.2,1.6 \mathrm{~Hz}, 1 \mathrm{H}), 1.49(\mathrm{~s}, 9 \mathrm{H})$.

${ }^{13} \mathrm{C}$ NMR $\left(126 \mathrm{MHz}\right.$, DMSO-d $\left.d_{6}\right) \delta$ 153.2, 152.8, 149.0, 148.4, 137.8, 129.19, 129.16, 126.7, 116.2, 109.5, 79.6, 28.0.

ESI MS: $271.2(\mathrm{M}+\mathrm{H})$

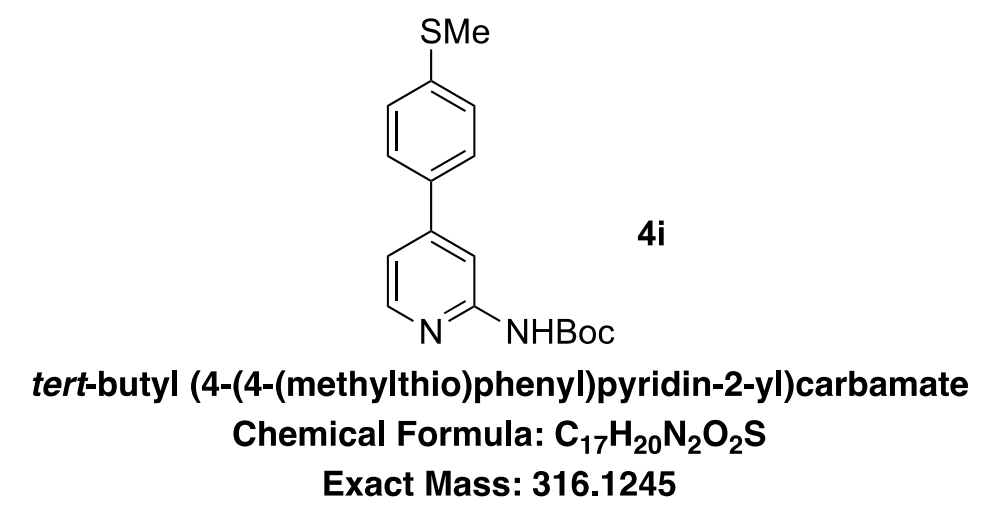

The compound was prepared using the standard procedure on $0.5 \mathrm{mmol}$ scale. The product was purified on silica gel with a gradient of 0-50\% EtOAc in hexanes, and obtained as a white solid in $73 \%$ yield.

${ }^{1} \mathrm{H}$ NMR $(500 \mathrm{MHz}$, DMSO-d6) $\delta 9.81(\mathrm{~s}, 1 \mathrm{H}), 8.28(\mathrm{~d}, J=5.2 \mathrm{~Hz}, 1 \mathrm{H}), 8.07(\mathrm{~d}, J=1.7 \mathrm{~Hz}, 1 \mathrm{H}), 7.70-7.64$ (m, 2H), $7.43-7.36(\mathrm{~m}, 2 \mathrm{H}), 7.32(\mathrm{dd}, J=5.3,1.7 \mathrm{~Hz}, 1 \mathrm{H}), 2.53(\mathrm{~s}, 3 \mathrm{H}), 1.49(\mathrm{~s}, 9 \mathrm{H})$.

${ }^{13} \mathrm{C}$ NMR $(126 \mathrm{MHz}$, DMSO-d6) $\delta$ 153.2, 152.8, 148.46, 148.30, 139.9, 133.9, 127.1, 126.2, 115.7, 109.0, 79.6, 28.0, 14.4 .

ESI MS: $317.2(\mathrm{M}+\mathrm{H})$ 


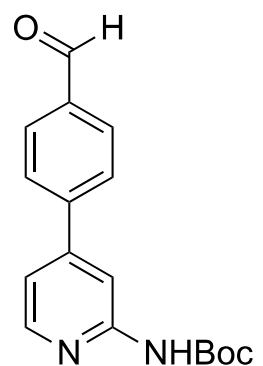

tert-butyl (4-(4-formylphenyl)pyridin-2-yl)carbamate

Chemical Formula: $\mathrm{C}_{17} \mathrm{H}_{18} \mathrm{~N}_{2} \mathrm{O}_{3}$

Exact Mass: 298.1317

The compound was prepared using the standard procedure on $0.5 \mathrm{mmol}$ scale. The product was purified on silica gel with a gradient of 0-50\% EtOAc in hexanes, and obtained as a white solid in $77 \%$ yield.

${ }^{1} \mathrm{H}$ NMR (500 MHz, DMSO-d6) $\delta 10.09(\mathrm{~s}, 1 \mathrm{H}), 9.92(\mathrm{~s}, 1 \mathrm{H}), 8.36(\mathrm{~d}, J=5.2 \mathrm{~Hz}, 1 \mathrm{H}), 8.15(\mathrm{~d}, J=1.7 \mathrm{~Hz}$, $1 \mathrm{H}), 8.06(\mathrm{~d}, J=8.3 \mathrm{~Hz}, 2 \mathrm{H}), 7.95(\mathrm{~d}, J=8.3 \mathrm{~Hz}, 2 \mathrm{H}), 7.41(\mathrm{dd}, J=5.3,1.7 \mathrm{~Hz}, 1 \mathrm{H}), 1.49(\mathrm{~s}, 9 \mathrm{H})$.

${ }^{13} \mathrm{C}$ NMR $(126 \mathrm{MHz}$, DMSO-d $) \delta 192.8,153.3,152.8,148.7,147.8,143.3,136.3,130.3,127.6,116.4$, 109.8, 79.8, 28.0.

ESI MS: $299.2(\mathrm{M}+\mathrm{H})$

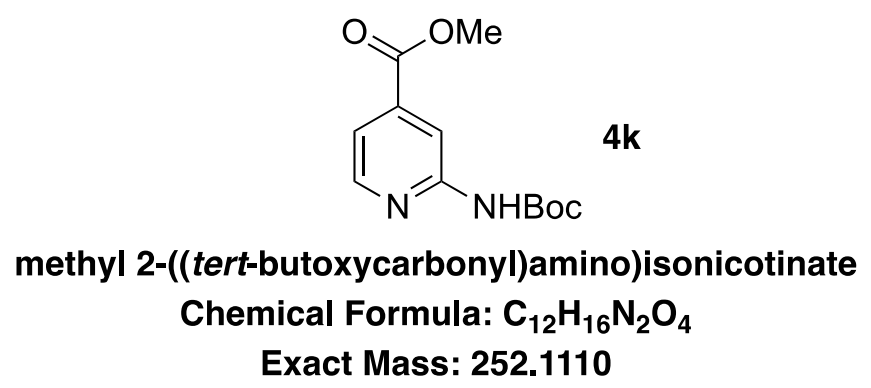

The compound was prepared using the standard procedure on $0.5 \mathrm{mmol}$ scale. The product was purified on silica gel with a gradient of $0-70 \%$ EtOAc in hexanes, and obtained as a white solid in $82 \%$ yield.

${ }^{1} \mathrm{H}$ NMR (500 MHz, DMSO-d $)^{\text {) } \delta ~} 10.10(\mathrm{~s}, 1 \mathrm{H}), 8.43$ (dd, $J=5.1,1.0 \mathrm{~Hz}, 1 \mathrm{H}$ ), 8.33 (app. t, $J=1.2 \mathrm{~Hz}, 1 \mathrm{H}$ ), $7.45(\mathrm{dd}, J=5.2,1.5 \mathrm{~Hz}, 1 \mathrm{H}), 3.89(\mathrm{~s}, 3 \mathrm{H}), 1.48(\mathrm{~s}, 9 \mathrm{H})$.

${ }^{13} \mathrm{C}$ NMR $\left(126 \mathrm{MHz}\right.$, DMSO- $\left.d_{6}\right) \delta$ 165.2, 153.5, 152.7, 149.0, 138.6, 117.0, 111.2, 80.0, 52.7, 28.0.

ESI MS: $253.2(\mathrm{M}+\mathrm{H})$ 
<smiles>CC(C)(C)OCc1cc(C(O)c2cccc(Cl)c2)ccn1</smiles>

\section{tert-butyl (4-((3-chlorophenyl)(hydroxy)methyl)pyridin-2-yl)carbamate Chemical Formula: $\mathrm{C}_{17} \mathrm{H}_{19} \mathrm{CIN}_{2} \mathrm{O}_{3}$}

Exact Mass: 334.1084

The compound was prepared using the standard procedure on $0.5 \mathrm{mmol}$ scale. The product was purified on silica gel with a gradient of $0-100 \%$ EtOAc in hexanes, and obtained as a white solid in $82 \%$ yield. As noted in the manuscript, the ketone group of $\mathbf{3}$ l was reduced to the secondary alcohol during the $\mathrm{Zn}$ mediated reduction step.

${ }^{1} \mathrm{H}$ NMR $\left(500 \mathrm{MHz}\right.$, DMSO-d $\mathrm{d}_{\mathrm{f}} \delta 9.67(\mathrm{~s}, 1 \mathrm{H}), 8.14(\mathrm{~d}, J=5.2 \mathrm{~Hz}, 1 \mathrm{H}), 7.87$ (s, 1H), 7.43 (app. t, $J=1.9 \mathrm{~Hz}$, $1 \mathrm{H}), 7.40-7.27(\mathrm{~m}, 3 \mathrm{H}), 7.00(\mathrm{dd}, J=5.2,1.5 \mathrm{~Hz}, 1 \mathrm{H}), 6.22(\mathrm{~d}, J=4.0 \mathrm{~Hz}, 1 \mathrm{H}), 5.70(\mathrm{~d}, J=3.9 \mathrm{~Hz}, 1 \mathrm{H})$, $1.46(\mathrm{~s}, 9 \mathrm{H})$.

${ }^{13} \mathrm{C}$ NMR $(126 \mathrm{MHz}$, DMSO-d6) $\delta 155.3,152.62,152.56,147.6,146.9,132.9,130.2,127.1,126.1,125.1$, $116.1,109.4,79.5,72.6,28.0$.

ESI MS: $335.2(\mathrm{M}+\mathrm{H})$

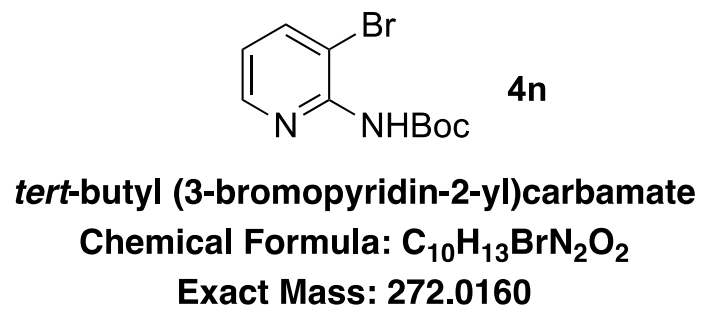

The compound was prepared using the standard procedure on $0.5 \mathrm{mmol}$ scale. The assay yield was determined to be $83 \%$ (major : minor $=61: 39$ ) by diluting the entire reaction mixture into a volumetric flask with 3:1 MeCN:water and analyzing the resulting solution on a UPLC instrument calibrated to authentic $4 \mathbf{e}$ (CAS \# 5470-49-5).

${ }^{1} \mathrm{H}$ NMR $\left(500 \mathrm{MHz}, \mathrm{DMSO}-d_{6}\right) \delta 9.31(\mathrm{~s}, 1 \mathrm{H}), 8.38(\mathrm{dd}, J=4.7,1.6 \mathrm{~Hz}, 1 \mathrm{H}), 8.10(\mathrm{dd}, J=7.9,1.6 \mathrm{~Hz}, 1 \mathrm{H})$, 7.19 (dd, $J=7.9,4.7 \mathrm{~Hz}, 1 \mathrm{H}), 1.44(\mathrm{~s}, 9 \mathrm{H})$.

${ }^{13} \mathrm{C}$ NMR $(126 \mathrm{MHz}$, DMSO-d6) $\delta 152.6,149.3,147.3,141.9,122.9,117.1,79.3,28.0$. 


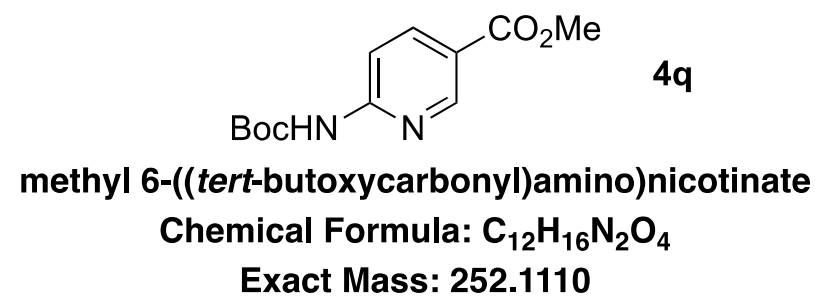

The compound was prepared using the standard procedure on $0.5 \mathrm{mmol}$ scale. The product was purified on silica gel with a gradient of $0-100 \%$ EtOAc in hexanes, and obtained as a white solid in $82 \%$ yield (major $:$ minor $=8: 1)$. The major isomer was isolated in $68 \%$ yield.

${ }^{1} \mathrm{H}$ NMR $\left(500 \mathrm{MHz}\right.$, DMSO- $\left.d_{6}\right) \delta 10.31(\mathrm{~s}, 1 \mathrm{H}), 8.77(\mathrm{~d}, J=2.3 \mathrm{~Hz}, 1 \mathrm{H}), 8.22(\mathrm{dd}, J=8.9,2.4 \mathrm{~Hz}, 1 \mathrm{H}), 7.94$ (d, J = 8.4 Hz, 1H), $3.85(\mathrm{~s}, 3 \mathrm{H}), 1.49(\mathrm{~s}, 9 \mathrm{H})$.

${ }^{13} \mathrm{C}$ NMR $(126 \mathrm{MHz}$, DMSO-d $) \delta$ 165.0, 155.9, 152.4, 149.5, 139.0, 119.8, 111.3, 80.3, 52.0, 27.9.

ESI MS: $253.2(\mathrm{M}+\mathrm{H})$<smiles>CC(C)(C)OCc1ccccc1</smiles>

tert-butyl (5-phenylpyridin-2-yl)carbamate Chemical Formula: $\mathrm{C}_{16} \mathrm{H}_{18} \mathrm{~N}_{2} \mathrm{O}_{2}$

Exact Mass: 270.1368

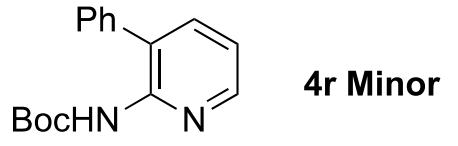

tert-butyl (3-phenylpyridin-2-yl)carbamate Chemical Formula: $\mathrm{C}_{16} \mathrm{H}_{18} \mathrm{~N}_{2} \mathrm{O}_{2}$ Exact Mass: 270.1368

The compound was prepared using the standard procedure on $0.5 \mathrm{mmol}$ scale. The products were purified on silica gel with a gradient of $0-100 \%$ EtOAc in hexanes, and obtained as a white solids in $79 \%$ combined yield $($ major : minor $=79: 21$ ).

\section{4r Major}

${ }^{1} \mathrm{H}$ NMR $\left(500 \mathrm{MHz}, \mathrm{DMSO}-d_{6}\right) \delta 9.87(\mathrm{~s}, 1 \mathrm{H}), 8.57(\mathrm{dd}, J=2.6,0.8 \mathrm{~Hz}, 1 \mathrm{H}), 8.04(\mathrm{dd}, J=8.7,2.6 \mathrm{~Hz}, 1 \mathrm{H})$, $7.88(\mathrm{dd}, J=8.7,0.8 \mathrm{~Hz}, 1 \mathrm{H}), 7.71-7.65(\mathrm{~m}, 2 \mathrm{H}), 7.47(\mathrm{t}, J=7.7 \mathrm{~Hz}, 2 \mathrm{H}), 7.40-7.33(\mathrm{~m}, 1 \mathrm{H}), 1.49$ (s, $9 \mathrm{H})$.

${ }^{13} \mathrm{C}$ NMR $\left(126 \mathrm{MHz}\right.$, DMSO- $\left.d_{6}\right) \delta$ 152.7, 151.7, 145.6, 136.90, 135.99, 130.1, 129.0, 127.5, 126.2, 112.1, 79.6, 28.0.

ESI MS: $271.2(\mathrm{M}+\mathrm{H})$

\section{4r Minor}

${ }^{1} \mathrm{H}$ NMR $\left(500 \mathrm{MHz}, \mathrm{DMSO}-d_{6}\right) \delta 9.09(\mathrm{~s}, 1 \mathrm{H}), 8.37$ (dd, $\left.J=4.8,1.8 \mathrm{~Hz}, 1 \mathrm{H}\right), 7.76(\mathrm{dd}, J=7.6,1.9 \mathrm{~Hz}, 1 \mathrm{H})$, $7.49-7.39(\mathrm{~m}, 4 \mathrm{H}), 7.34$ (ddd, $J=8.3,5.6,2.8 \mathrm{~Hz}, 2 \mathrm{H}), 1.15$ (s, 9H).

${ }^{13} \mathrm{C}$ NMR $(126 \mathrm{MHz}$, DMSO-d $d) \delta 152.7,148.5,147.1,139.0,138.5,132.8,128.29,128.01,127.2,121.8$, 78.5, 27.7 . 
<smiles>CC(C)(C)OC(=O)Nc1ncc(Cl)c(NC(=O)c2ccc(OC(F)F)c(OCC3CC3)c2)c1Cl</smiles>

tert-butyl (3,5-dichloro-4-(3-(cyclopropylmethoxy)-4-(difluoromethoxy)benzamido)pyridin-2-yl)carbamate Chemical Formula: $\mathrm{C}_{22} \mathrm{H}_{23} \mathrm{Cl}_{2} \mathrm{~F}_{2} \mathrm{~N}_{3} \mathrm{O}_{5}$

Exact Mass: $\mathbf{5 1 7 . 0 9 8 3}$

The compound was prepared using the standard procedure on $0.5 \mathrm{mmol}$ scale. The product was purified on silica gel with a gradient of $0-80 \%$ EtOAc in hexanes, and obtained as a white solid in $42 \%$ yield.

${ }^{1} \mathrm{H}$ NMR $\left(500 \mathrm{MHz}, \mathrm{DMSO}-\mathrm{d}_{6}\right) \delta 10.61(\mathrm{~s}, 1 \mathrm{H}), 9.63(\mathrm{~s}, 1 \mathrm{H}), 8.56(\mathrm{~s}, 1 \mathrm{H}), 7.71(\mathrm{~d}, J=2.0 \mathrm{~Hz}, 1 \mathrm{H}), 7.65$ (dd, $J=8.3,2.0 \mathrm{~Hz}, 1 \mathrm{H}), 7.35(\mathrm{~d}, J=8.3 \mathrm{~Hz}, 1 \mathrm{H}), 7.22(\mathrm{t}, J=74.1 \mathrm{~Hz}, 1 \mathrm{H}), 3.99(\mathrm{~d}, J=7.0 \mathrm{~Hz}, 2 \mathrm{H}), 1.45(\mathrm{~s}$, $9 \mathrm{H}), 0.86(\mathrm{t}, J=6.9 \mathrm{~Hz}, 1 \mathrm{H}), 0.63-0.54(\mathrm{~m}, 2 \mathrm{H}), 0.44-0.33(\mathrm{~m}, 2 \mathrm{H})$.

${ }^{13} \mathrm{C}$ NMR $\left(126 \mathrm{MHz}\right.$, DMSO- $\left.d_{6}\right) \delta 163.7,152.4,149.7,148.4,145.5,143.0(\mathrm{t}, J=3.2 \mathrm{~Hz}), 142.6,130.5$, $127.4,126.1,120.9,120.4,116.5(t, J=258.6 \mathrm{~Hz}), 113.7,79.7,73.3,27.9,9.9$, 3.0.

ESI MS: $518.2(\mathrm{M}+\mathrm{H})$

\section{Reaction monitoring by NMR spectroscopy}

To a screw-cap vial containing a magnetic stirbar was added pyridine $(0.25 \mathrm{mmol}, 1.0$ equiv), N,Obis(trimethylsilyl)acetamide $\left(0.75 \mathrm{mmol}, 3.0\right.$ equiv), and dioxane- $d_{8}(1 \mathrm{~mL})$. To the resulting mixture was added 2 ( $0.375 \mathrm{mmol}, 1.50$ equiv). The vial was sealed, stirred for approximately 10 seconds, then transferred to an NMR tube. The progress of the reaction at room temperature was monitored over approximately $2 \mathrm{~h}$ in the NMR instrument, and intermediates $(\mathbf{5}+\mathbf{6})$ and other species present were characterized through ${ }^{1} \mathrm{H},{ }^{13} \mathrm{C}$, COSY, HSQC, HMBC, LR-HSQMBC,NOESY, and ${ }^{1} \mathrm{H} /{ }^{15} \mathrm{~N} H M B C$ experiments.

In a separate experiment, a screw-cap vial containing a magnetic stirbar was added pyridine $(0.25 \mathrm{mmol}$, 1.0 equiv), $N, O$-bis(trimethylsilyl)acetamide $\left(0.75 \mathrm{mmol}, 3.0\right.$ equiv), and dioxane- $d_{8}(1 \mathrm{~mL})$. To the resulting mixture was added $2\left(0.375 \mathrm{mmol}, 1.50\right.$ equiv). The vial was sealed, and heated at $80^{\circ} \mathrm{C}$ for $3 \mathrm{~h}$.

The reaction mixture was cooled to ambient temperature and transferred to an NMR tube. The intermediate formed in the reaction was characterized through ${ }^{1} \mathrm{H},{ }^{13} \mathrm{C}$, COSY, HSQC, HMBC, LR-HSQMBC,NOESY, and ${ }^{1} \mathrm{H} /{ }^{15} \mathrm{~N}$ HMBC experiments and determined to be 7. The contents of the NMR tube were transferred back to the starting vial, AcOD- $d_{4}(1 \mathrm{~mL})$ and $Z n$ powder $(1.25 \mathrm{mmol}, 5.00$ equiv) were added, and the slurry was stirred vigorously for $3 \mathrm{~h}$. The excess $\mathrm{Zn}$ dust was allowed to settle, and the supernatant was transferred to an NMR tube to characterize the final species formed $(4 a+8)$ through the experiments listed above. 
<smiles>N#Cc1nc2c(nc1C#N)N1C=CC=CC1N(C(=O)O)O2</smiles>

tert-butyl 2,3-dicyanopyrazino[2,3-e]pyrido[2,1-c][1,2,4]oxadiazine-6(6a $H)$-carboxylate

Chemical Formula: $\mathrm{C}_{16} \mathrm{H}_{14} \mathrm{~N}_{6} \mathrm{O}_{3}$

Exact Mass: 338.1127

${ }^{1} \mathrm{H}$ NMR $(600 \mathrm{MHz}, 1,4-$ Dioxane- $d 8) \delta 7.38(\mathrm{~d}, J=7.8 \mathrm{~Hz}, 1 \mathrm{H}), 6.57(\mathrm{~d}, J=3.0 \mathrm{~Hz}, 1 \mathrm{H}), 6.10$ (ddd, $J=9.3$, 6.0, $2.3 \mathrm{~Hz}, 1 \mathrm{H}), 5.87(\mathrm{dd}, J=10.3,3.0 \mathrm{~Hz}, 1 \mathrm{H}), 5.47(\mathrm{t}, J=6.9 \mathrm{~Hz}, 1 \mathrm{H}), 1.41(\mathrm{~s}, 9 \mathrm{H})$.

${ }^{13} \mathrm{C}$ NMR $\left(151 \mathrm{MHz}, 1,4-\right.$ Dioxane- $\left.d_{8}\right) \delta$ 155.5, 151.1, 139.5, 127.7, 122.7, 121.93, 121.49, 118.4, 114.34, $114.25,105.5,87.0,74.9,28.0$.<smiles>COc1nc(C#N)c(C#N)nc1-n1cccc/c1=N\C(=O)OCc1ccccc1</smiles>

tert-butyl (E)-(1-(5,6-dicyano-3-((trimethylsilyl)oxy)pyrazin-2-yl)pyridin-2(1H)-ylidene)carbamate Chemical Formula: $\mathrm{C}_{19} \mathrm{H}_{22} \mathrm{~N}_{6} \mathrm{O}_{3} \mathrm{Si}$

Exact Mass: 410.1523

${ }^{1} \mathrm{H}$ NMR $\left(600 \mathrm{MHz}, 1,4-\right.$-Dioxane- $\left.d_{8}\right) \delta 7.87$ (d, $\left.J=9.6 \mathrm{~Hz}, 1 \mathrm{H}\right), 7.57$ (dd, $\left.J=7.1,1.8 \mathrm{~Hz}, 1 \mathrm{H}\right), 7.47$ (ddd, $J$ $=9.7,6.6,1.8 \mathrm{~Hz}, 1 \mathrm{H}), 6.48(\mathrm{td}, J=6.8,1.2 \mathrm{~Hz}, 1 \mathrm{H}), 1.39(\mathrm{~s}, 9 \mathrm{H}), 0.39(\mathrm{~s}, 9 \mathrm{H})$.

${ }^{13} \mathrm{C}$ NMR (151 MHz, 1,4-Dioxane-d8) $\delta 160.7,159.4,155.8,145.4,140.3,136.6,132.3,125.0,119.7$, $114.02,113.96,109.5,78.7,28.6,-0.3$.

ESI MS: 339.2 (loss of TMS) 


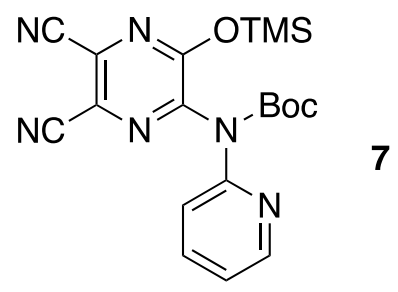

tert-butyl (5,6-dicyano-3-((trimethylsilyl)oxy)pyrazin-2-yl)(pyridin-2-yl)carbamate Chemical Formula: $\mathrm{C}_{19} \mathrm{H}_{22} \mathrm{~N}_{6} \mathrm{O}_{3} \mathrm{Si}$

Exact Mass: 410.1523

${ }^{1} \mathrm{H}$ NMR $(600 \mathrm{MHz}, 1,4-$-Dioxane- $d 8) \delta 8.11$ (ddd, $J=4.9,1.9,0.9 \mathrm{~Hz}, 1 \mathrm{H}$ ), 7.81 (ddd, $J=8.2,7.4,1.9 \mathrm{~Hz}$, $1 \mathrm{H}), 7.66(\mathrm{~d}, J=8.2 \mathrm{~Hz}, 1 \mathrm{H}), 7.14(\mathrm{ddd}, J=7.4,4.9,1.0 \mathrm{~Hz}, 1 \mathrm{H}), 1.47(\mathrm{~s}, 9 \mathrm{H}), 0.26(\mathrm{~s}, 9 \mathrm{H})$.

${ }^{13} \mathrm{C}$ NMR $\left(151 \mathrm{MHz}, 1,4-\right.$-Dioxane- $\left.d_{8}\right) \delta 156.5,154.4,152.0,148.4,146.4,138.8,130.3,125.3,121.7$, $119.4,114.25,114.18,84.4,28.2,-0.3$.

ESI MS: 239.2 (loss of TMS and Boc)

ESI MS (negative detection): 337.2 (loss of TMS)<smiles>[2H]C1([2H])NC(=O)C(C#N)=C(C#N)N1</smiles><smiles>[2H]C1NC(C#N)=C(C#N)NC1=O</smiles>

\section{8}

$$
\sim 90 \% \quad \sim 10 \%
$$

\section{5-oxo-1,4,5,6-tetrahydropyrazine-2,3-dicarbonitrile Chemical Formula: $\mathrm{C}_{6} \mathrm{H}_{4} \mathrm{~N}_{4} \mathrm{O}$ \\ Exact Mass: 148.0385}

${ }^{1} \mathrm{H}$ NMR (600 MHz, 1:1 1,4-Dioxane- $\left.d_{8} / \mathrm{CD}_{3} \mathrm{COOD}\right) \delta 3.85$ (br s, $\left.1 \mathrm{H}\right)$.

${ }^{13} \mathrm{C}$ NMR (151 MHz, 1:1 1,4-Dioxane- $\left.d_{8} / \mathrm{CD}_{3} \mathrm{COOD}\right) \delta 164.1,114.7,113.79,112.99,98.0,45.1\left(\mathrm{p}, \mathrm{JCD}_{\mathrm{C}}=\right.$ 21.6 Hz). 
${ }^{1} \mathrm{H}$ NMR $\left(600 \mathrm{MHz}\right.$, dioxane- $\left.\mathrm{d}_{8}\right)$

I
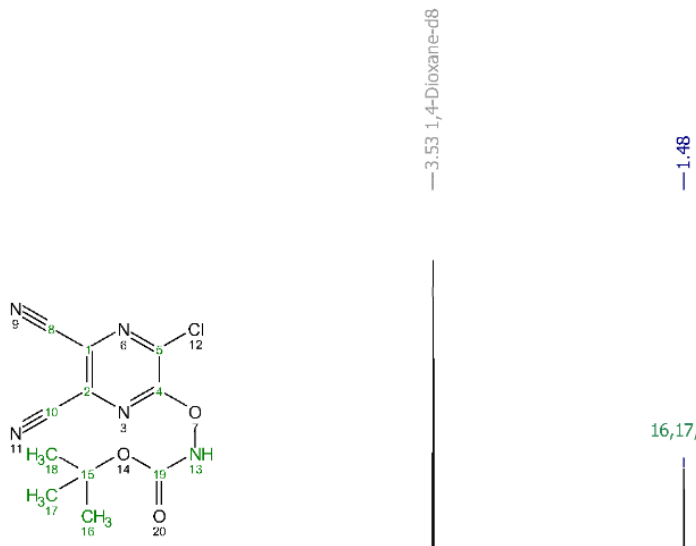

2

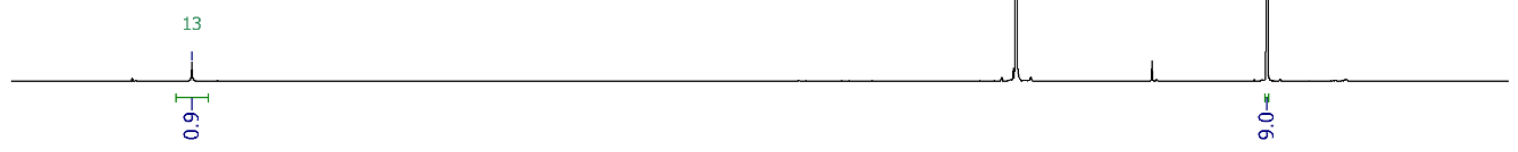

\begin{tabular}{lllllllllllllllllllllllllll}
\hline 11.5 & 11.0 & 10.5 & 10.0 & 9.5 & 9.0 & 8.5 & 8.0 & 7.5 & 7.0 & 6.5 & 6.0 & 5.5 & 5.0 & 4.5 & 4.0 & 3.5 & 3.0 & 2.5 & 2.0 & 1.5 & 1.0 & 0.5 & 0.0 & 1
\end{tabular}

${ }^{13} \mathrm{C}$ NMR $(151 \mathrm{MHz}$, dioxane-d $)$

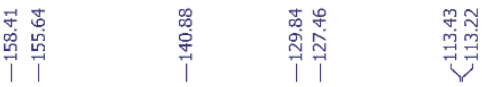
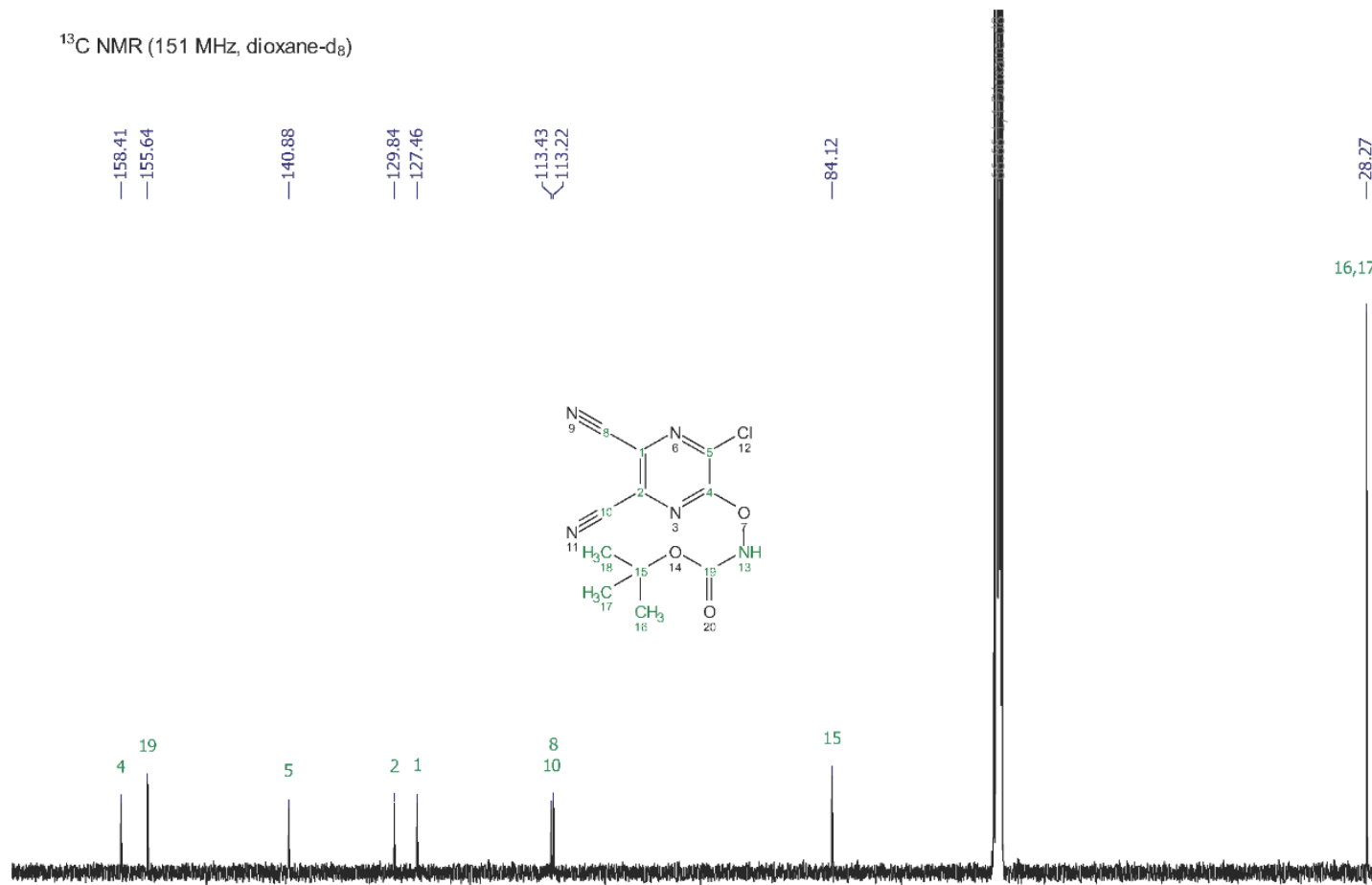

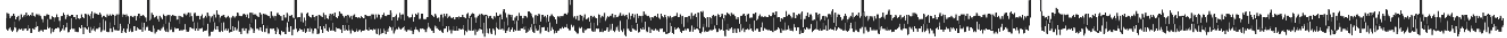

$\begin{array}{llllllllllllllllllllllllllllllllllllllll}165 & 160 & 155 & 150 & 145 & 140 & 135 & 130 & 125 & 120 & 115 & 110 & 105 & 100 & 95 & 90 & 85 & 80 & 75 & 70 & 65 & 60 & 55 & 50 & 45 & 40 & 35 & 30 & 25 & 2\end{array}$ 
${ }^{1} \mathrm{H} /{ }^{13} \mathrm{C}$ HMBC NMR $(600 / 151 \mathrm{MHz}, J$ opt. $=8 \mathrm{~Hz}$, dioxane-d $)$
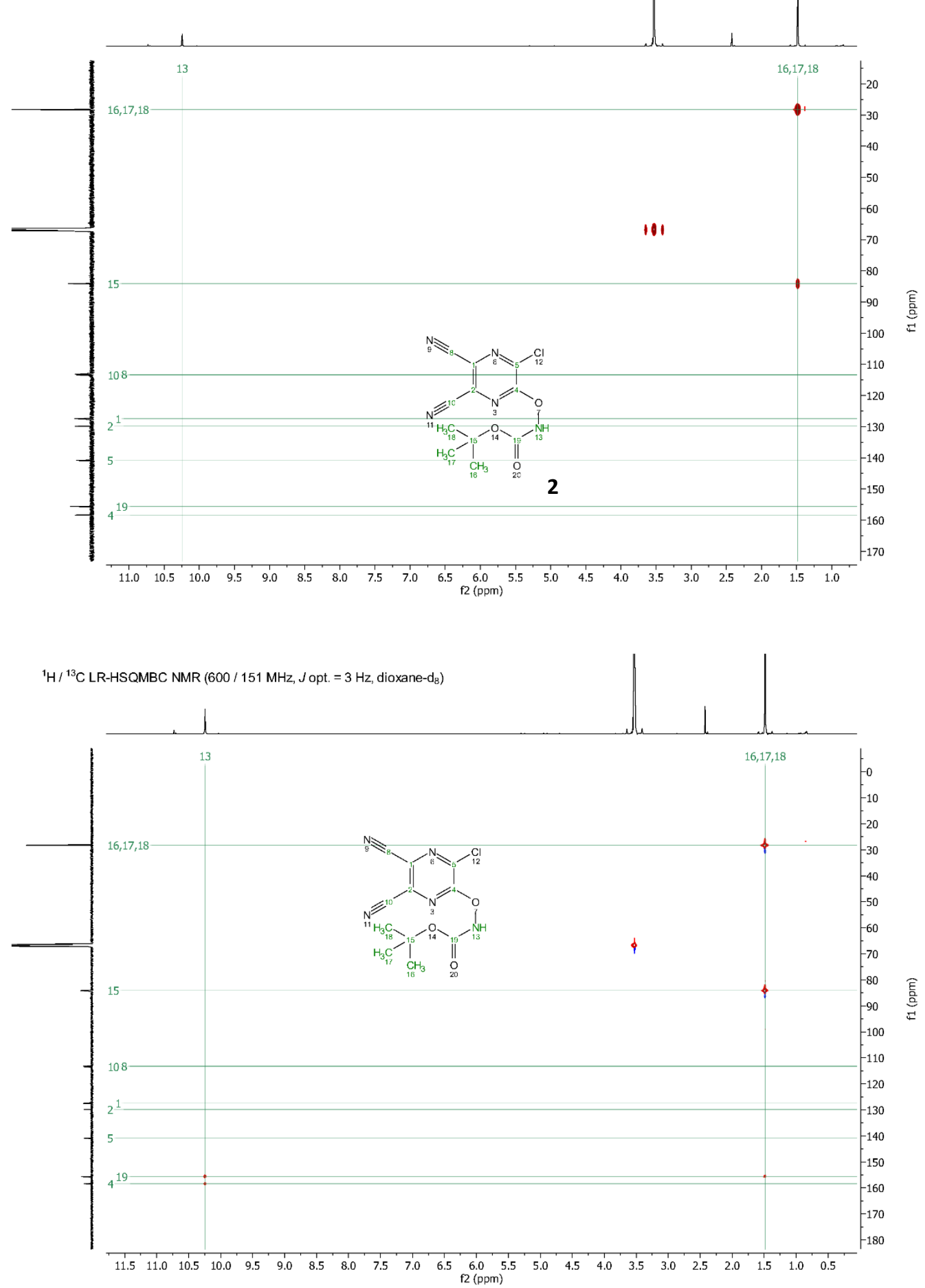


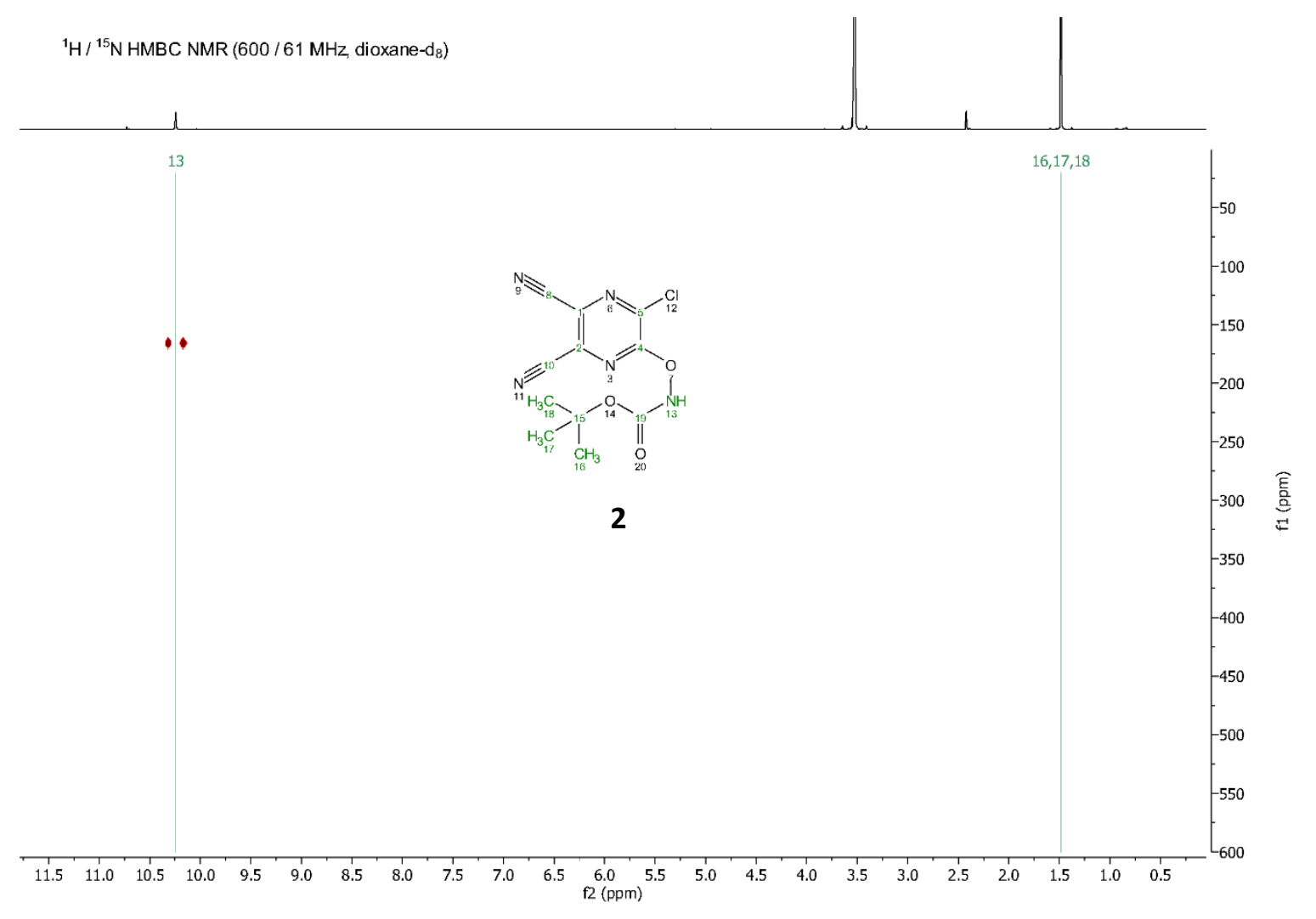


$\int$<smiles>N#Cc1nc(Cl)c(ONC(=O)OCc2ccccc2)nc1C#N</smiles>

${ }^{1} \mathrm{H}$ NMR (500 MHz, CD ${ }_{3} \mathrm{CN}$ )
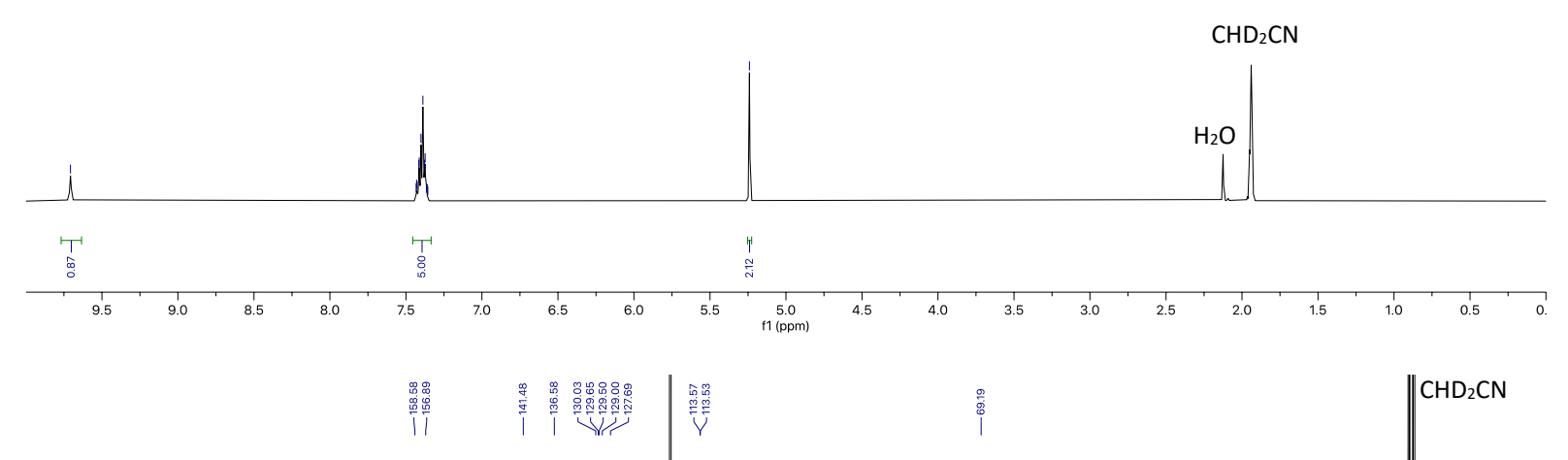

${ }^{13} \mathrm{C}$ NMR (126 MHz, $\mathrm{CD}_{3} \mathrm{CN}$ )
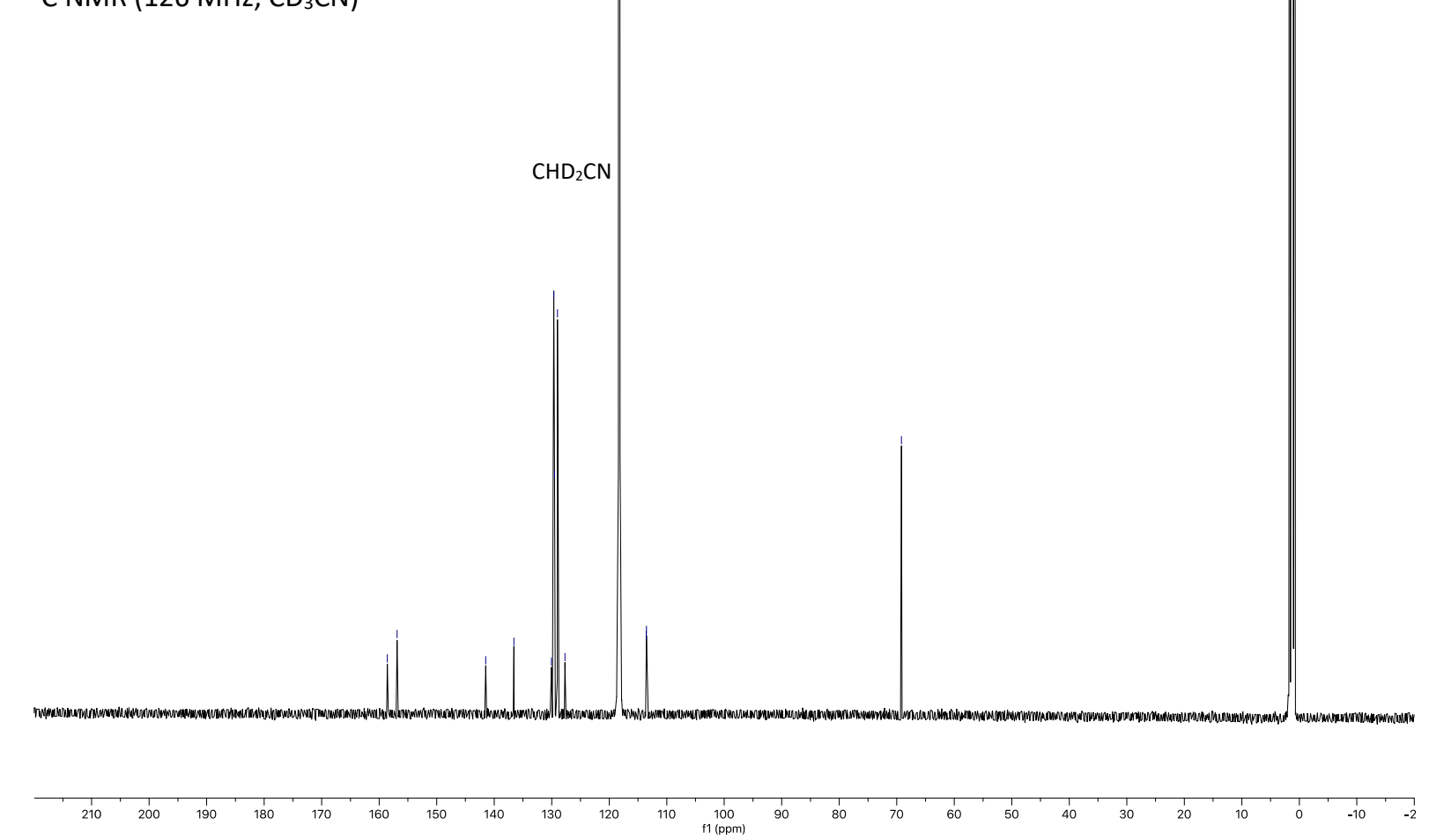

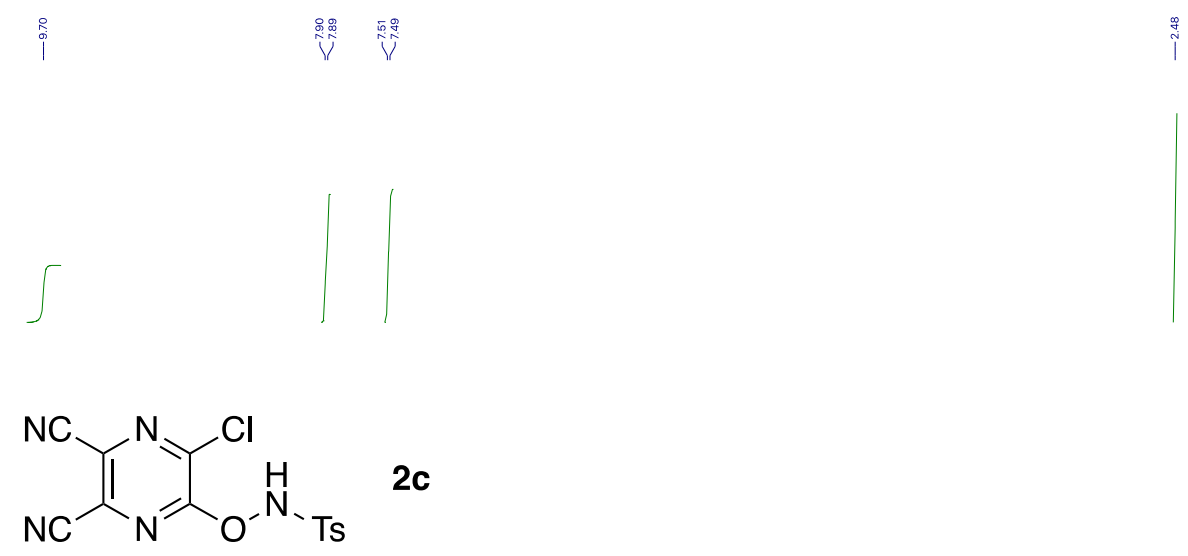

c
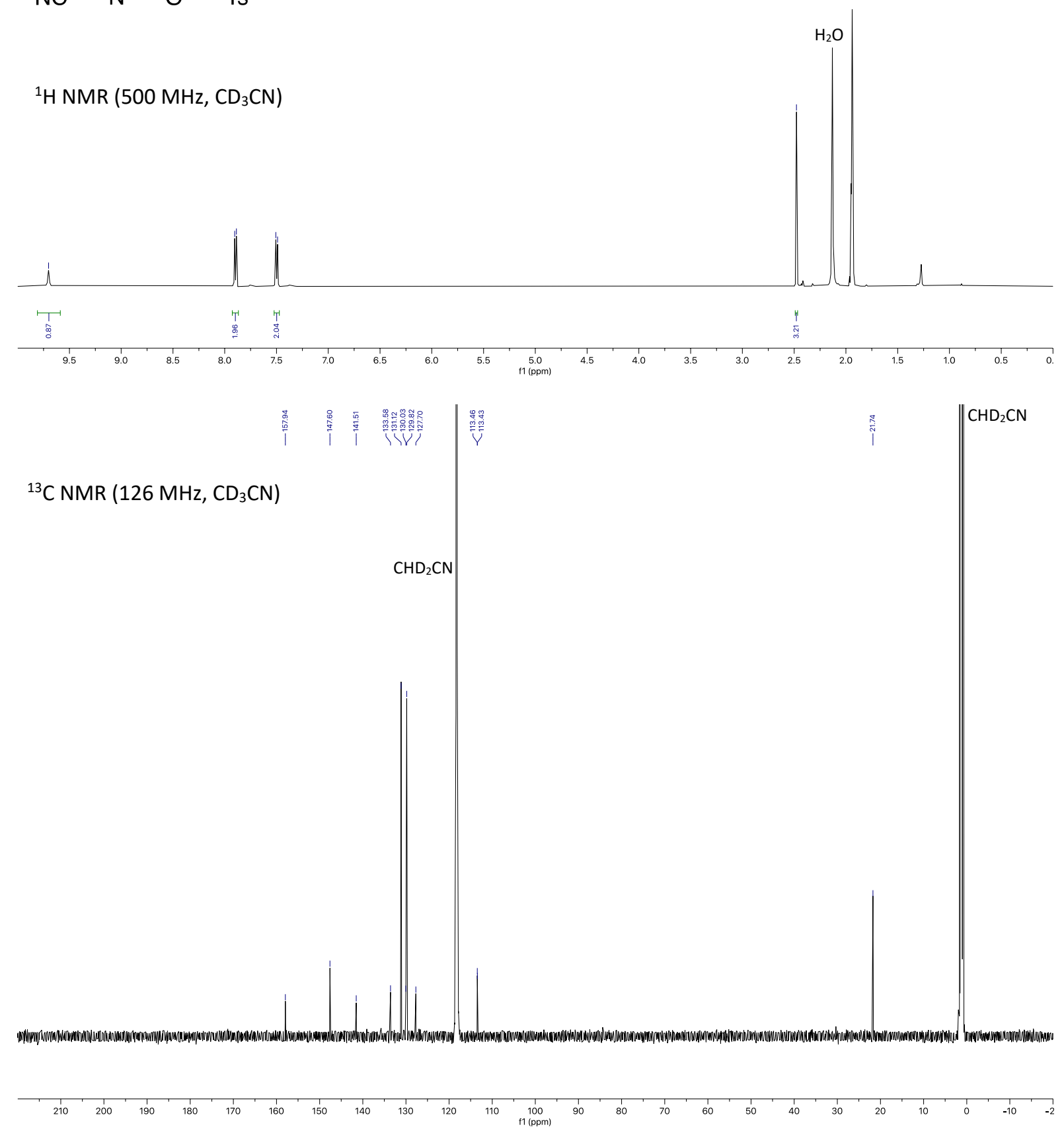


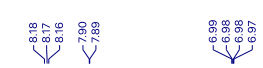

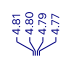

${ }^{1} \mathrm{H}$ NMR $\left(500 \mathrm{MHz}, \mathrm{CD}_{3} \mathrm{CN}\right)$

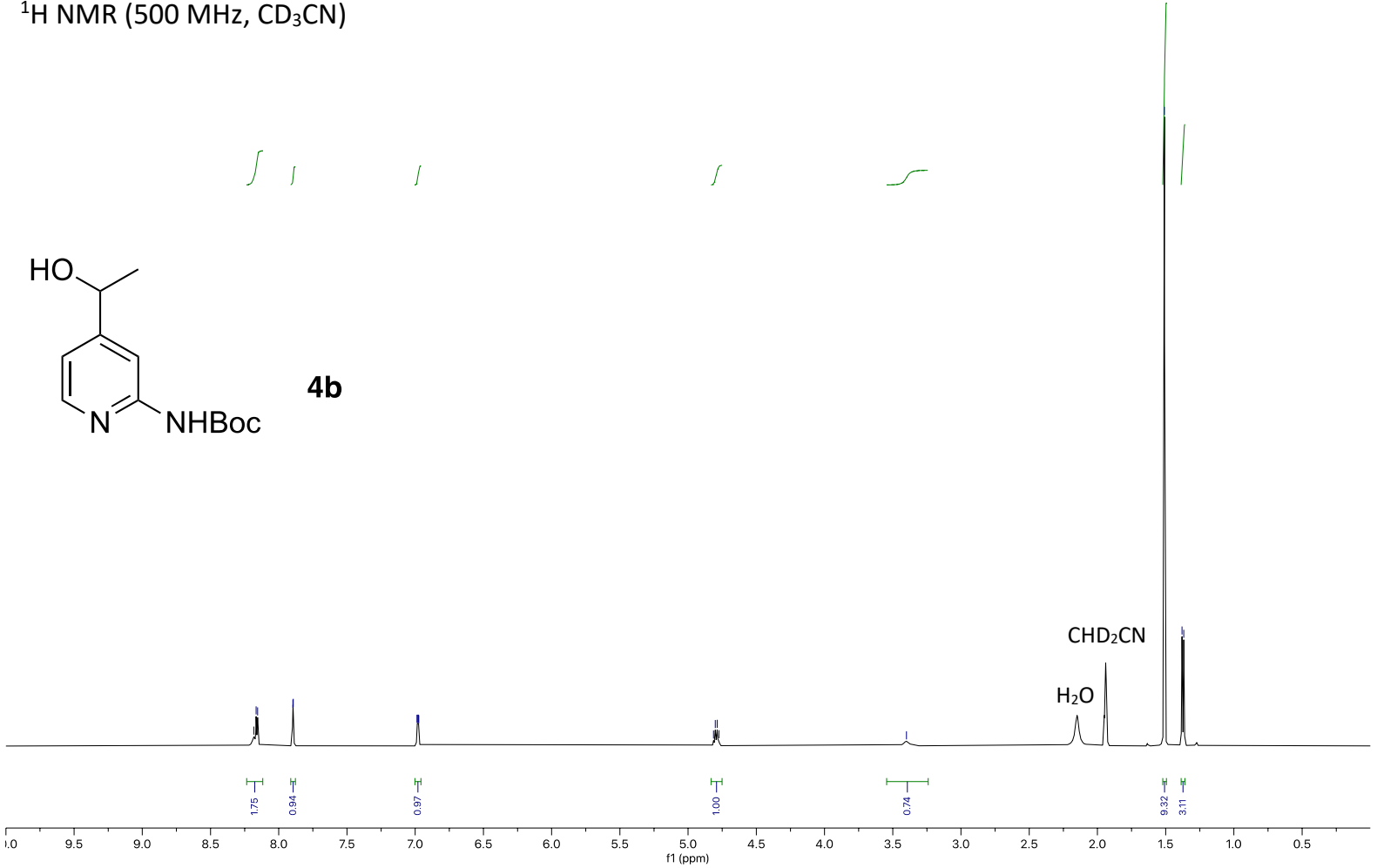

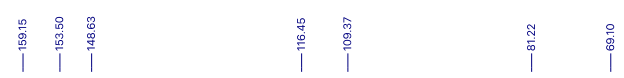

量善

${ }^{13} \mathrm{C}$ NMR $\left(126 \mathrm{MHz}, \mathrm{CD}_{3} \mathrm{CN}\right)$

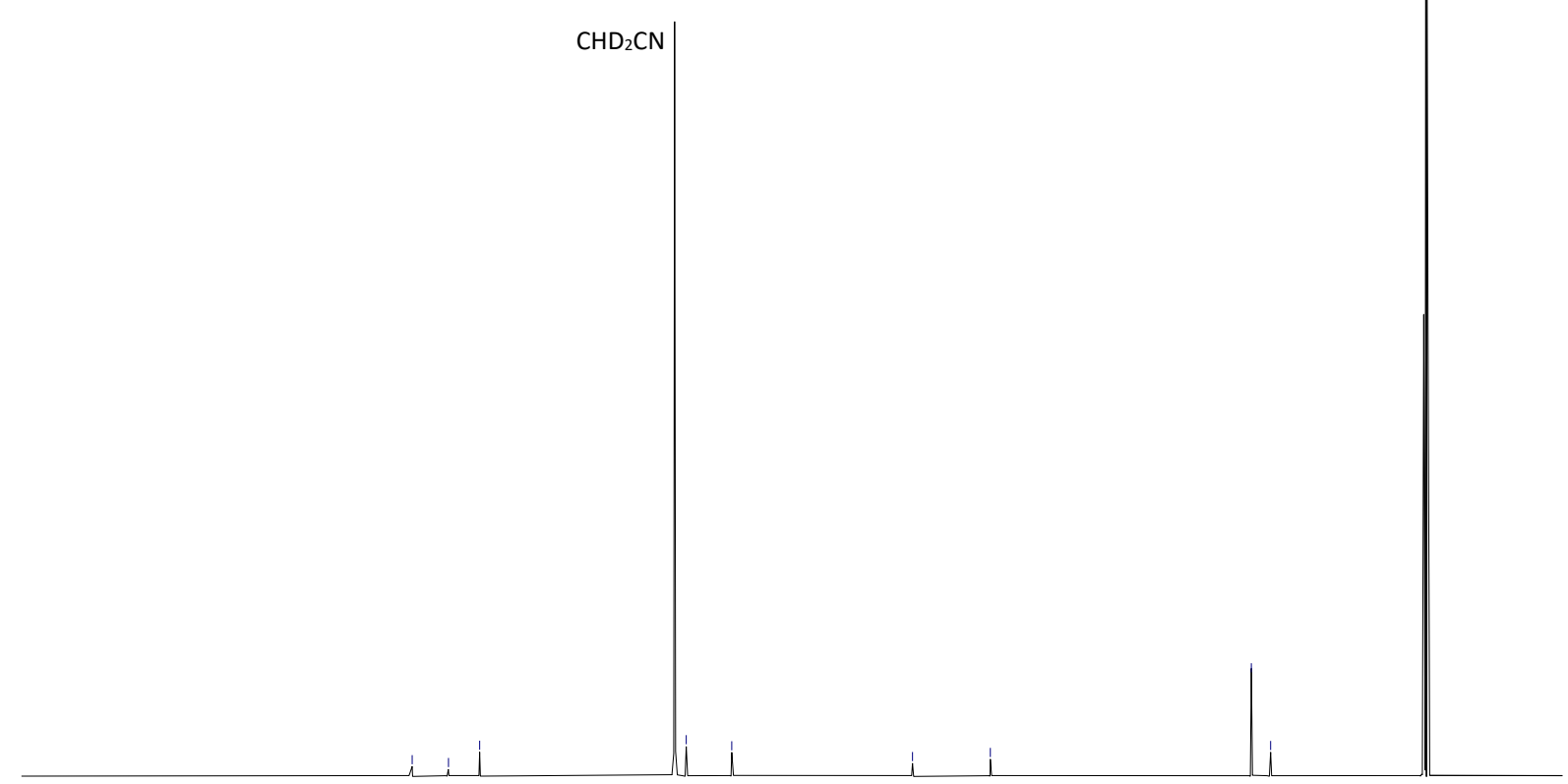

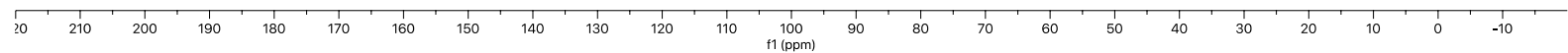



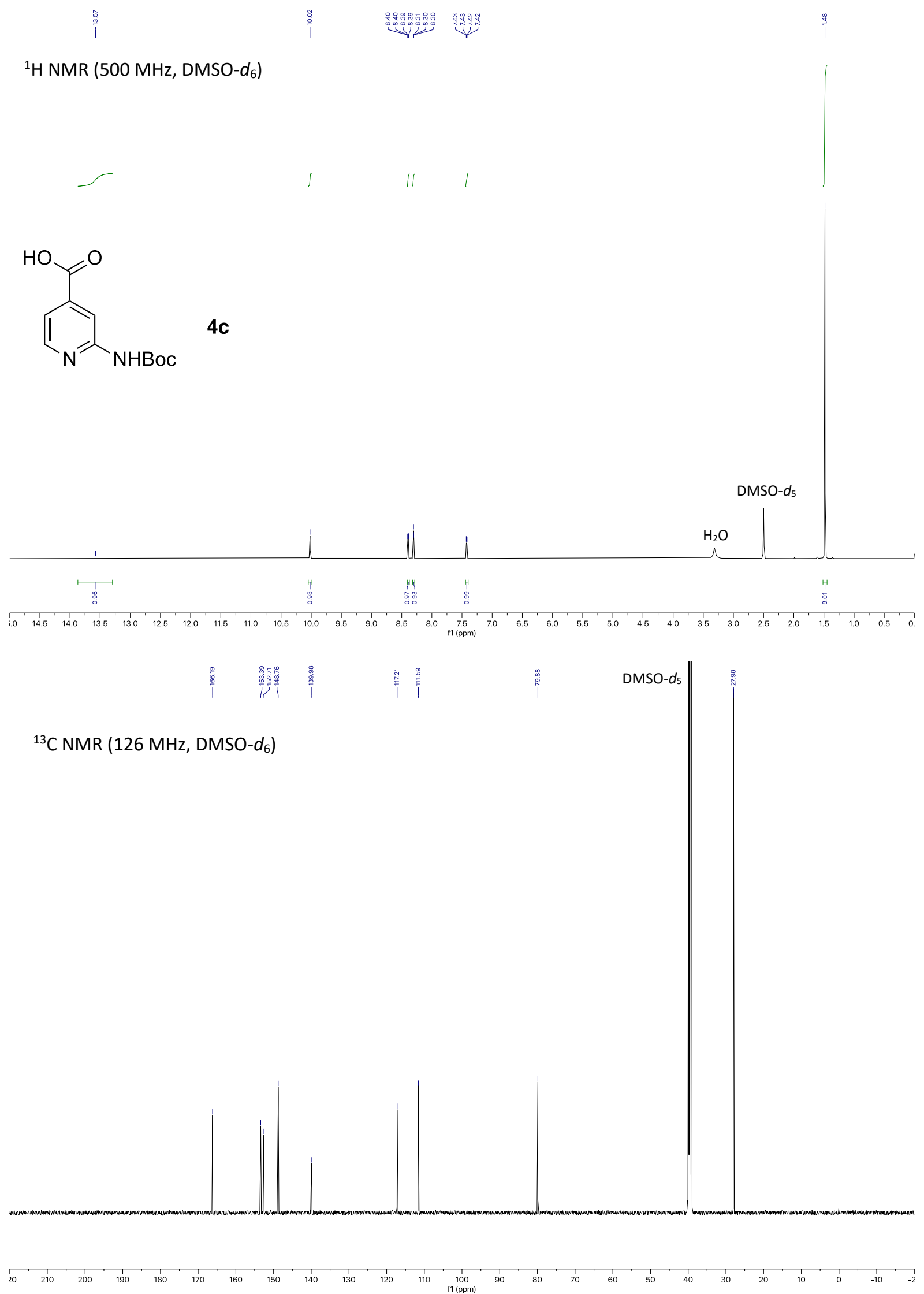


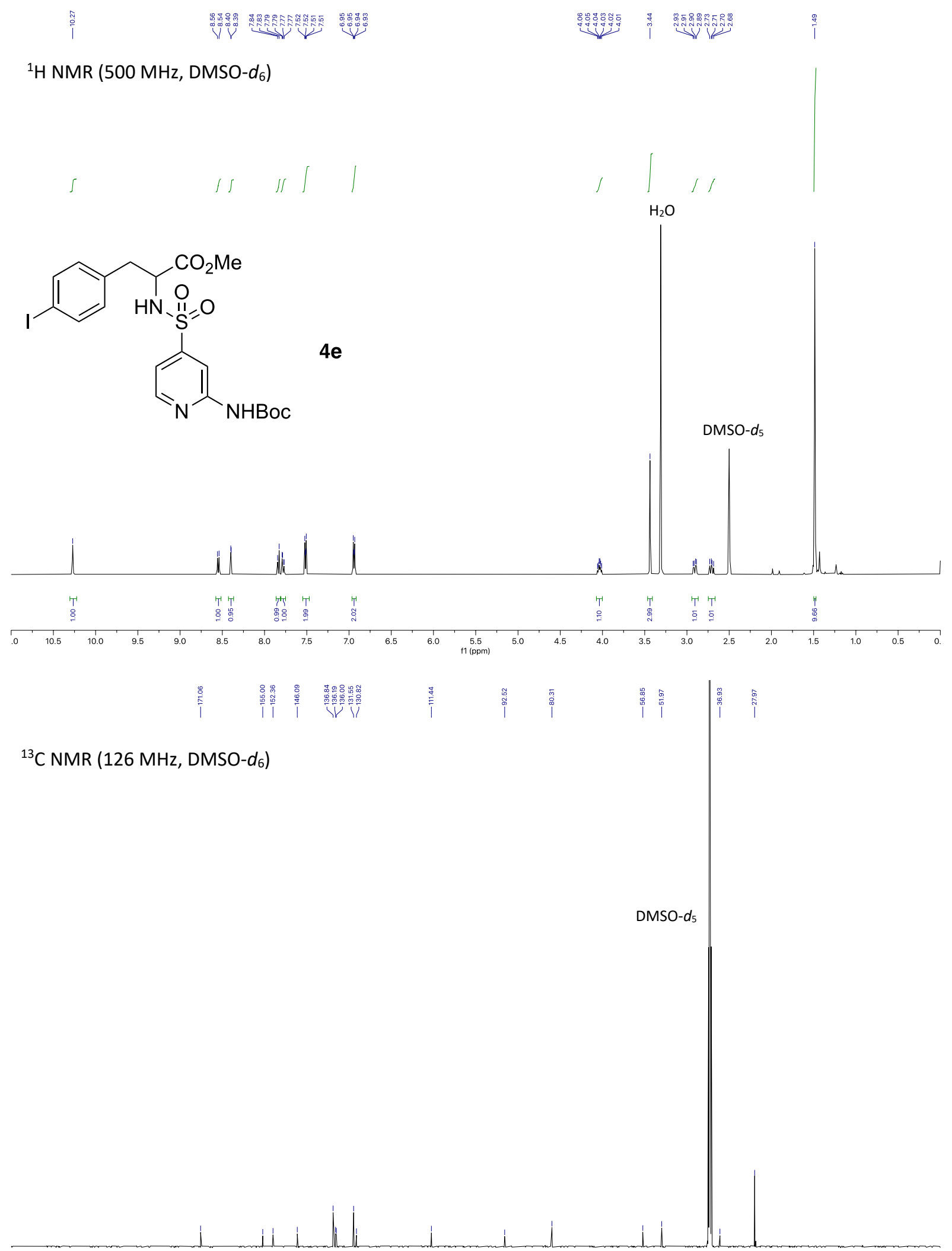

(N)

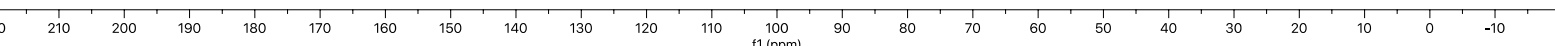



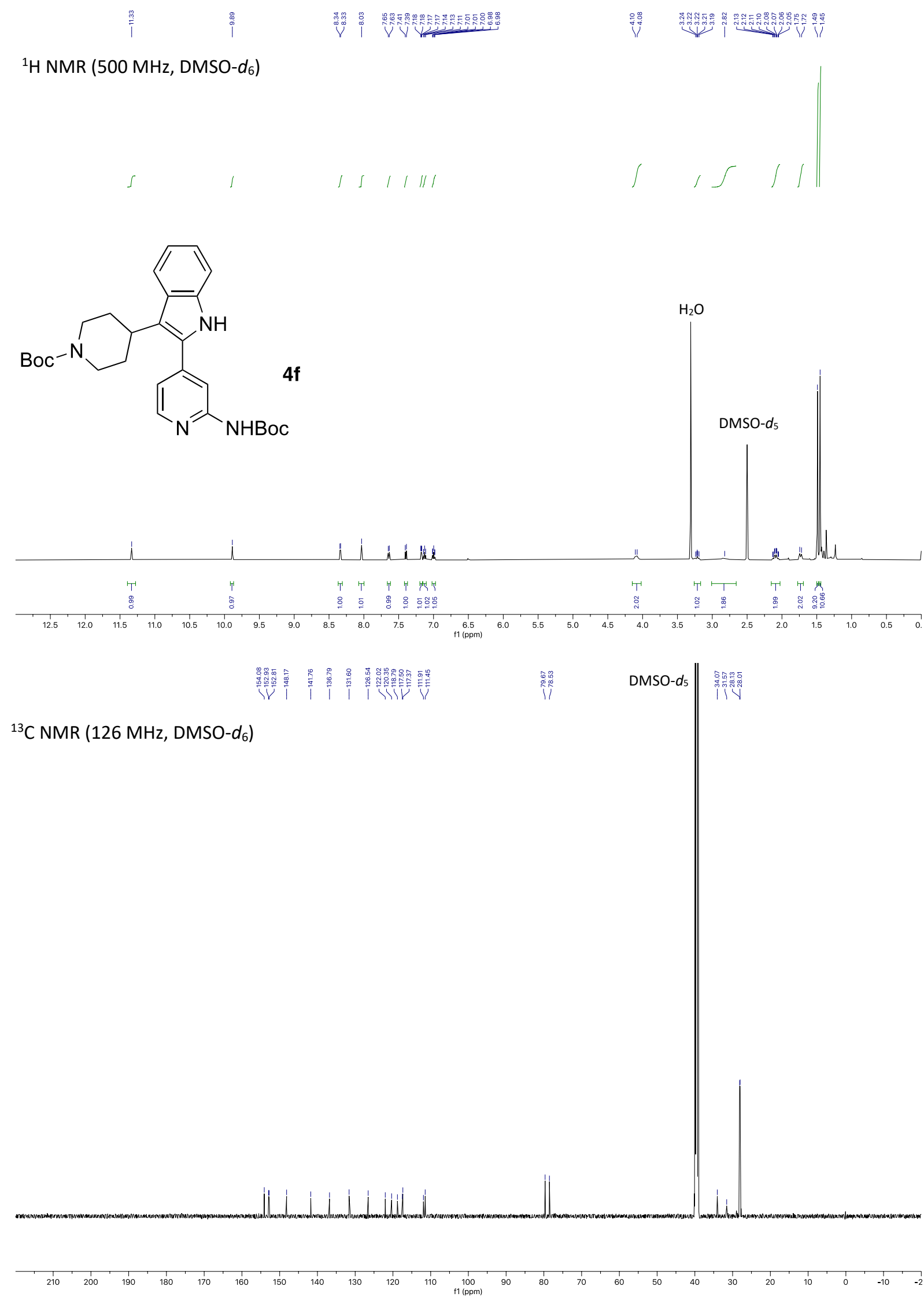


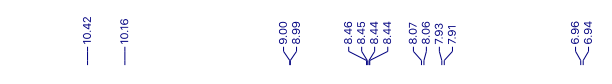

${ }^{1} \mathrm{H}$ NMR $\left(500 \mathrm{MHz}, \mathrm{DMSO}-d_{6}\right)$

$\mathrm{HO}$

g

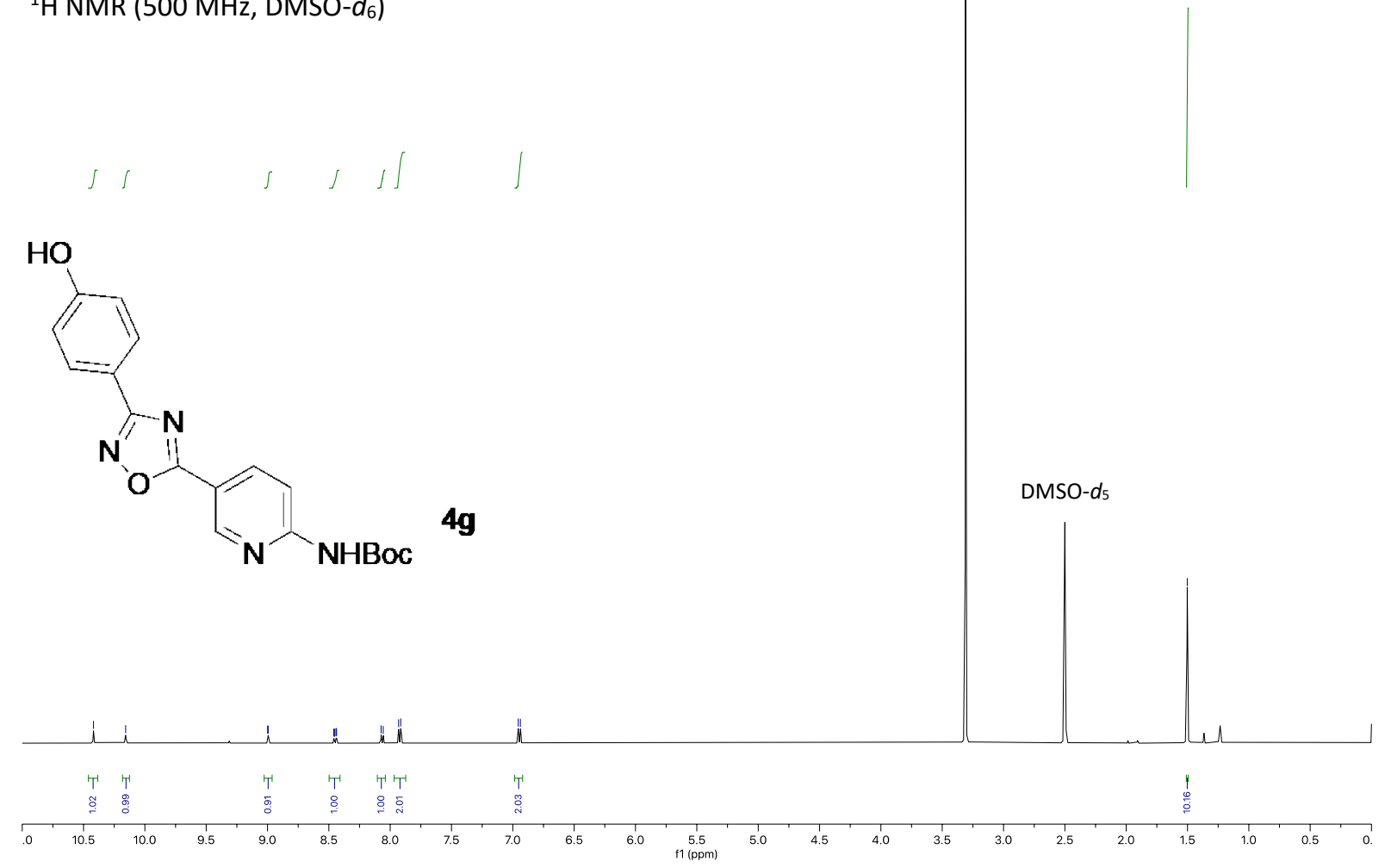

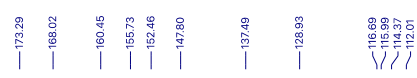

${ }^{13} \mathrm{C}$ NMR $\left(126 \mathrm{MHz}, \mathrm{DMSO}-d_{6}\right)$

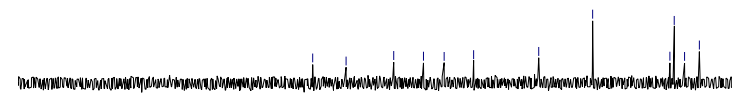

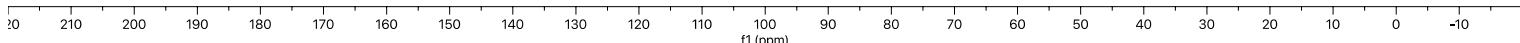




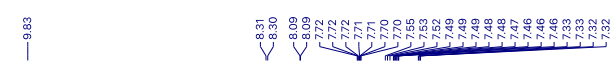

${ }^{1} \mathrm{H}$ NMR $\left(500 \mathrm{MHz}, \mathrm{DMSO}-d_{6}\right)$
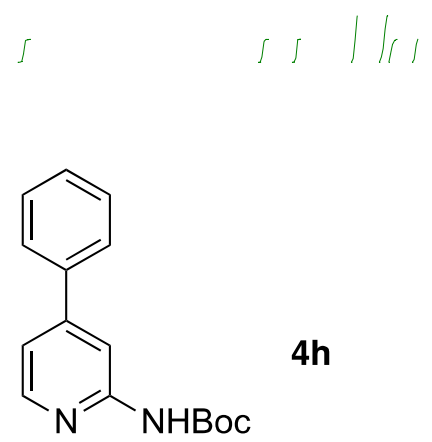

$4 h$

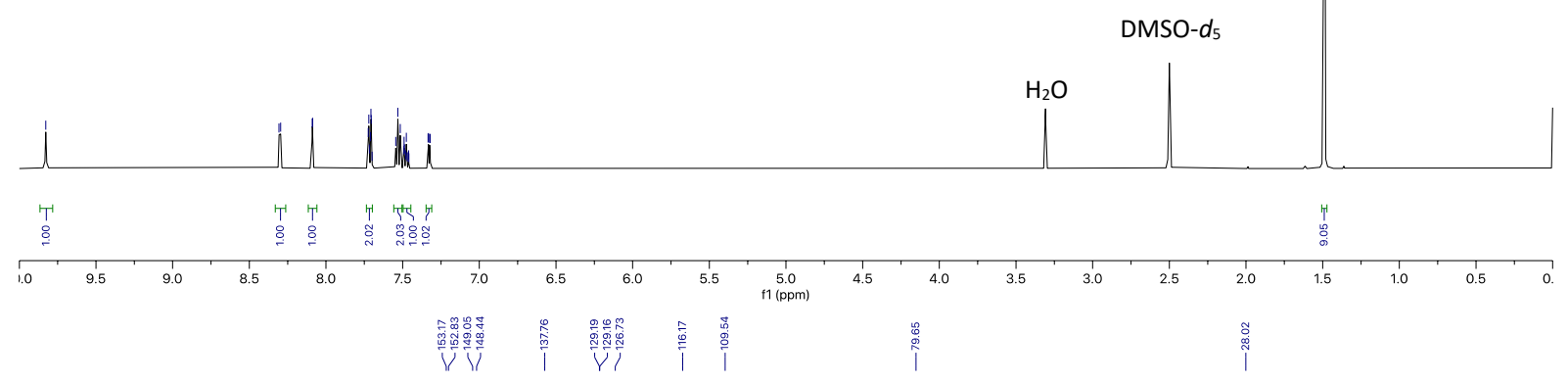

${ }^{13} \mathrm{C}$ NMR (126 MHz, DMSO- $d_{6}$ )

DMSO- $d_{5}$ 

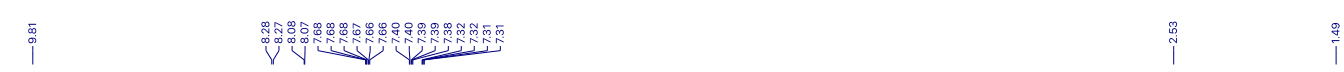

${ }^{1} \mathrm{H}$ NMR $\left(500 \mathrm{MHz}, \mathrm{DMSO}-d_{6}\right)$

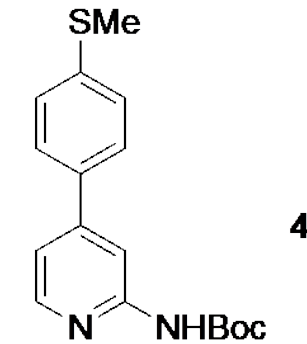

$4 \mathbf{1}$

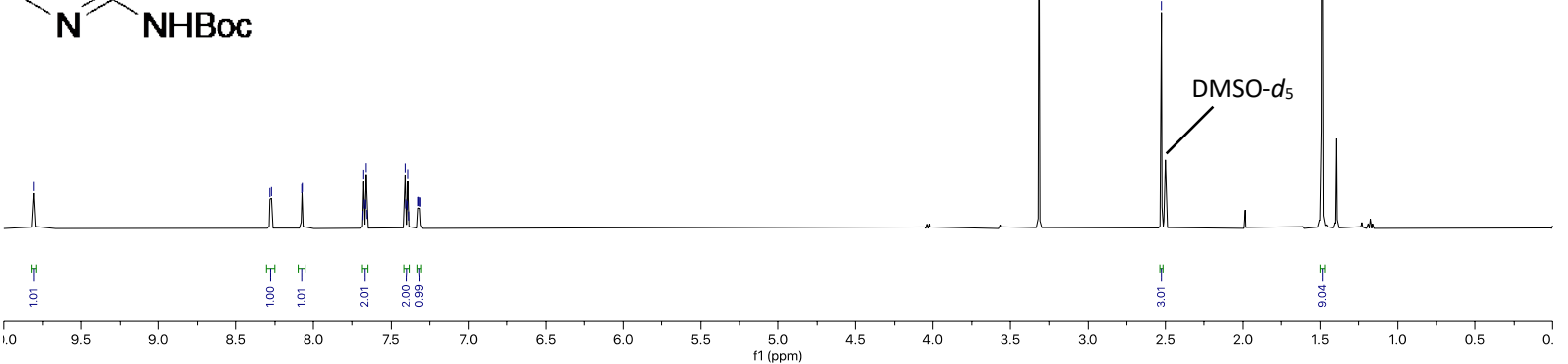

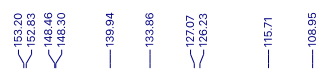

${ }^{13} \mathrm{C}$ NMR $\left(126 \mathrm{MHz}\right.$, DMSO- $\left.d_{6}\right)$

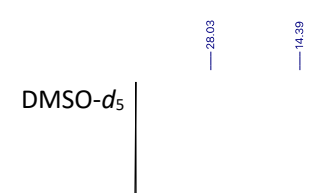

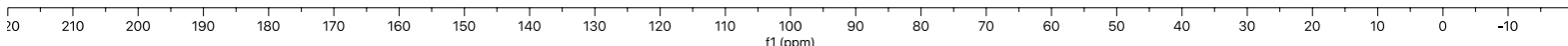


${ }^{1} \mathrm{H}$ NMR $\left(500 \mathrm{MHz}\right.$, DMSO- $\left.d_{6}\right)$
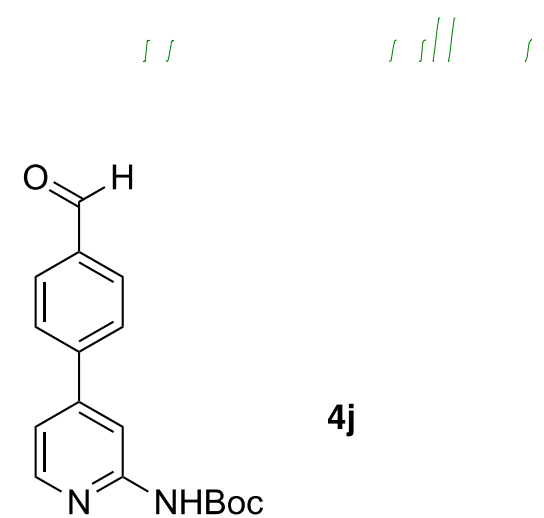

4j

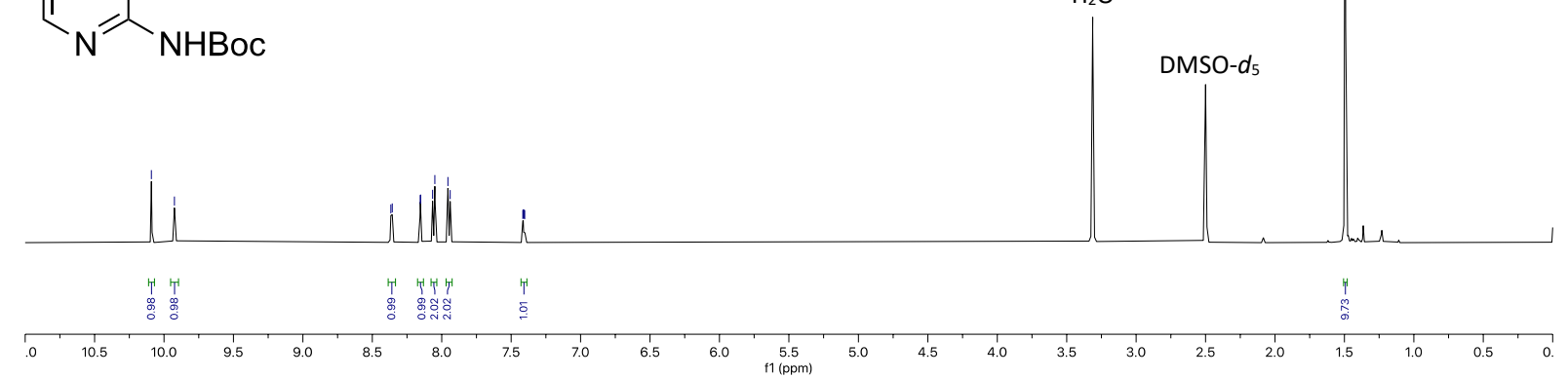

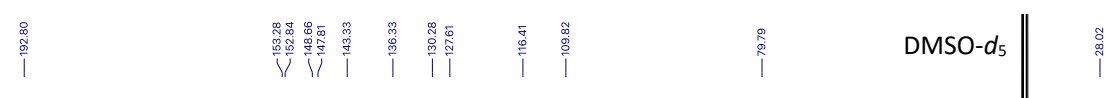

${ }^{13} \mathrm{C}$ NMR (126 MHz, DMSO- $\left.d_{6}\right)$

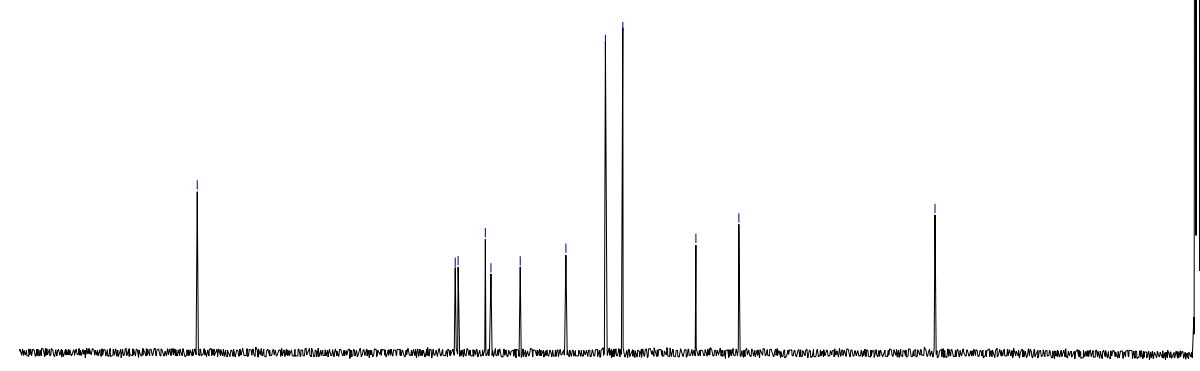

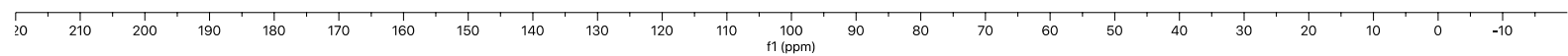




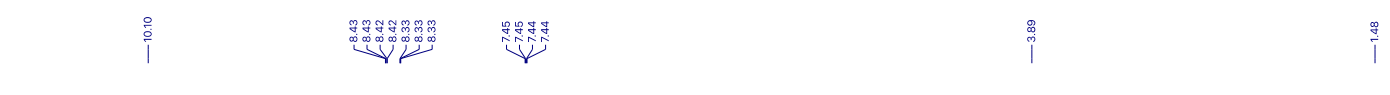

${ }^{1} \mathrm{H}$ NMR (500 MHz, DMSO- $d_{6}$ )

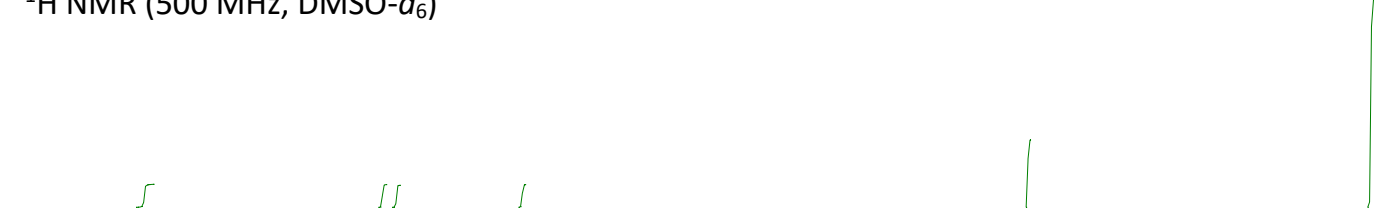
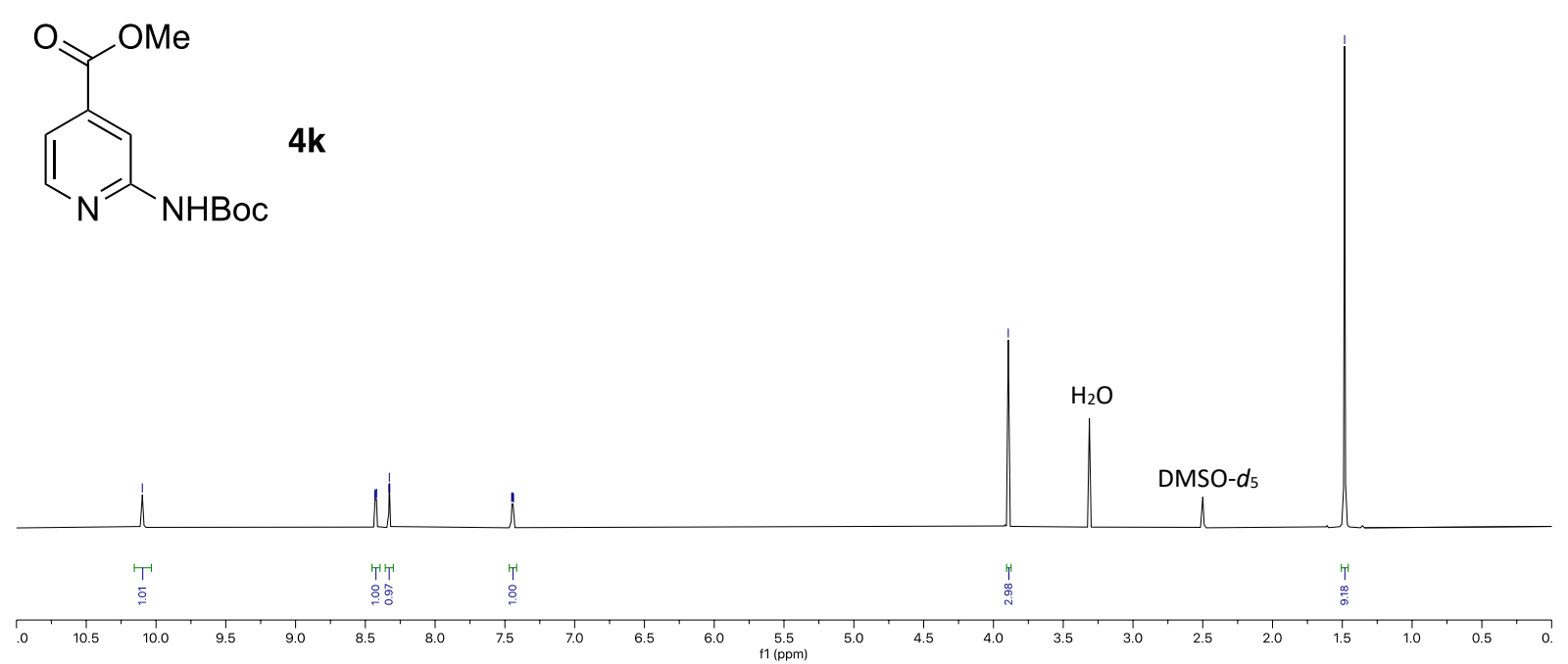

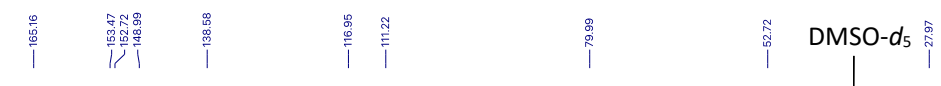

${ }^{13} \mathrm{C}$ NMR (126 MHz, DMSO- $d_{6}$ )
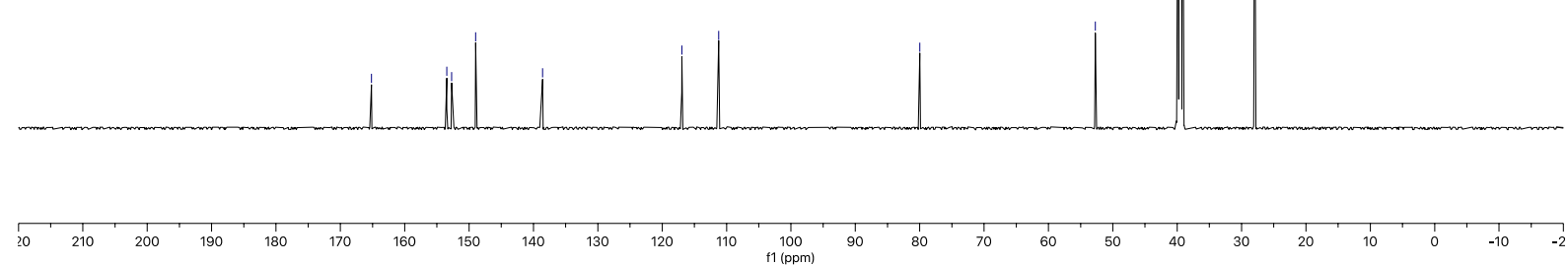


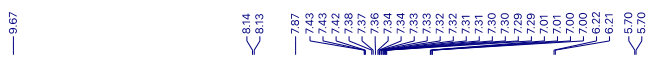

${ }^{1} \mathrm{H}$ NMR $\left(500 \mathrm{MHz}, \mathrm{DMSO}-d_{6}\right)$

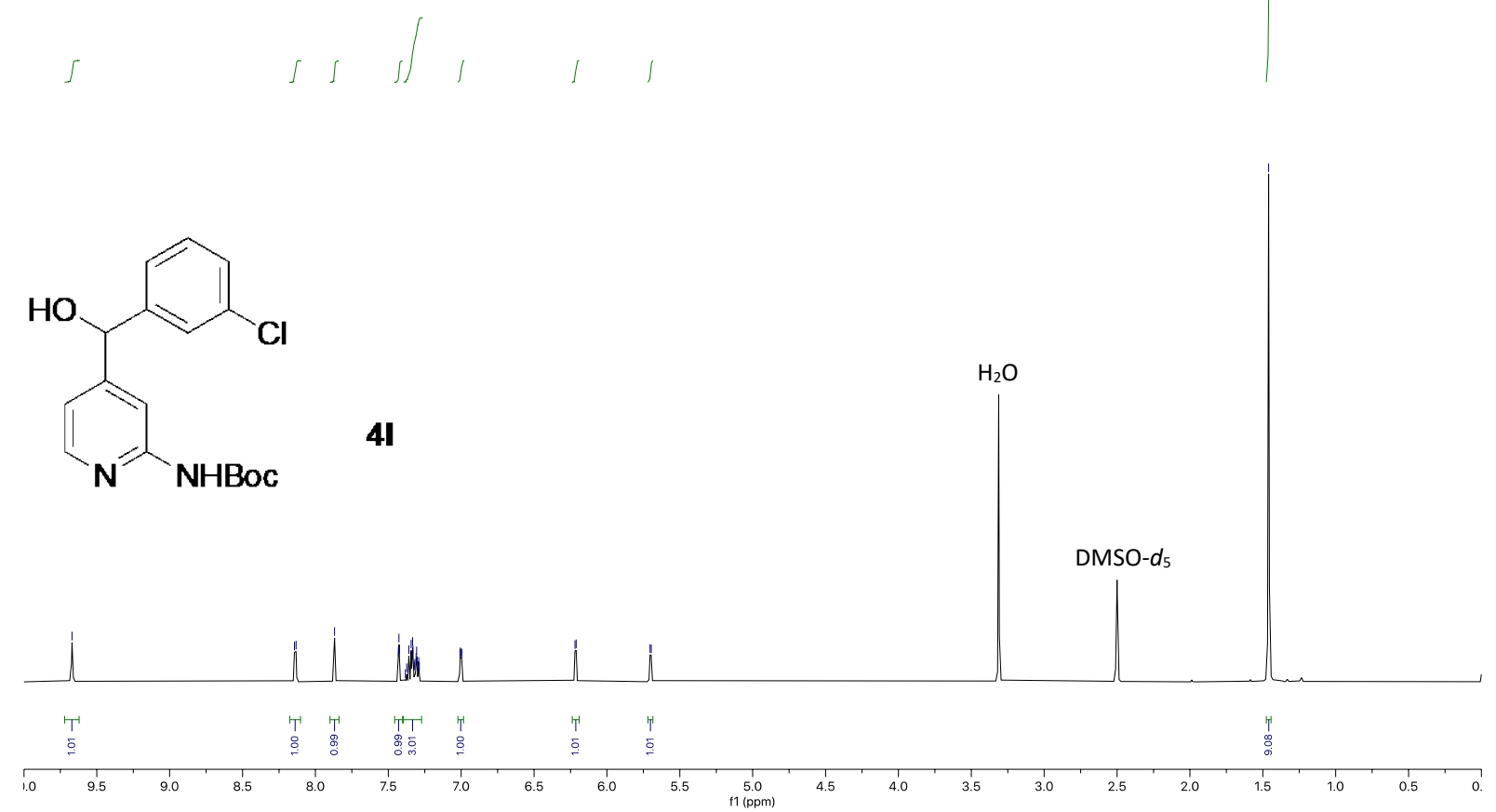

IV V V

${ }^{13} \mathrm{C}$ NMR (126 MHz, DMSO- $d_{6}$ )
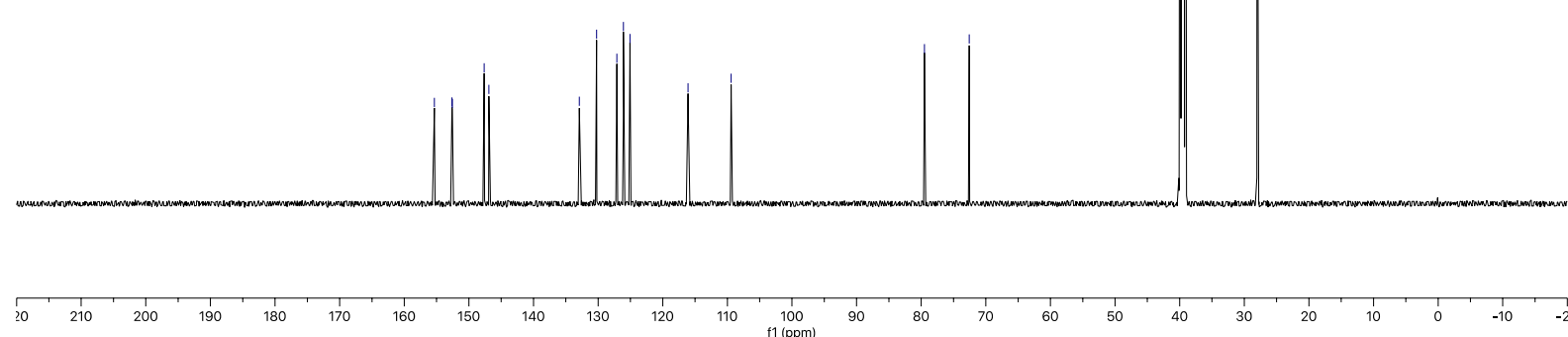


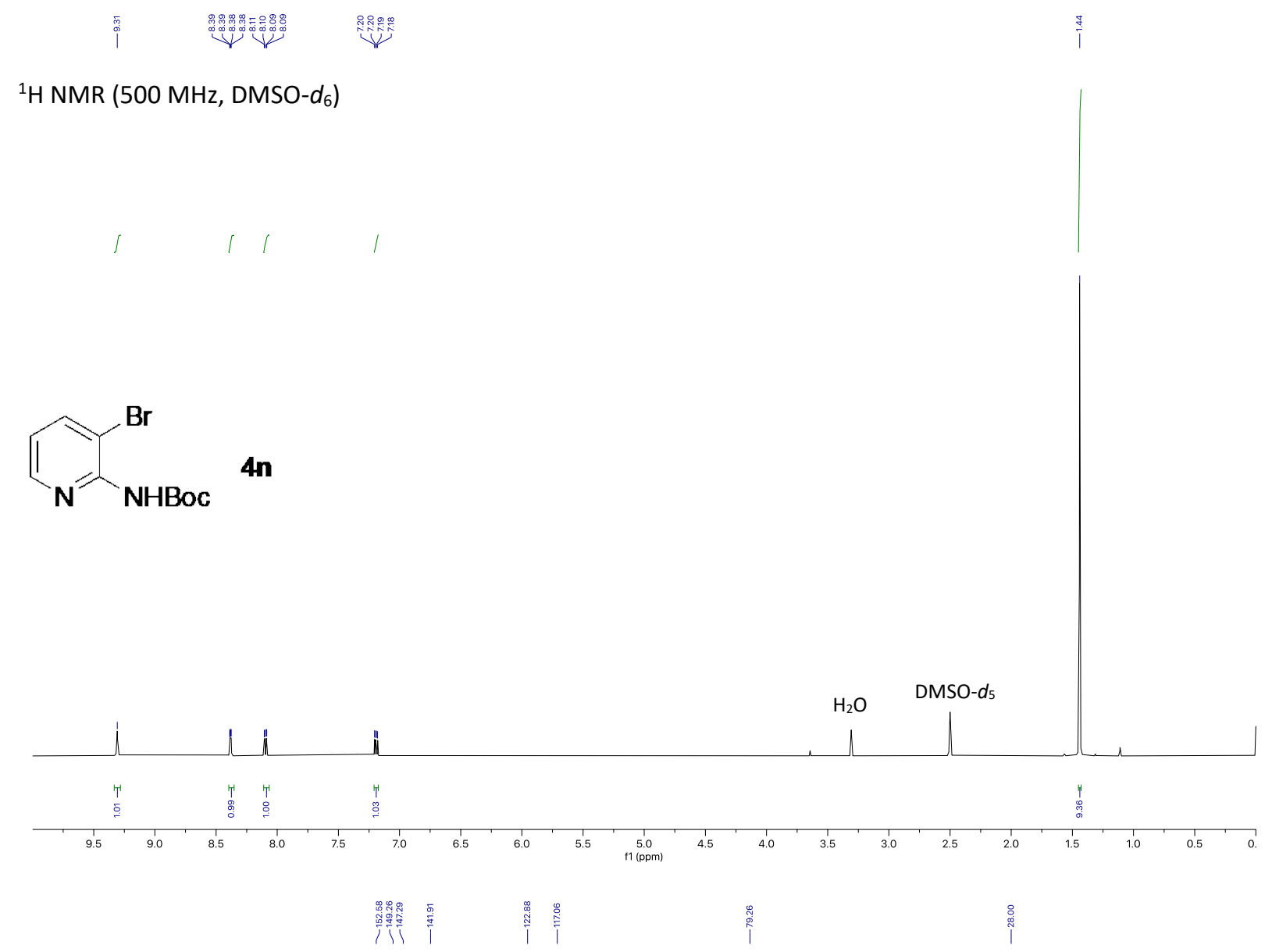

${ }^{13} \mathrm{C}$ NMR (126 MHz, DMSO- $d_{6}$ )

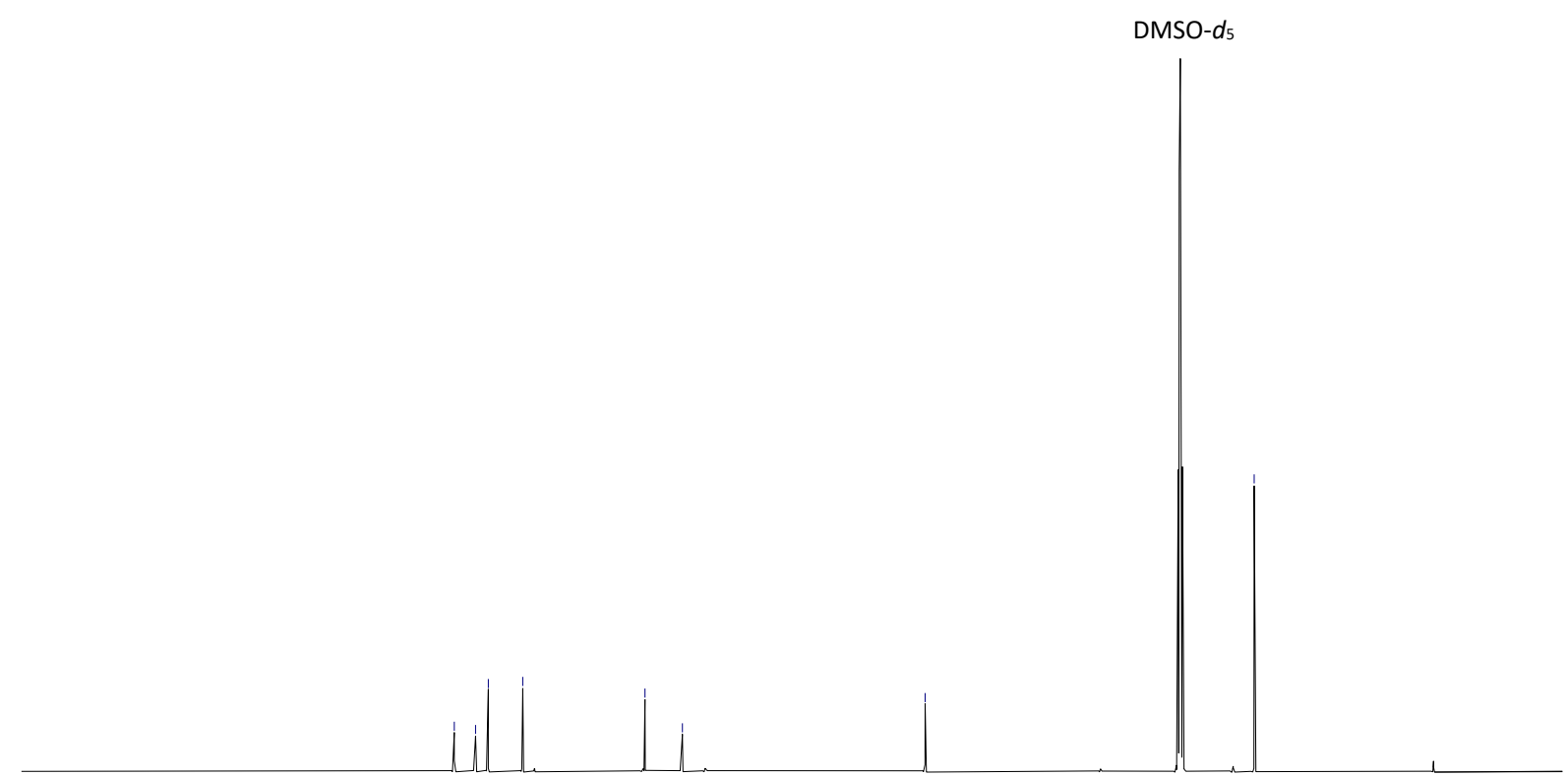

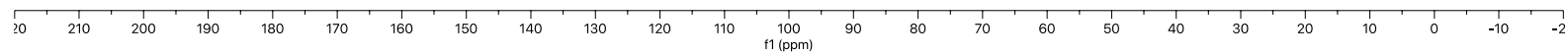



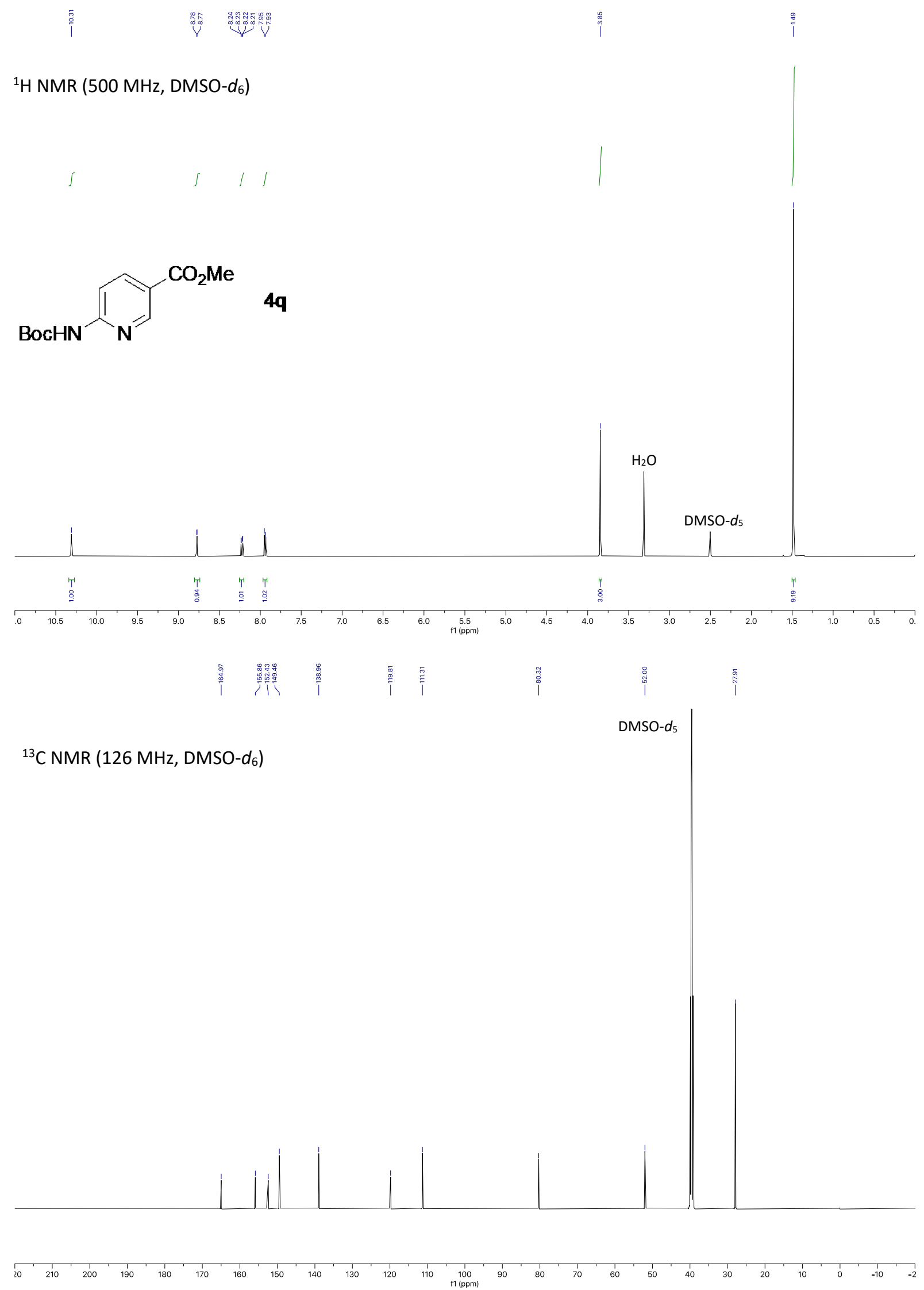
${ }^{1} \mathrm{H}$ NMR (500 MHz, DMSO- $d_{6}$ )

$\int \quad 1 / 1 / 1$

BocHN

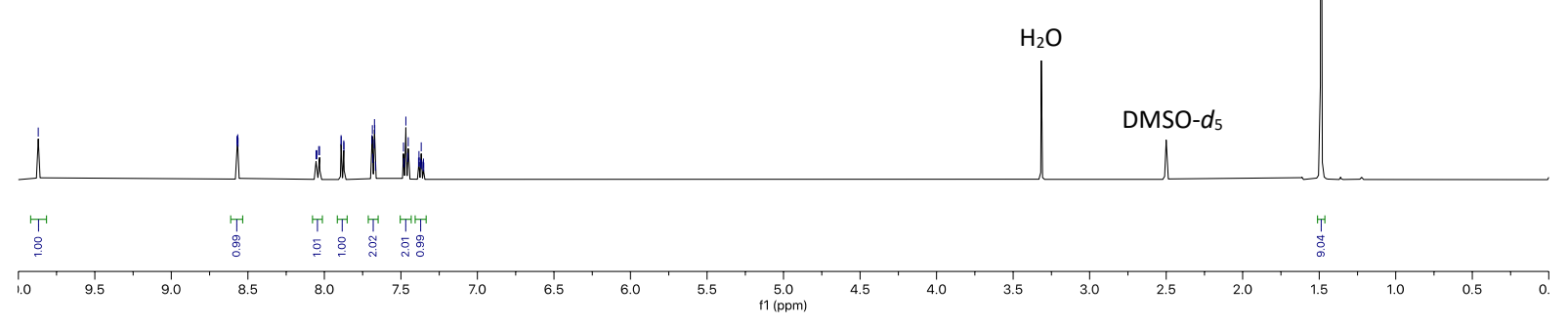

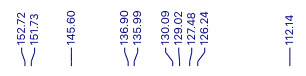

${ }^{13} \mathrm{C}$ NMR (126 MHz, DMSO- $d_{6}$ )

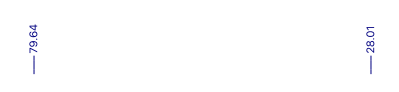

DMSO-d $d_{5}$

(13)

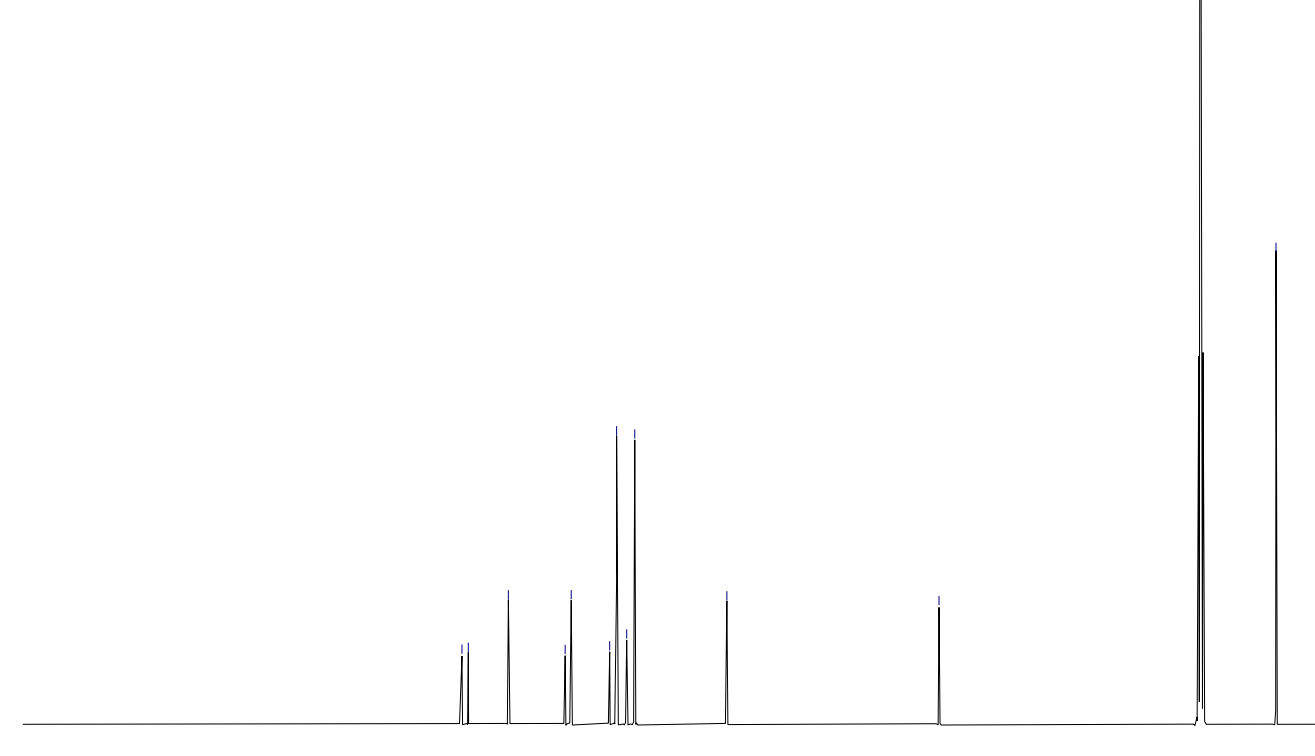

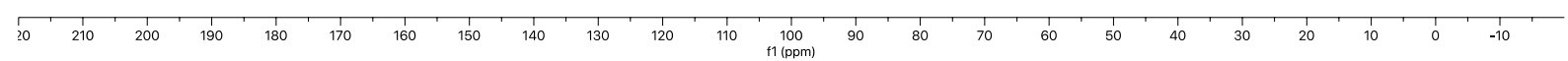




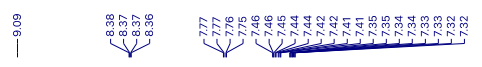

${ }^{1} \mathrm{H}$ NMR $\left(500 \mathrm{MHz}, \mathrm{DMSO}-d_{6}\right)$

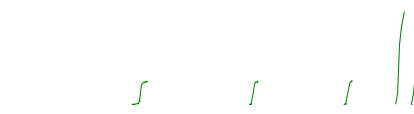

4r Minor

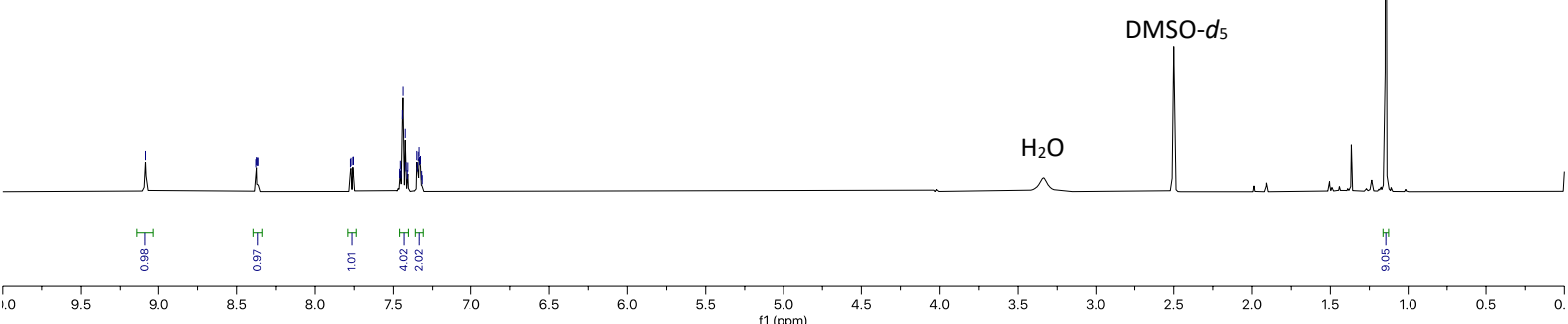

\section{|l|}

${ }^{13} \mathrm{C}$ NMR (126 MHz, DMSO- $d_{6}$ )

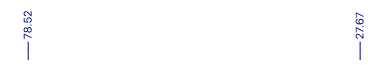

DMSO- $d_{5}$
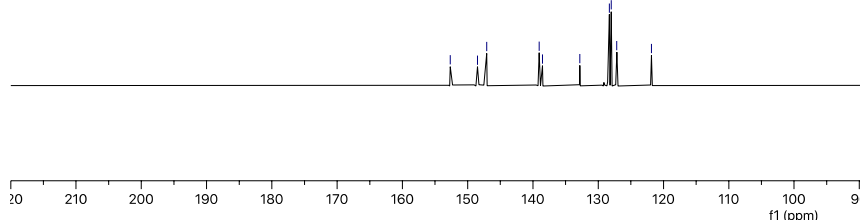


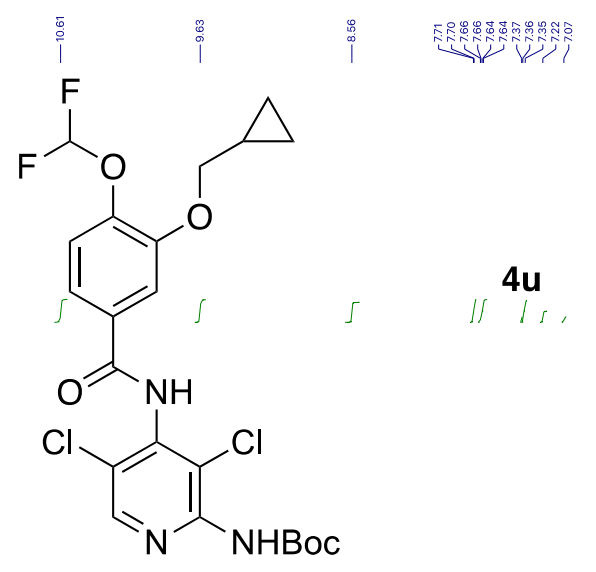

${ }^{1} \mathrm{H}$ NMR $\left(500 \mathrm{MHz}, \mathrm{DMSO}-d_{6}\right)$

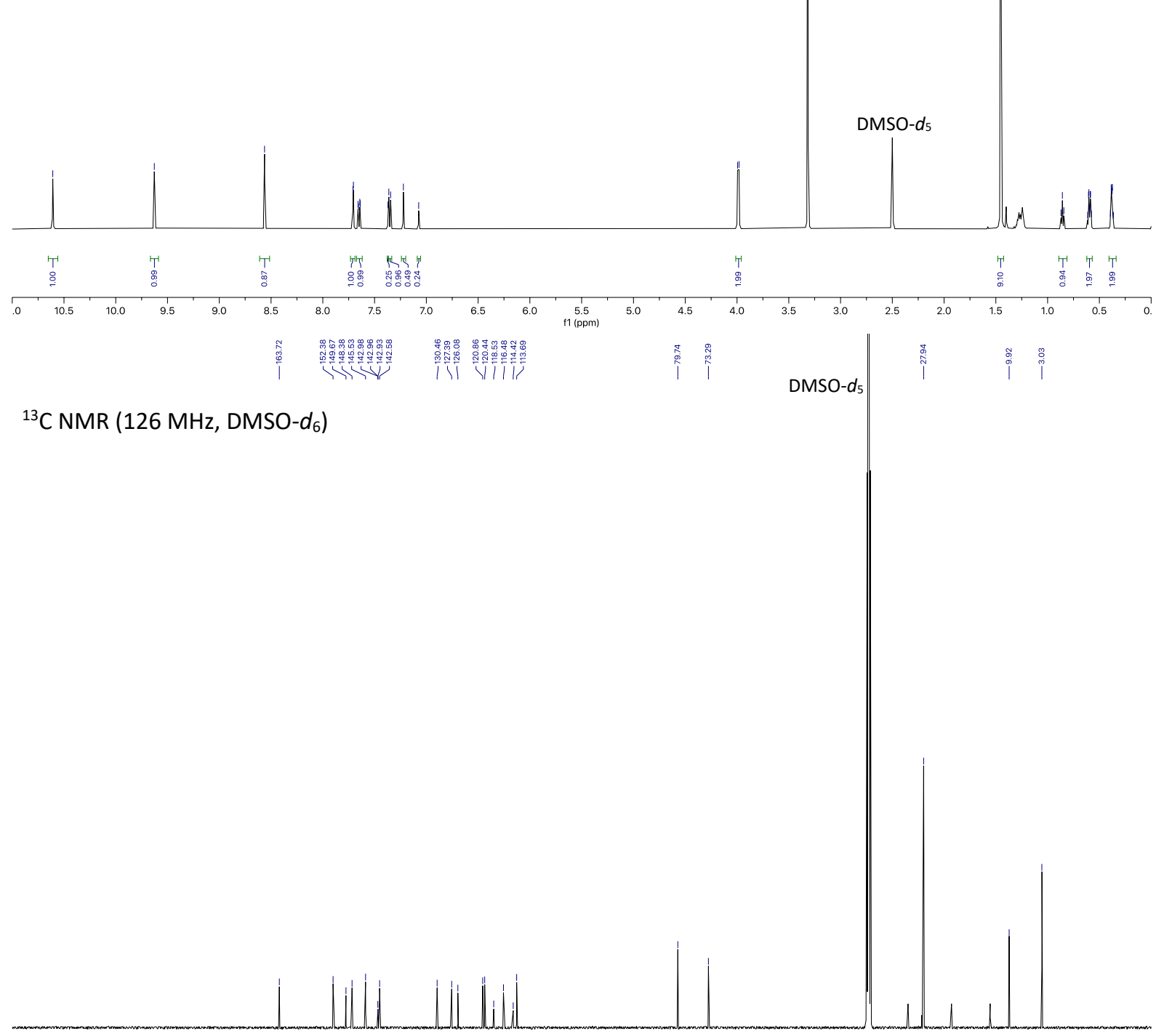


${ }^{1} \mathrm{H}$ NMR $\left(600 \mathrm{MHz}\right.$, dioxane- $\left.\mathrm{d}_{8}\right)$
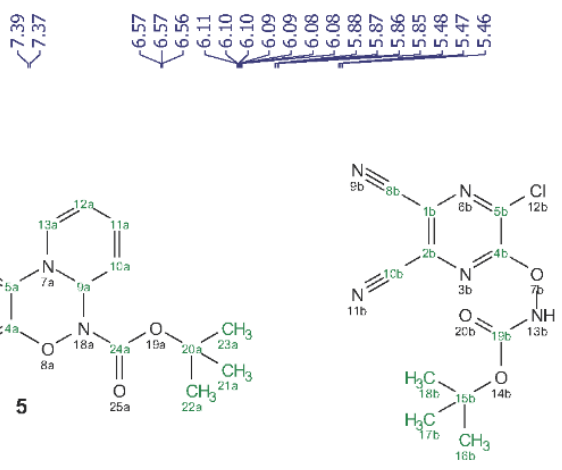

TMS-acetamide
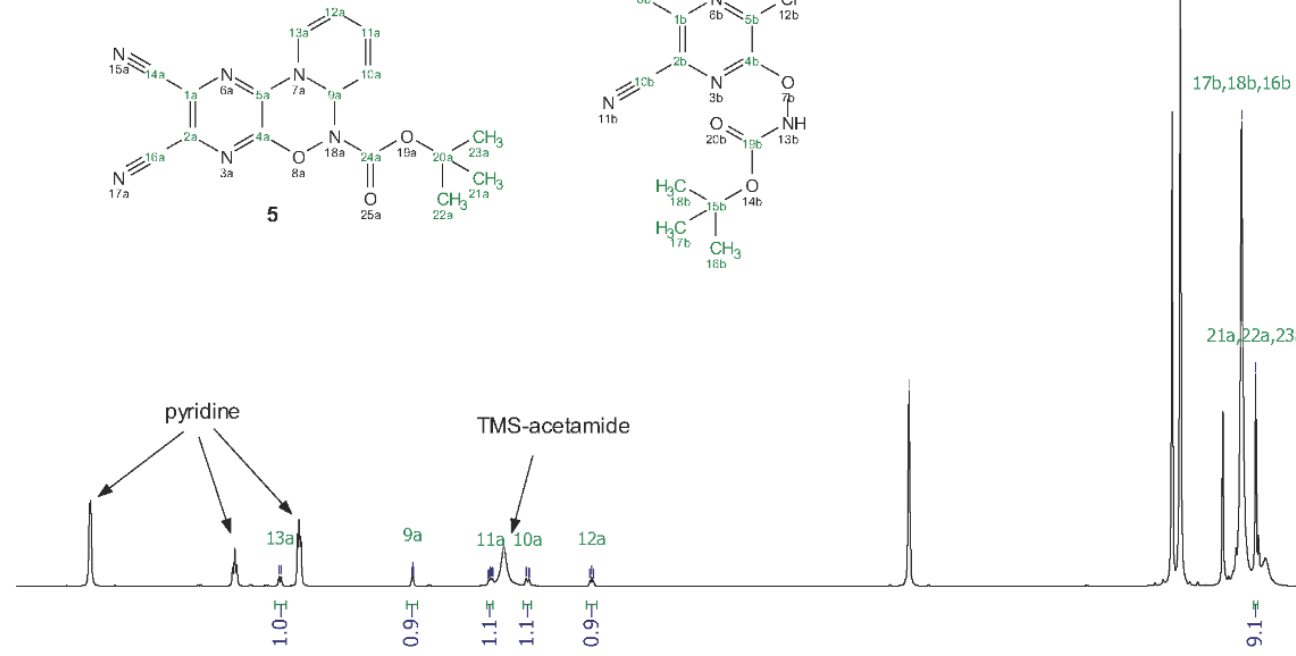

(ppm)

${ }^{13} \mathrm{C}$ NMR (151 MHz, dioxane- $\mathrm{d}_{8}$ )
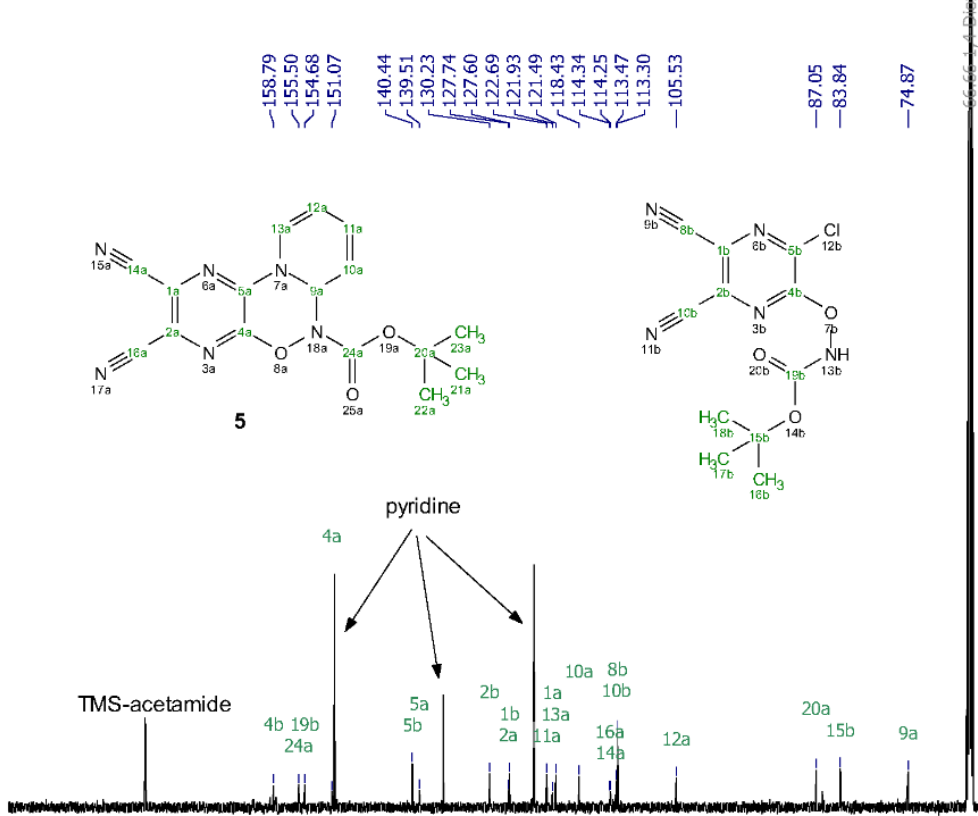

$190-180-170$

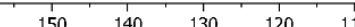

10090
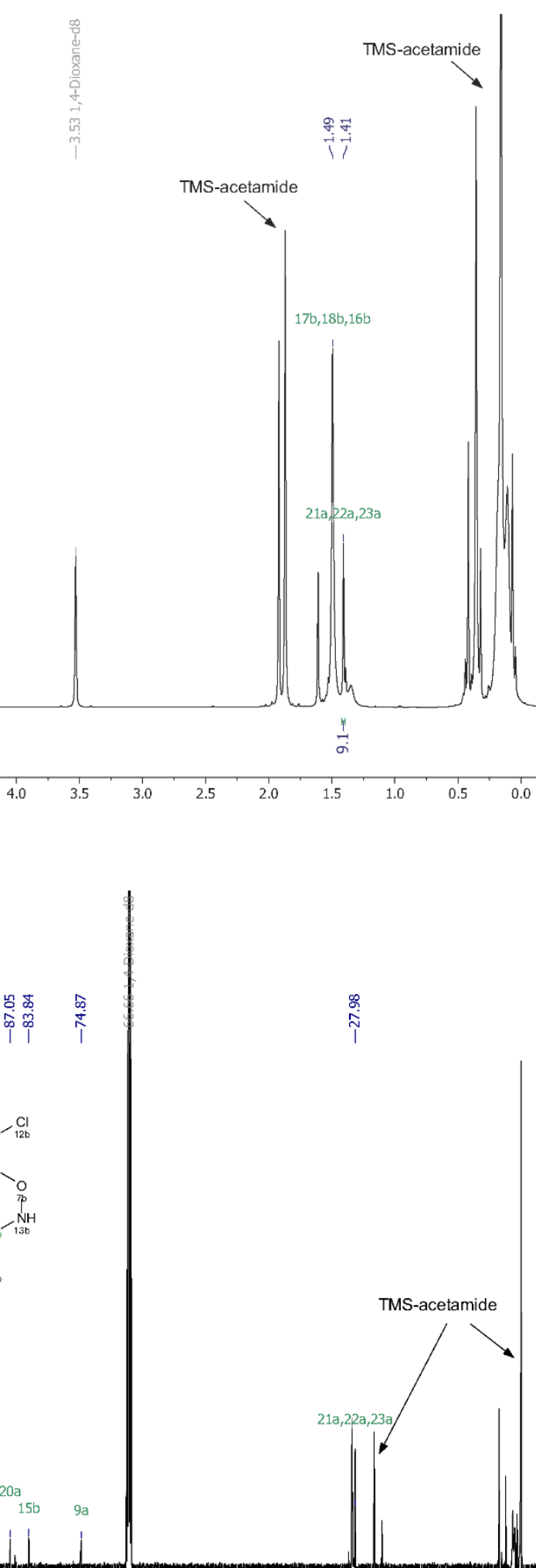
${ }^{1} \mathrm{H} /{ }^{1} \mathrm{H}$ COSY NMR $\left(600 / 600 \mathrm{MHz}\right.$, dioxane- $\left.\mathrm{d}_{8}\right)$
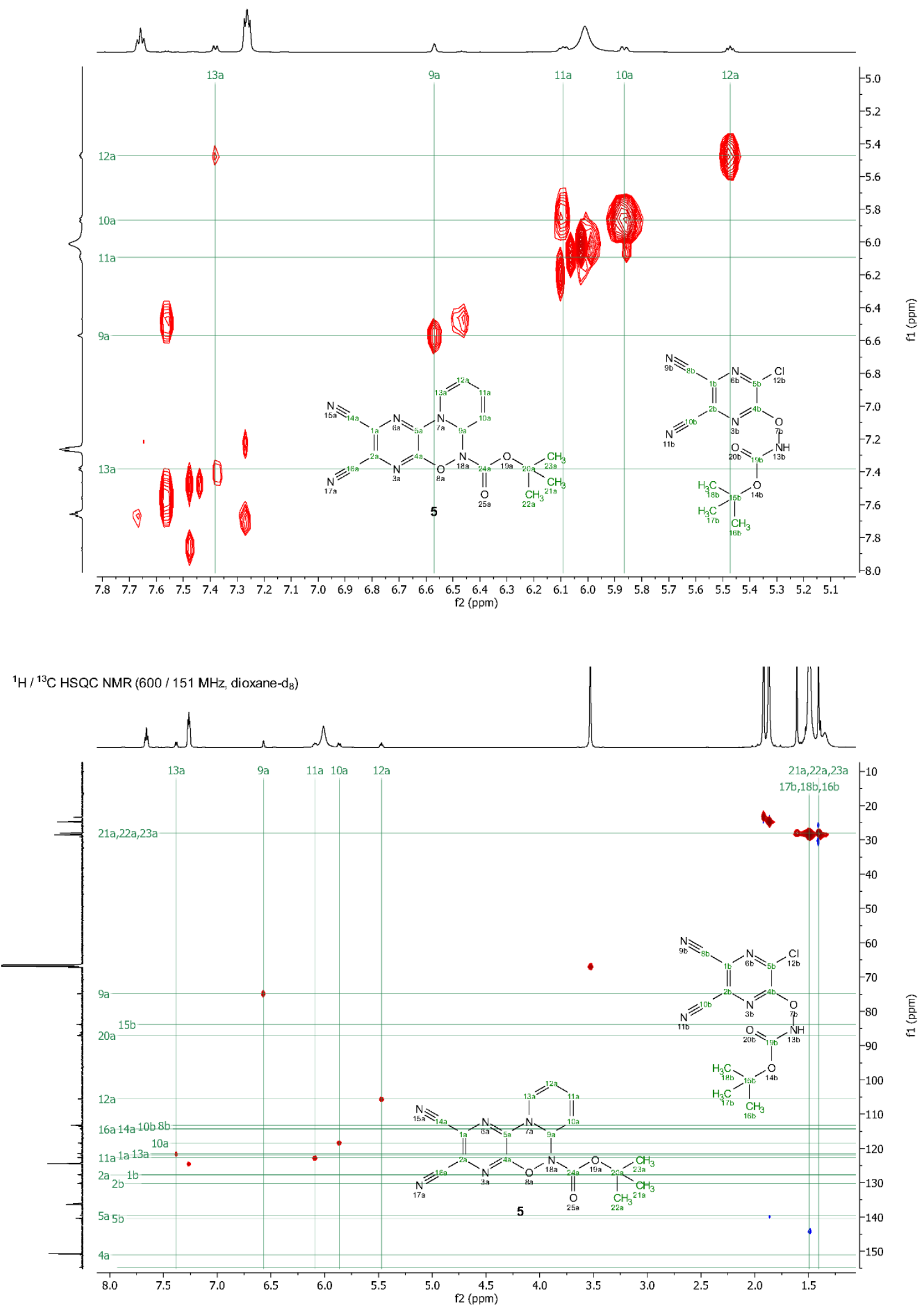


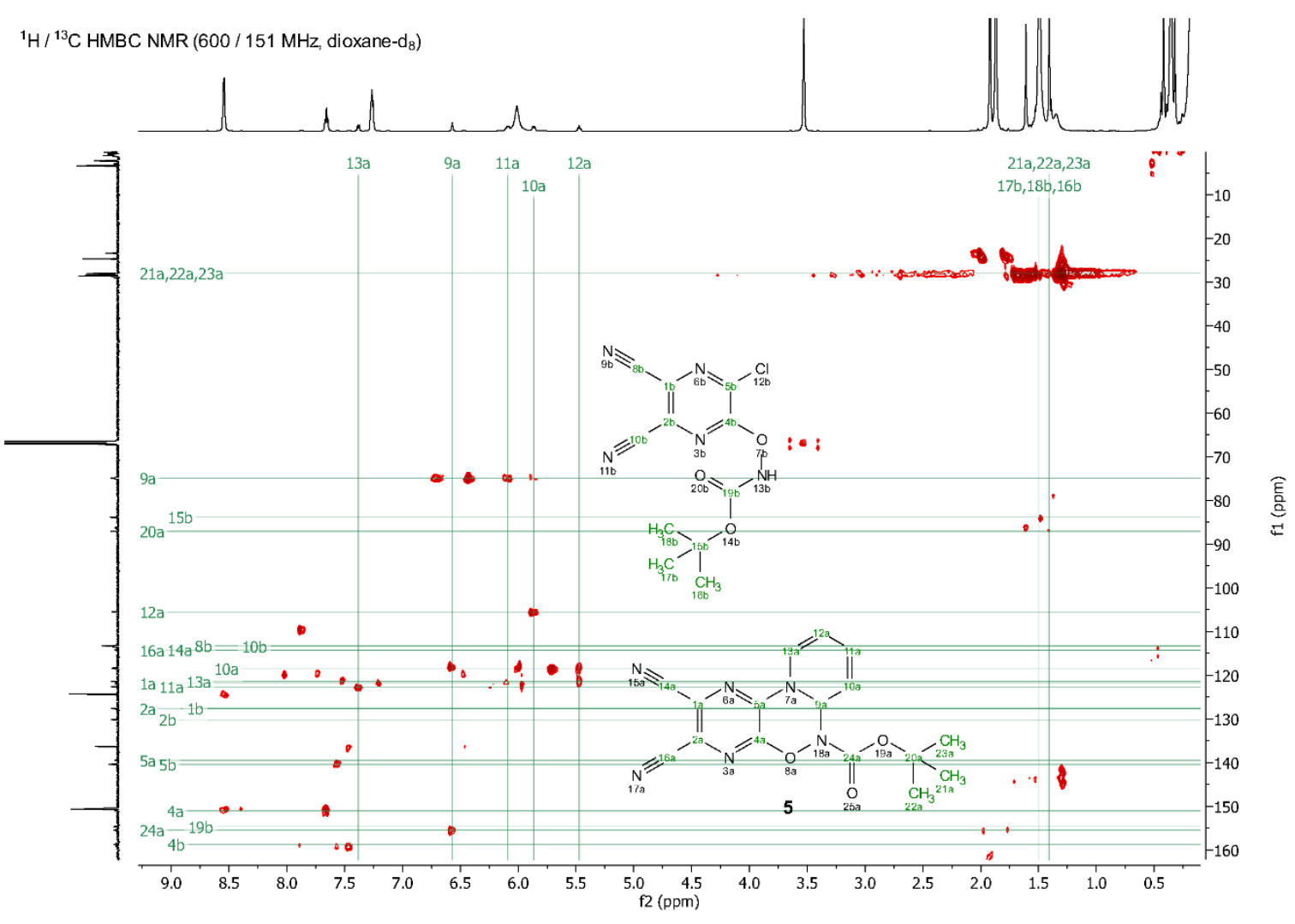

${ }^{1} \mathrm{H}$ NMR $\left(600 \mathrm{MHz}\right.$, dioxane- $\left.\mathrm{d}_{8}\right)$

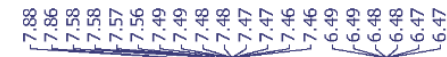
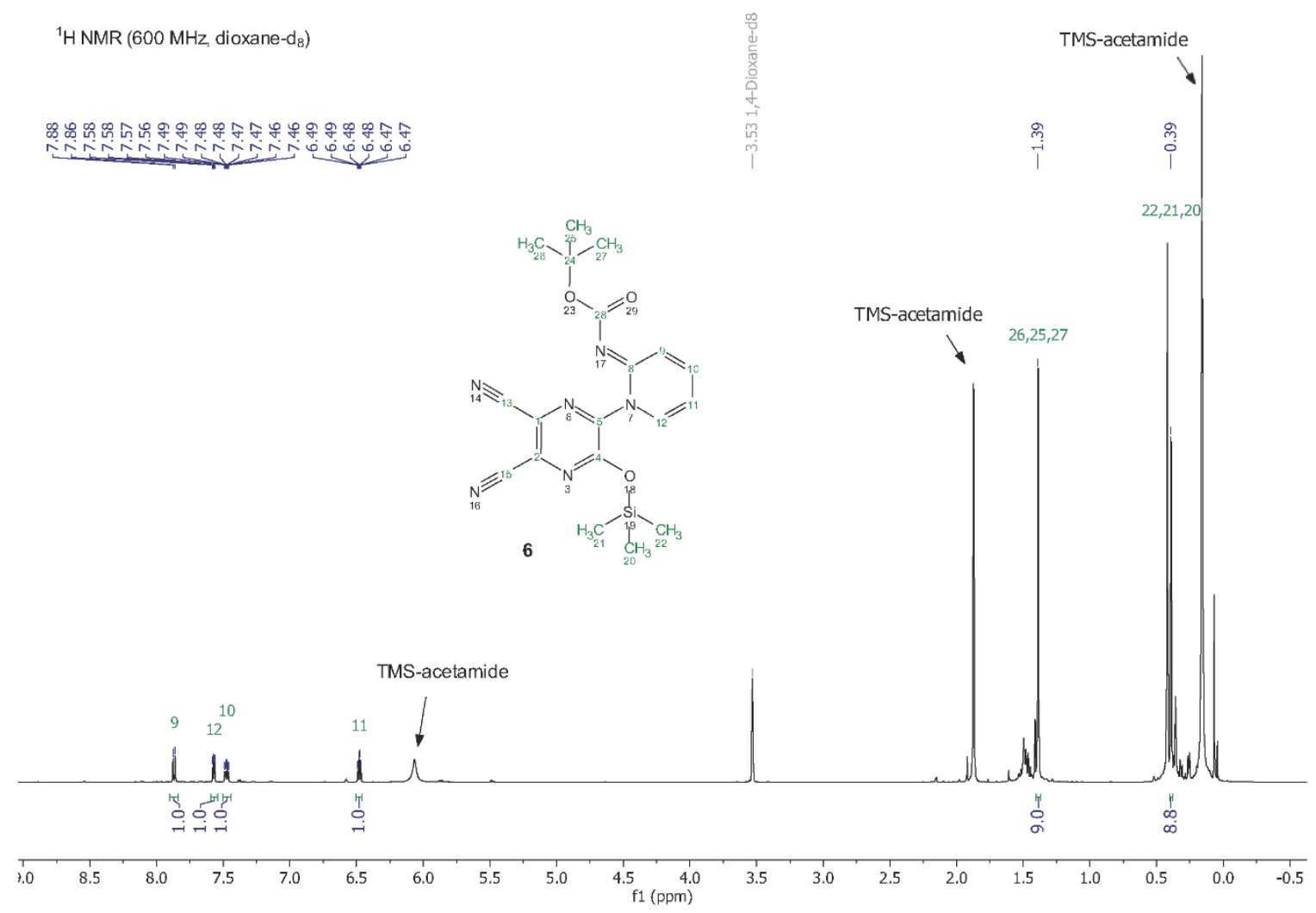
${ }^{13} \mathrm{C}$ NMR (151 MHz, dioxane- $\mathrm{d}_{8}$ )
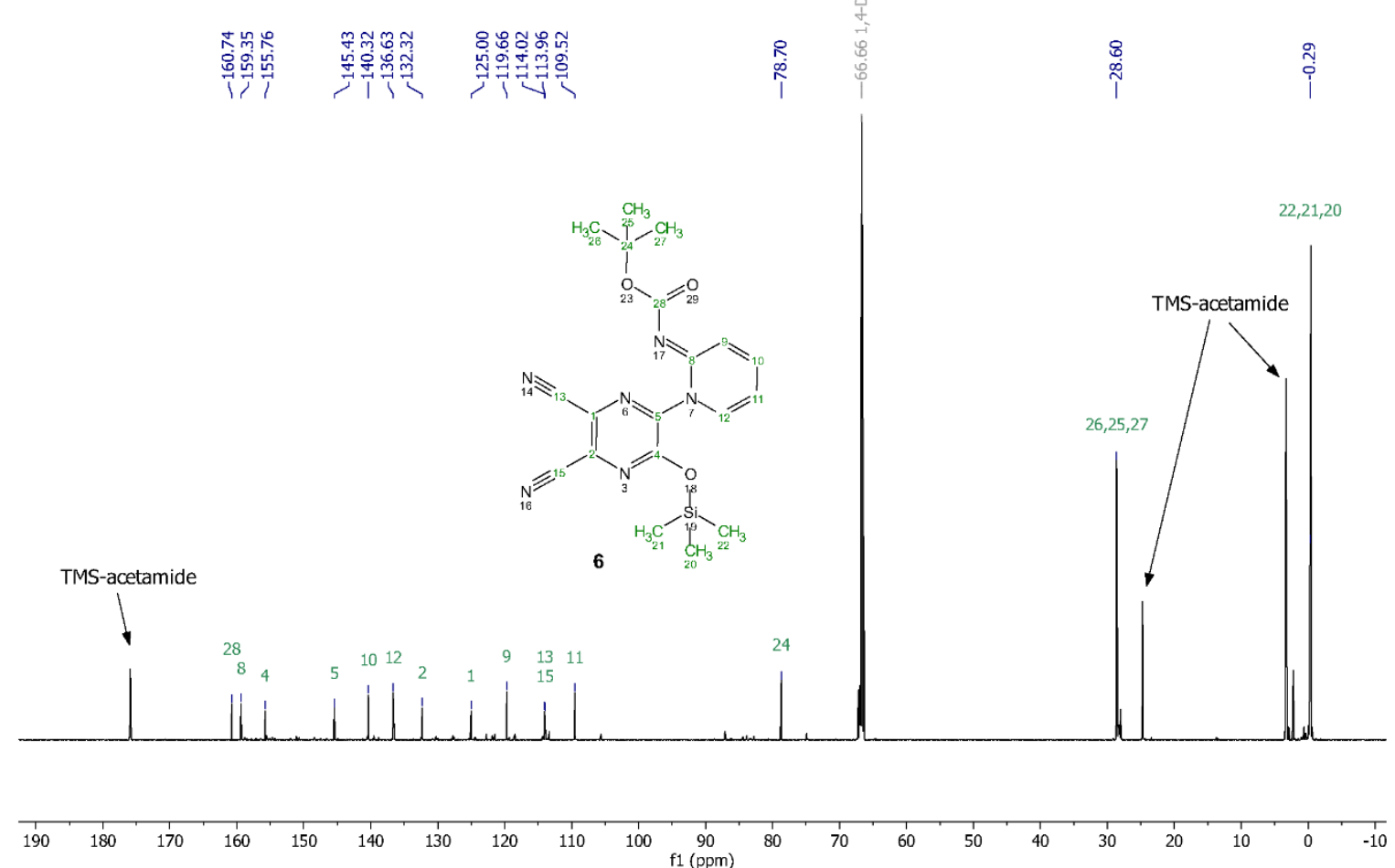

${ }^{1} \mathrm{H} /{ }^{1} \mathrm{H} \cos Y$ NMR $\left(600 / 600 \mathrm{MHz}\right.$, dioxane- $\left.\mathrm{d}_{8}\right)$

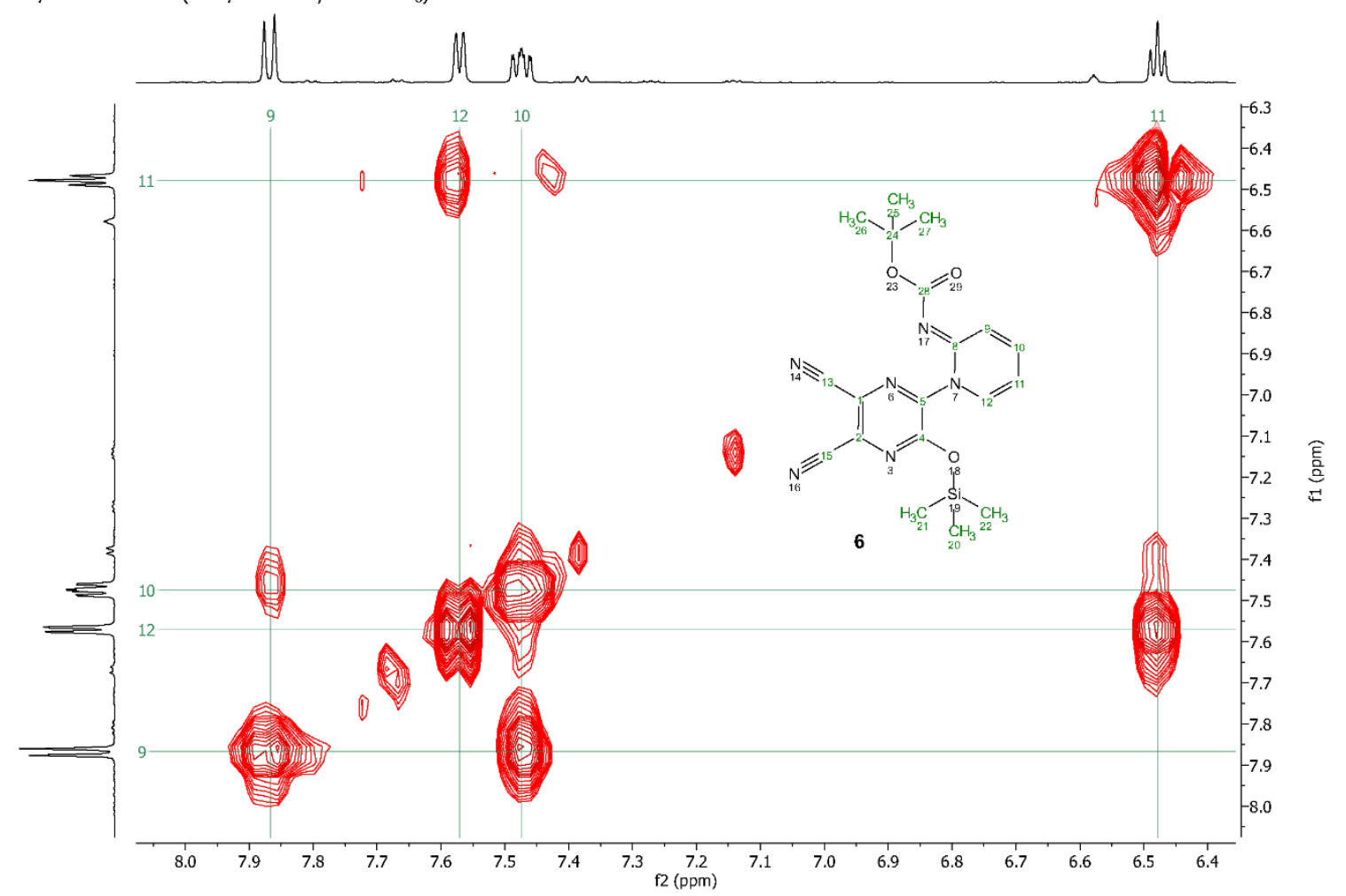



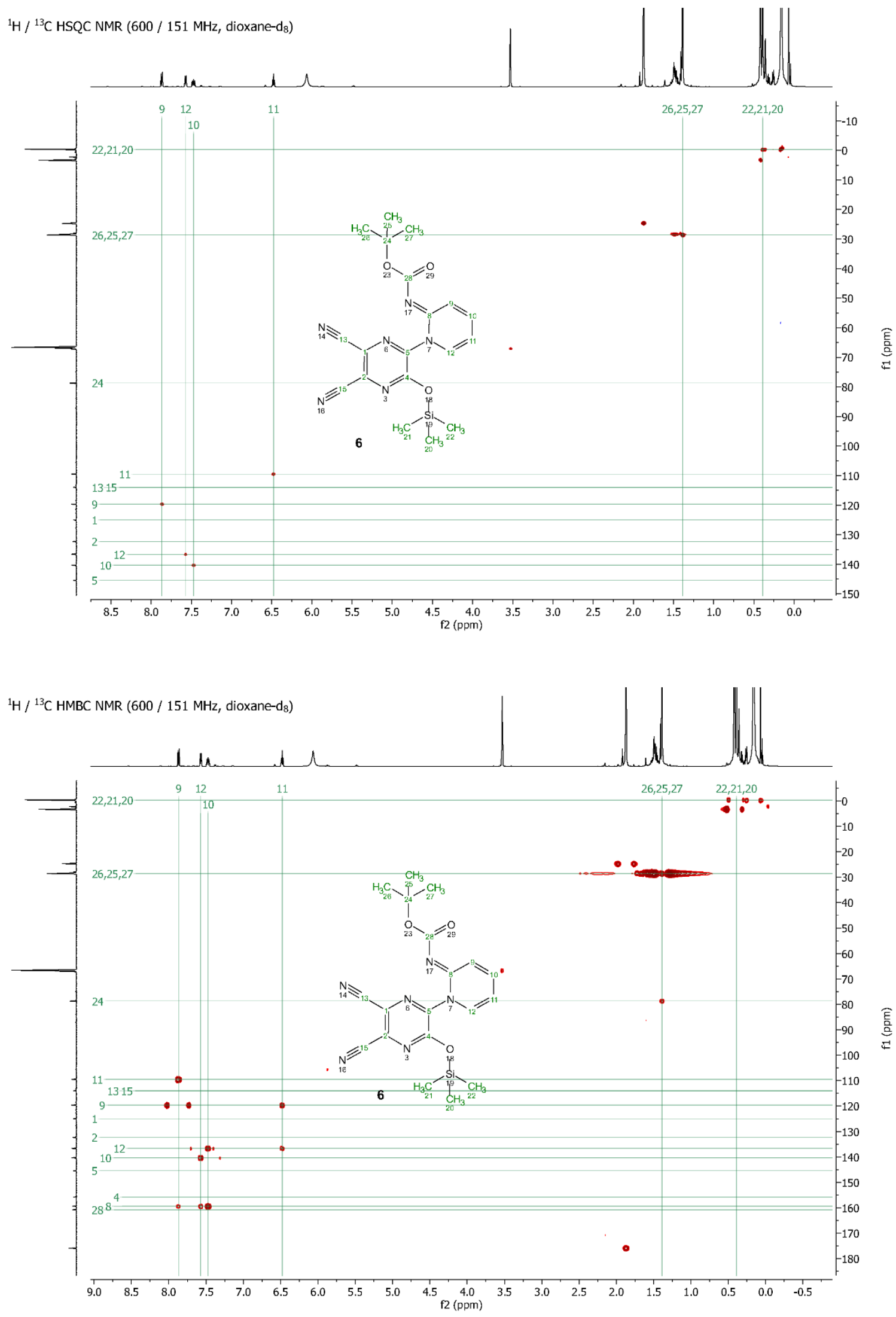
${ }^{1} \mathrm{H} /{ }^{13} \mathrm{C}$ LR-HSQMBC NMR (600 / $151 \mathrm{MHz}$, dioxane-d $)$

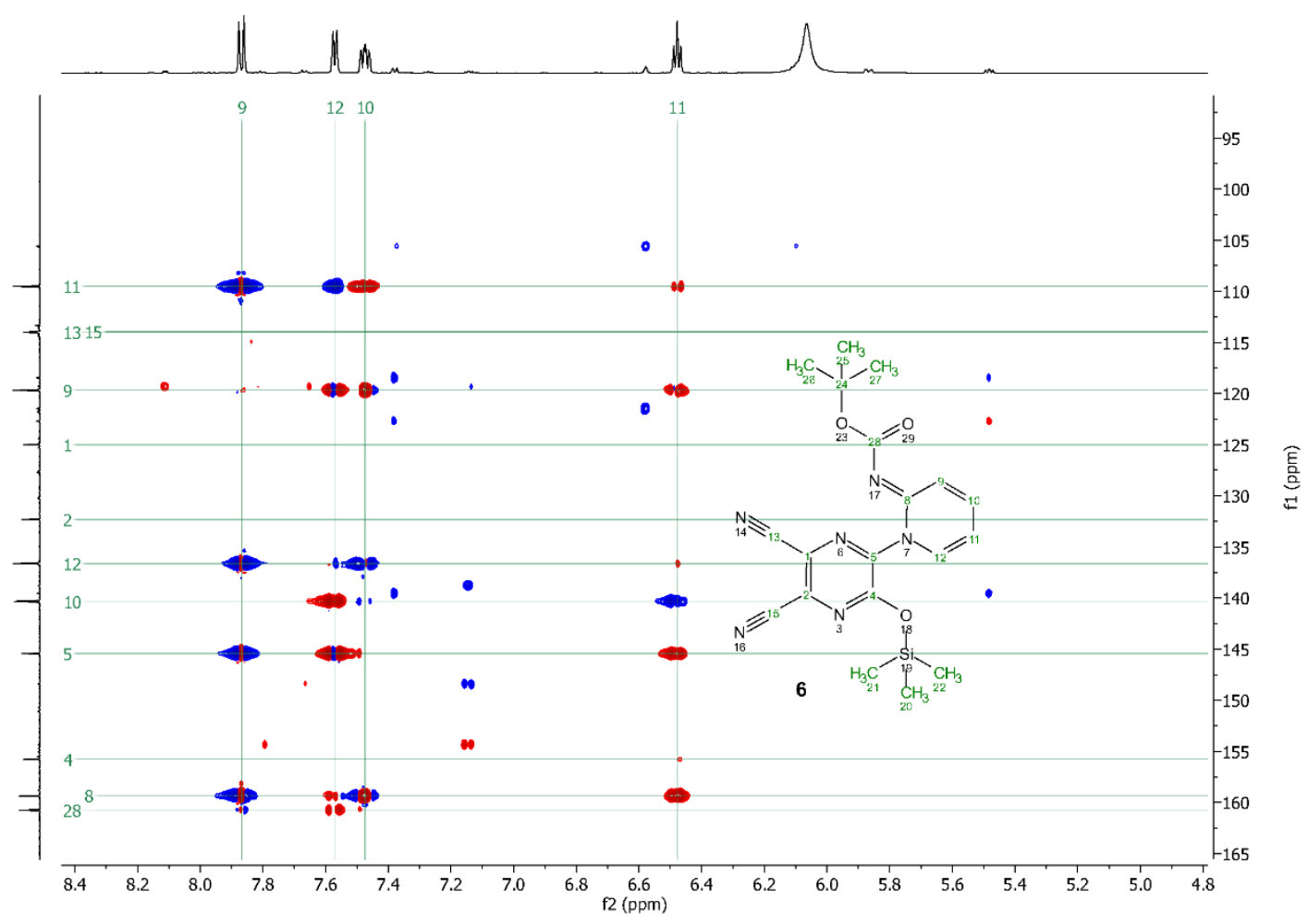

${ }^{1} \mathrm{H} /{ }^{1} \mathrm{H}$ NOESY NMR $(600 / 600 \mathrm{MHz}$, dioxane-d 8 )

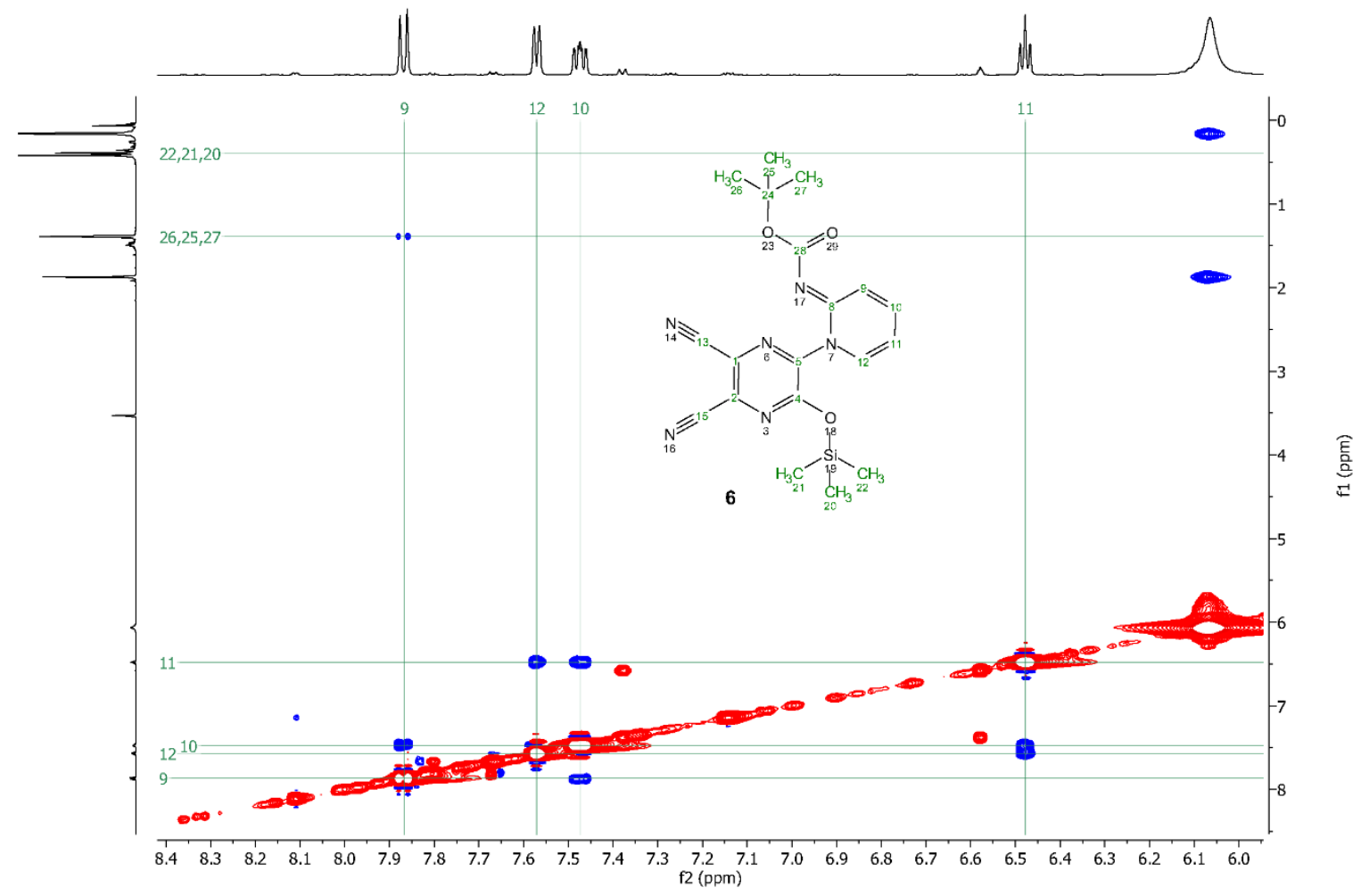




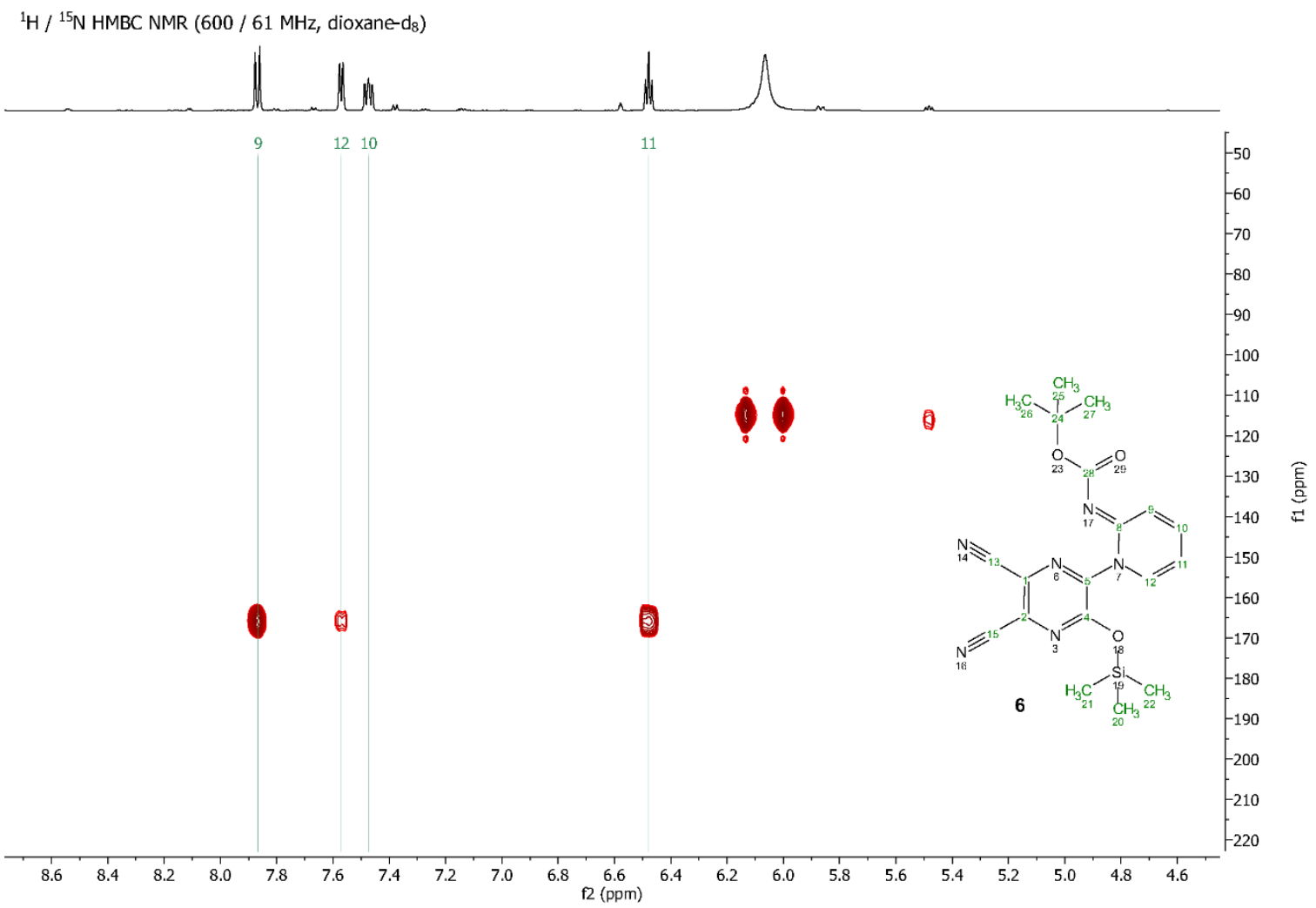



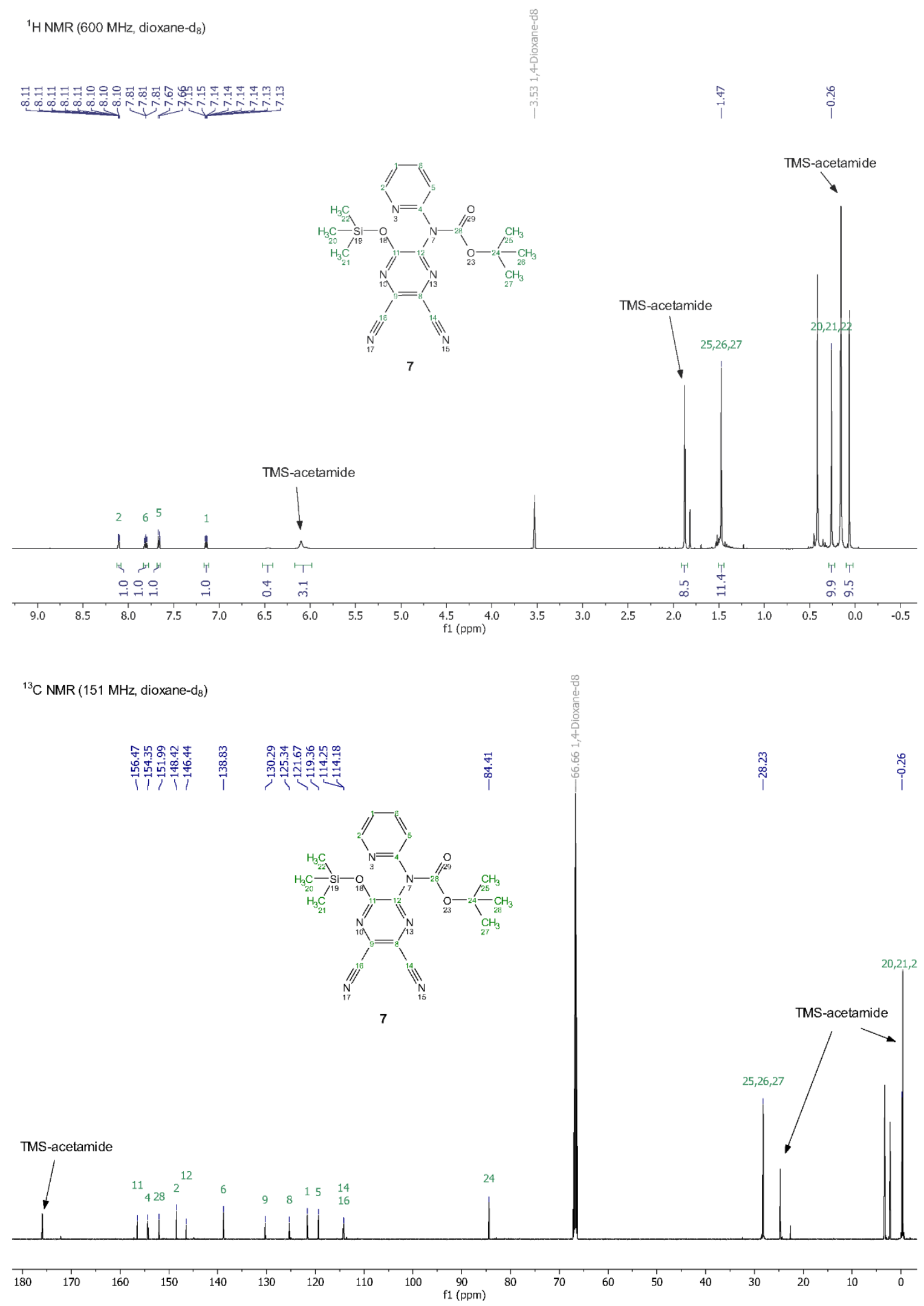
${ }^{1} \mathrm{H} /{ }^{1} \mathrm{H}$ COSY NMR $\left(600 / 600 \mathrm{MHz}\right.$, dioxane- $\left.\mathrm{d}_{8}\right)$

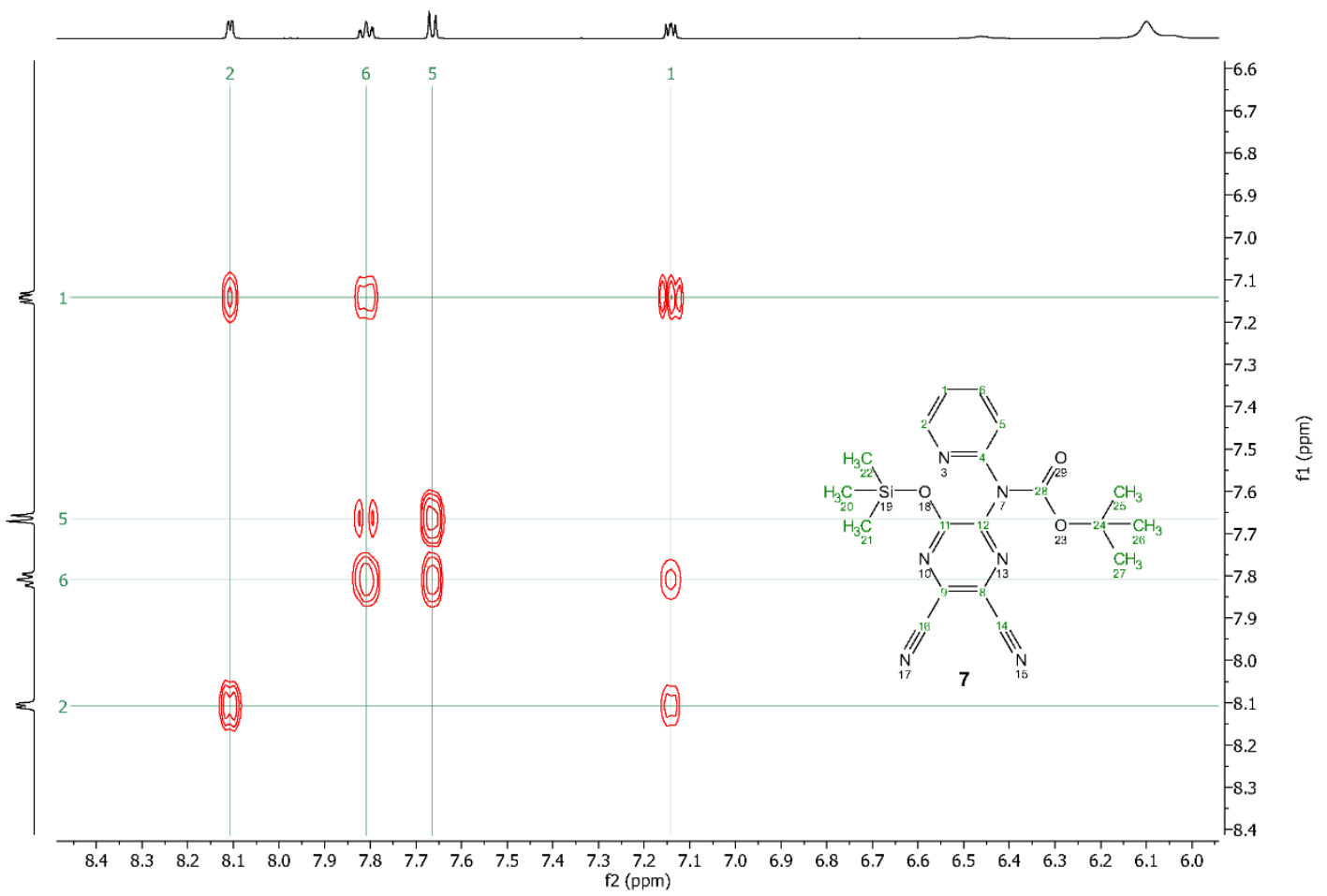

${ }^{1} \mathrm{H} /{ }^{13} \mathrm{C}$ HSQC NMR $\left(600 / 151 \mathrm{MHz}\right.$, dioxane- $\left.\mathrm{d}_{8}\right)$

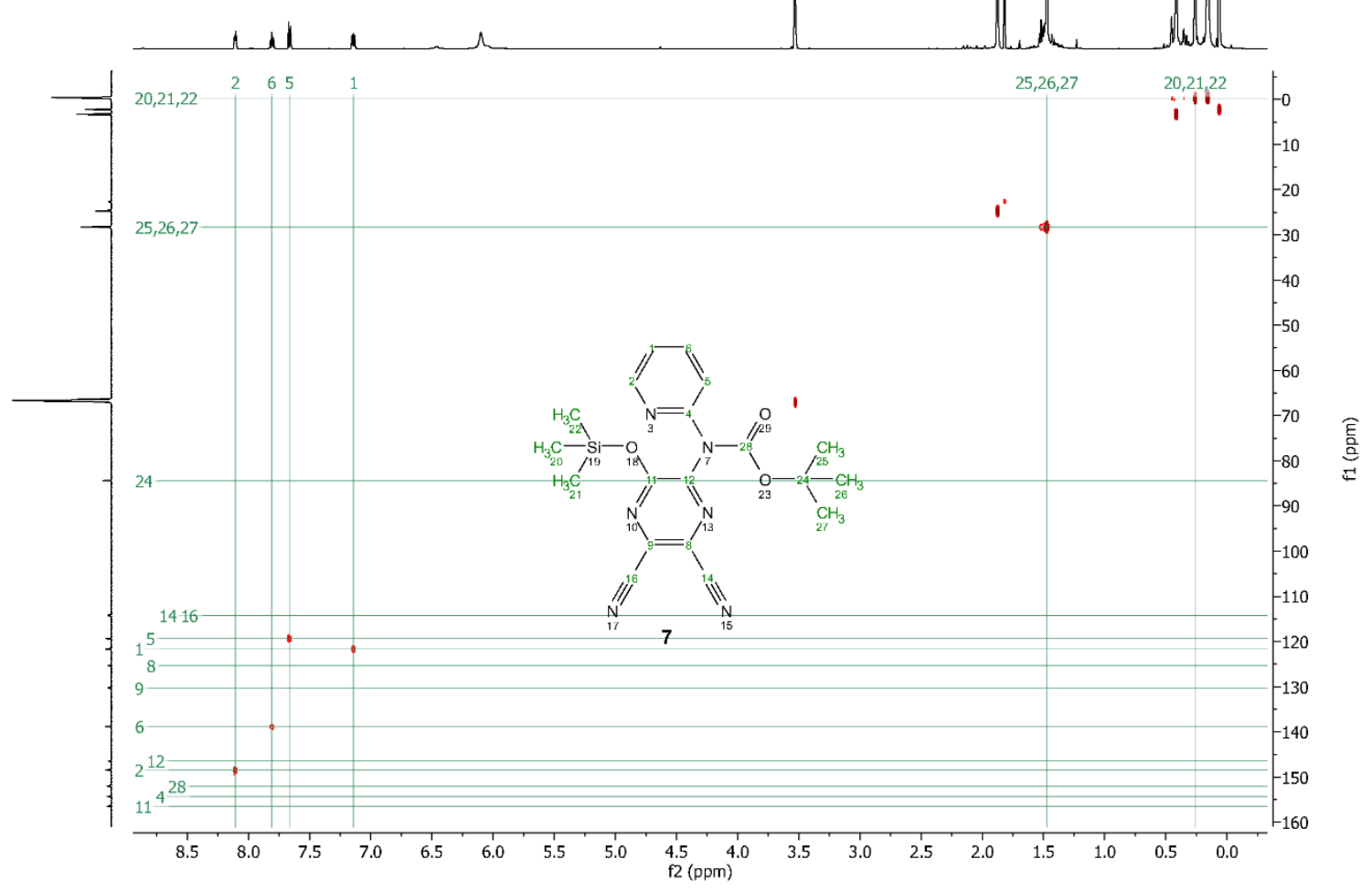




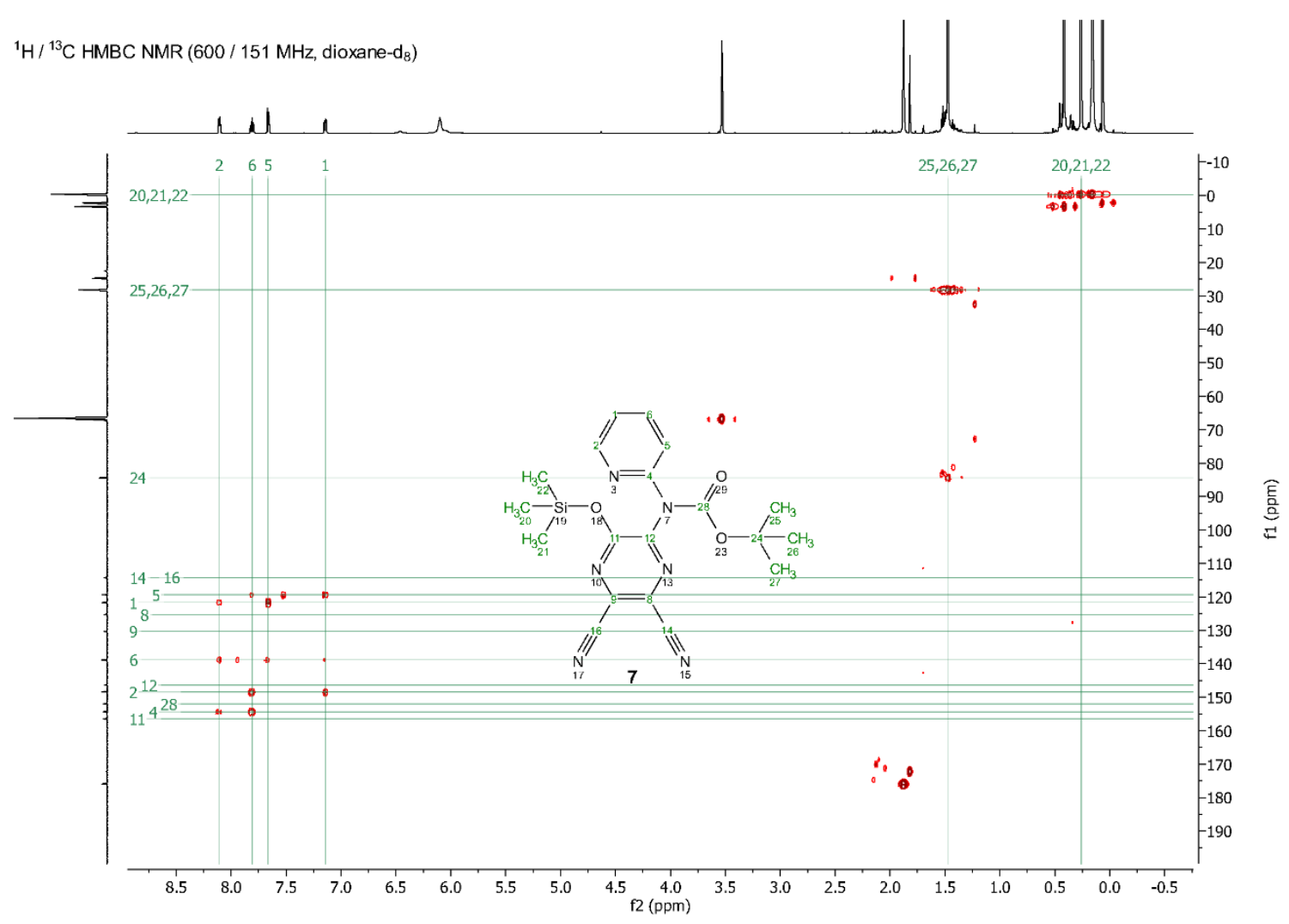

${ }^{1} \mathrm{H} /{ }^{1} \mathrm{H}$ NOESY NMR $\left(600 / 600 \mathrm{MHz}\right.$, dioxane- $\left.\mathrm{d}_{8}\right)$

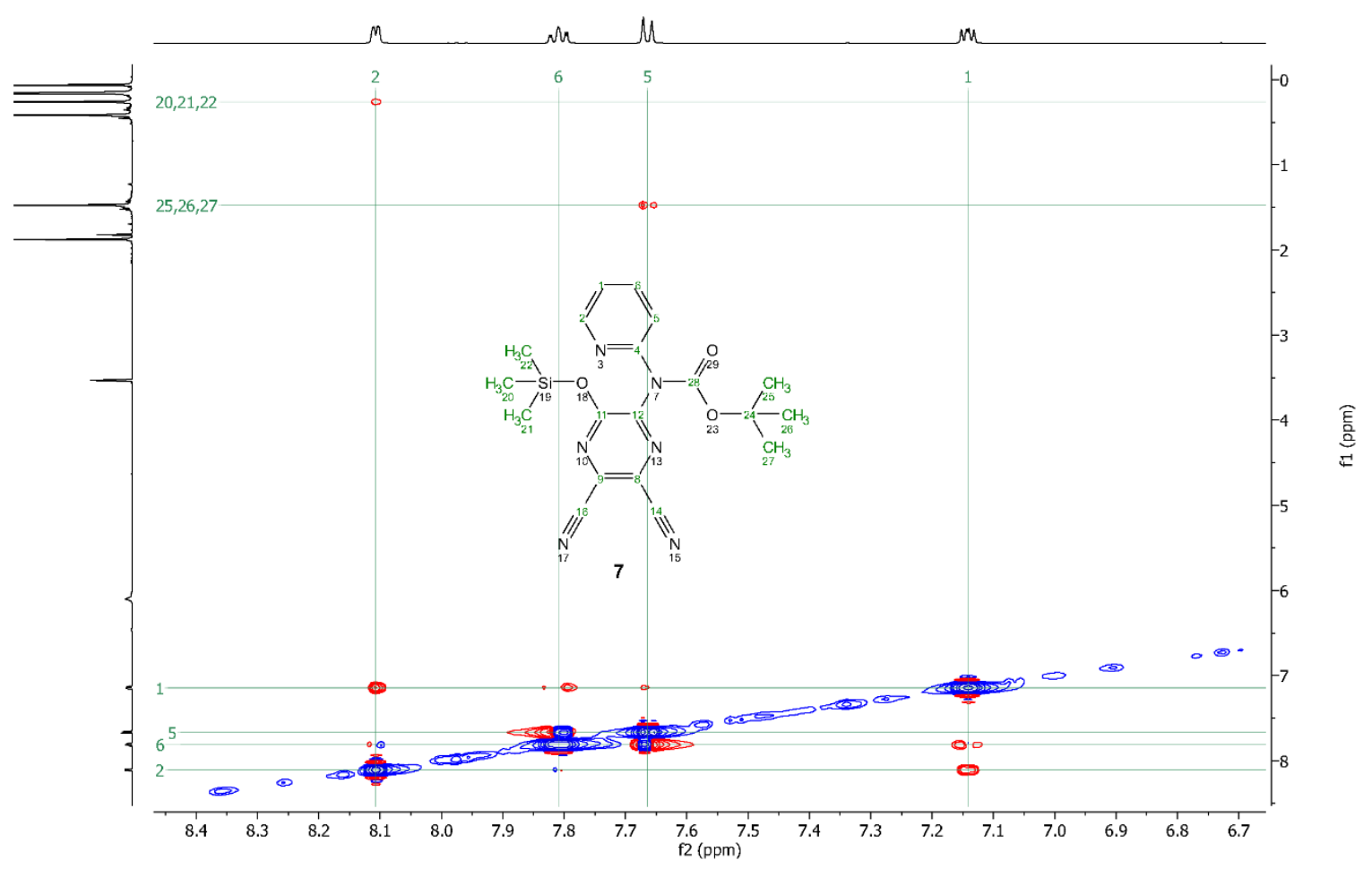



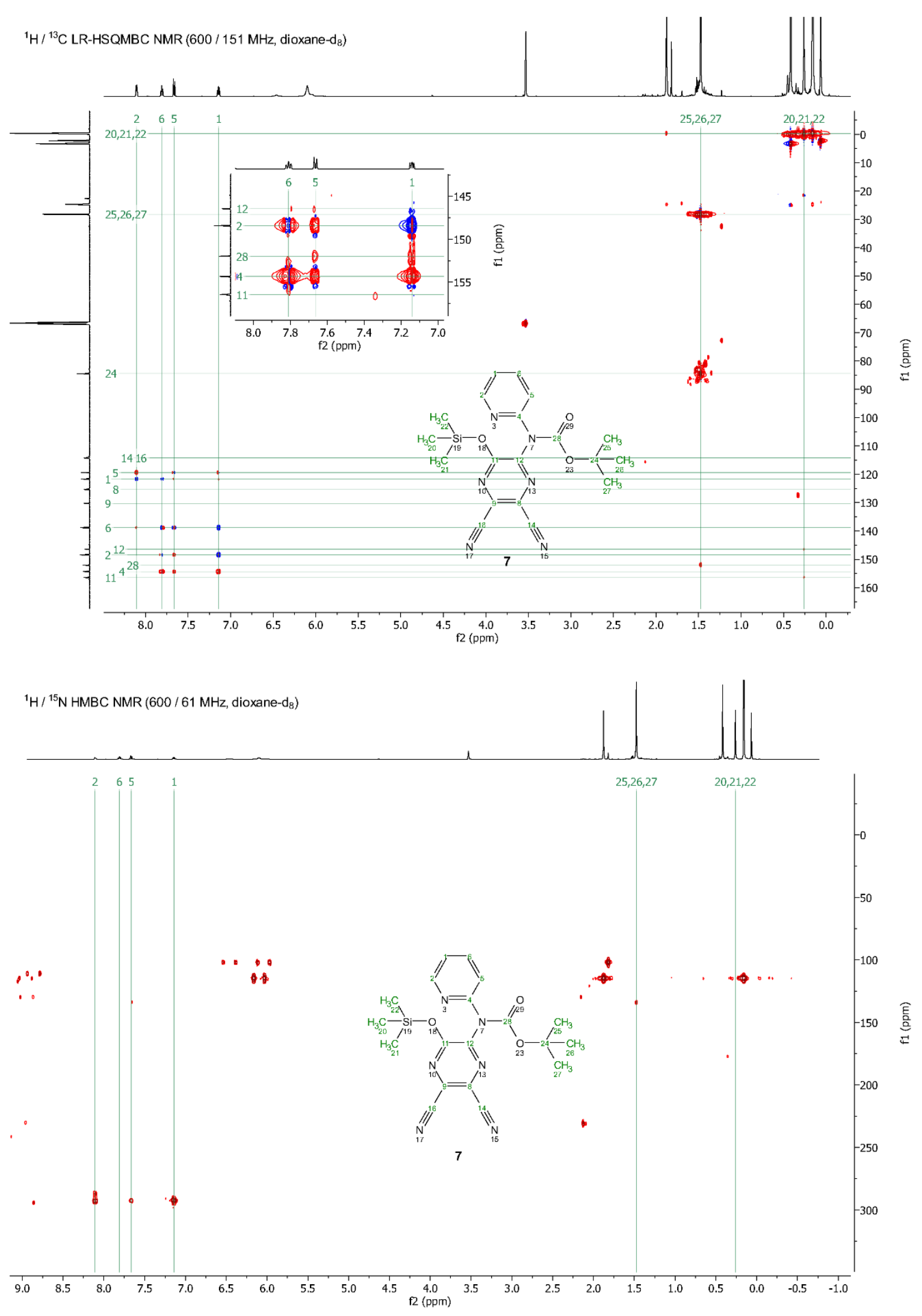
${ }^{1} \mathrm{H}$ NMR $\left(600 \mathrm{MHz}, 1: 1\right.$ dioxane- $\left.\mathrm{d}_{8} / \mathrm{CD}_{3} \mathrm{COOD}\right)$

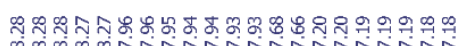

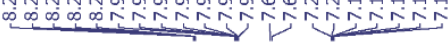

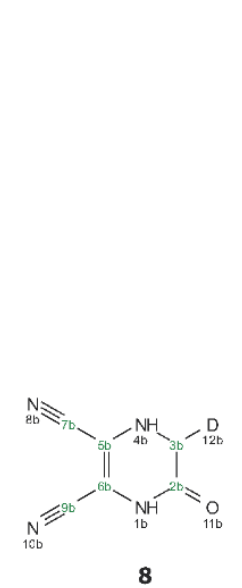

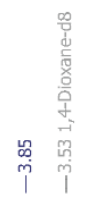

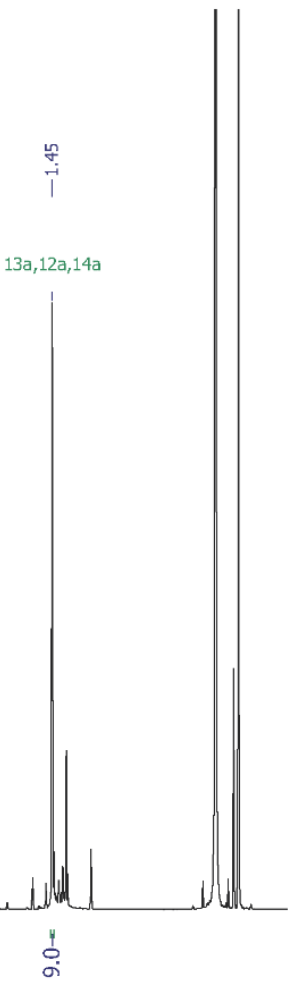

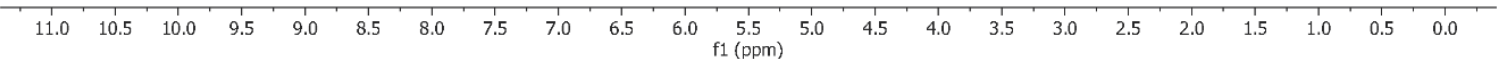

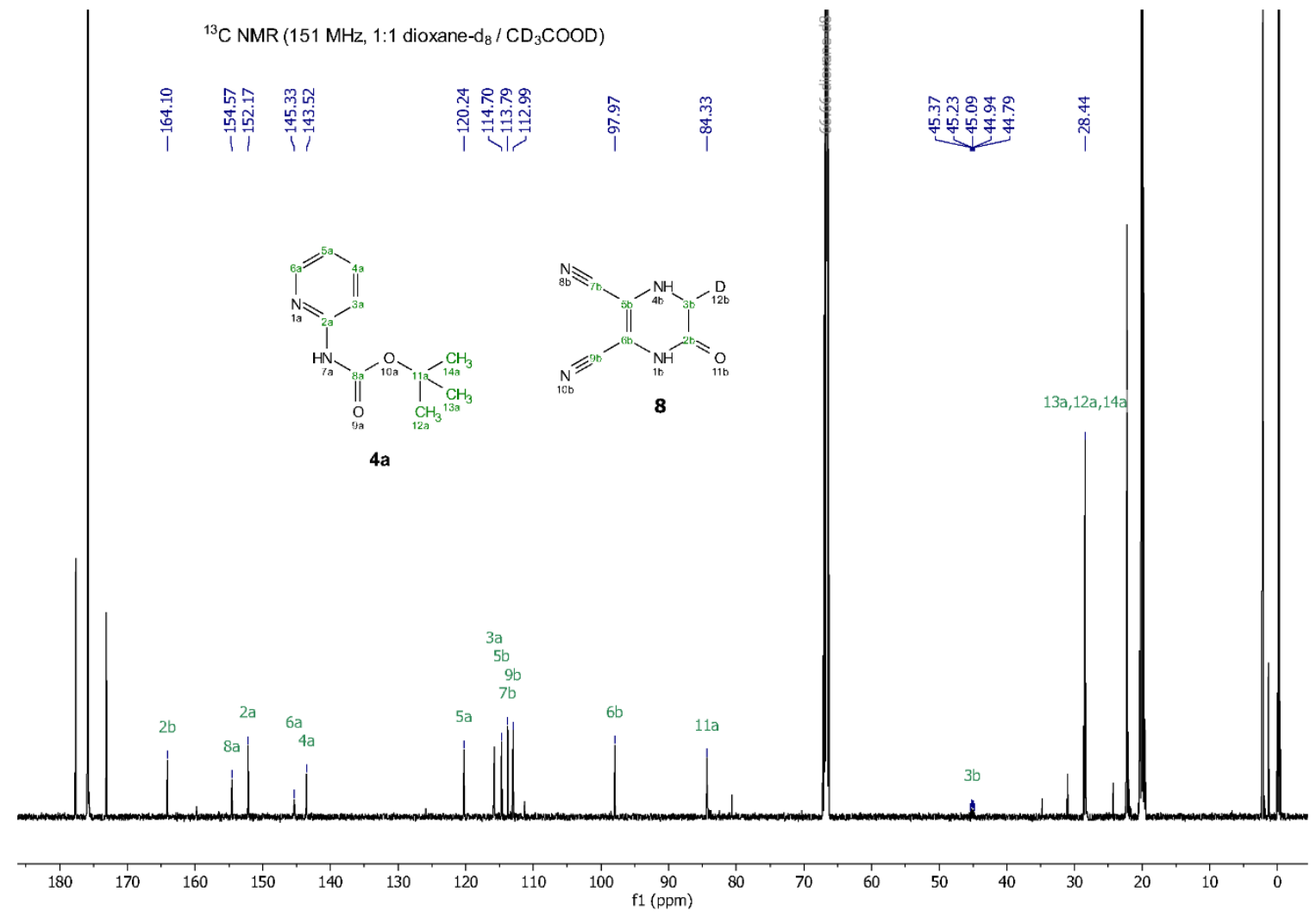


${ }^{1} \mathrm{H} /{ }^{1} \mathrm{H}$ COSY NMR $\left(600 / 600 \mathrm{MHz}, 1: 1\right.$ dioxane-d $\left./ \mathrm{CD}_{3} \mathrm{COOD}\right)$

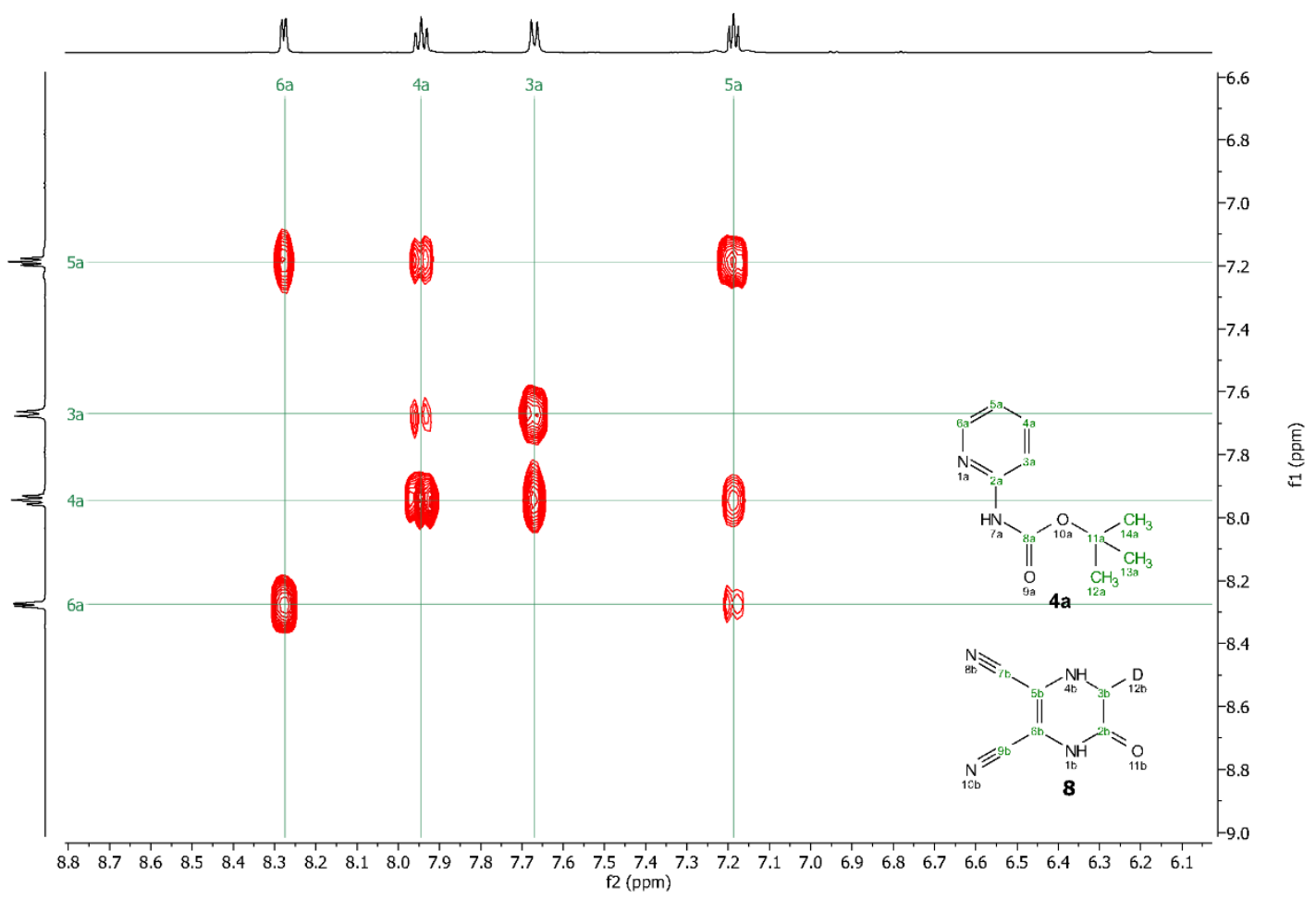

${ }^{1} \mathrm{H} /{ }^{13} \mathrm{C}$ HSQC NMR $\left(600 / 151 \mathrm{MHz}, 1: 1\right.$ dioxane- $\left.\mathrm{d}_{8} / \mathrm{CD}_{3} \mathrm{COOD}\right)$

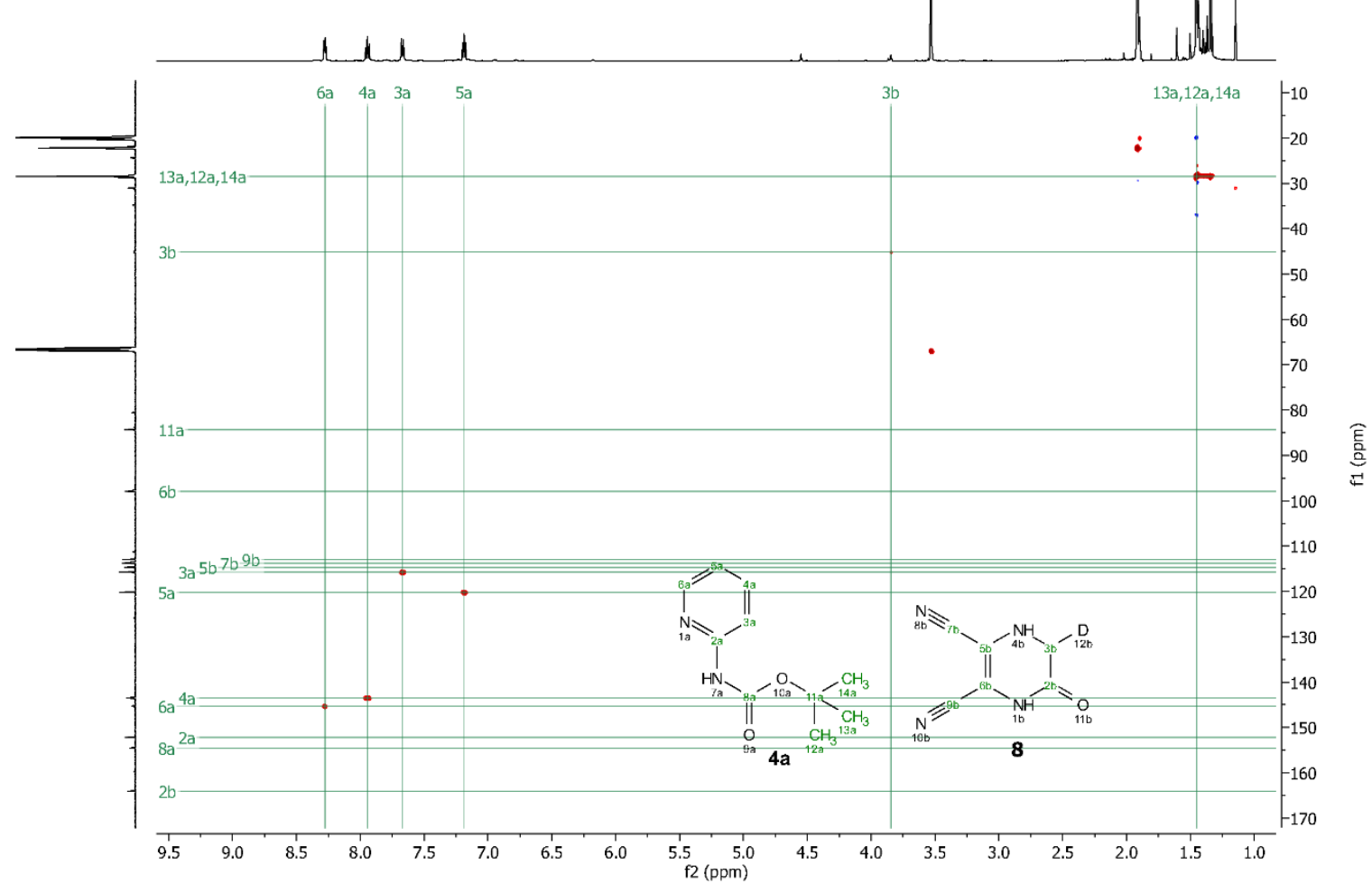


${ }^{1} \mathrm{H} /{ }^{13} \mathrm{C}$ HMBC NMR $\left(600 / 151 \mathrm{MHz}, 1: 1\right.$ dioxane- $\left.\mathrm{d}_{8} / \mathrm{CD}_{3} \mathrm{COOD}\right)$

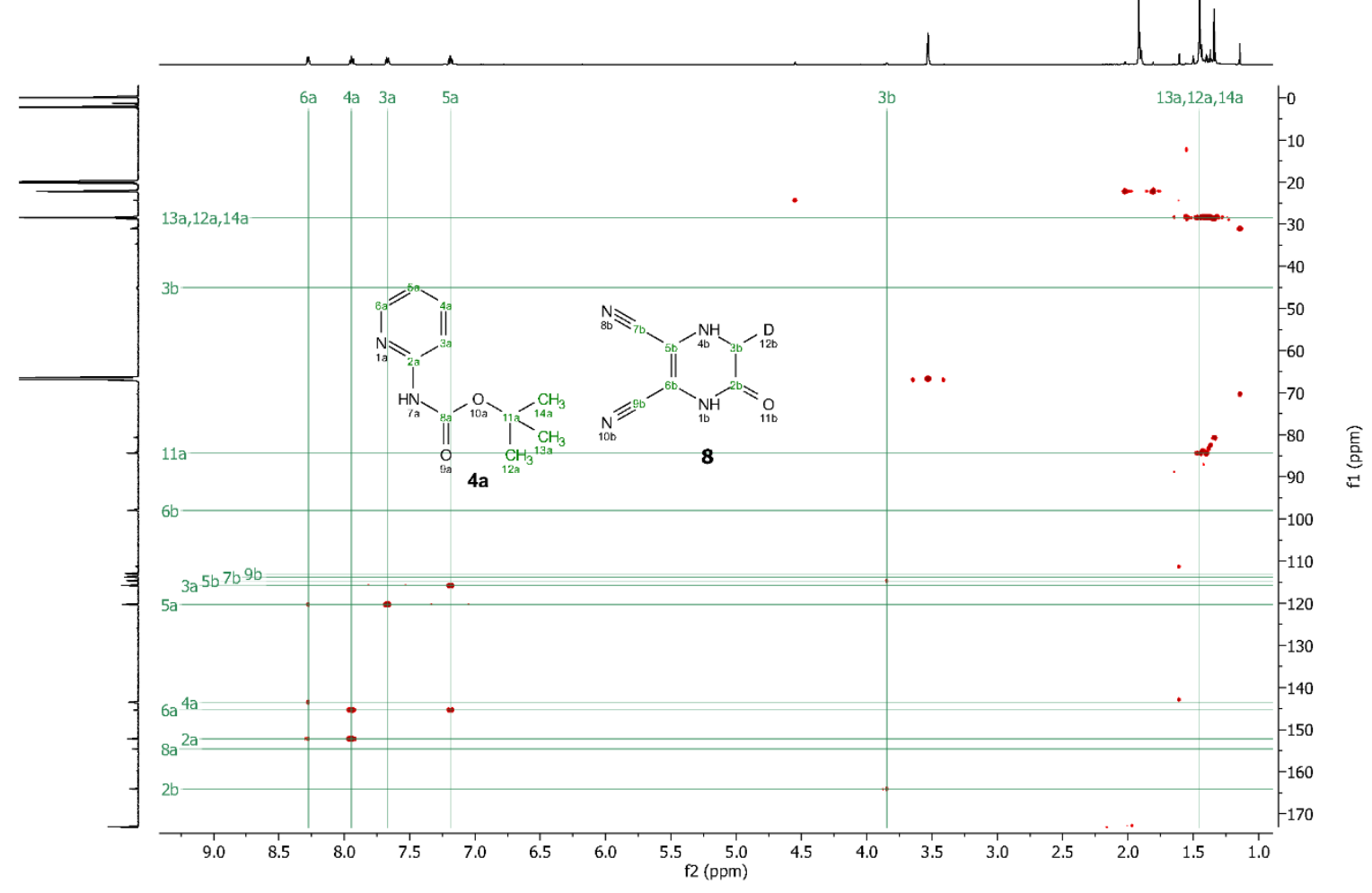

${ }^{1} \mathrm{H} /{ }^{13} \mathrm{C}$ LR-HSQMBC NMR (600/151 MHz, 1:1 dioxane-d $\left.\mathrm{d}_{8} / \mathrm{CD}_{3} \mathrm{COOD}\right)$

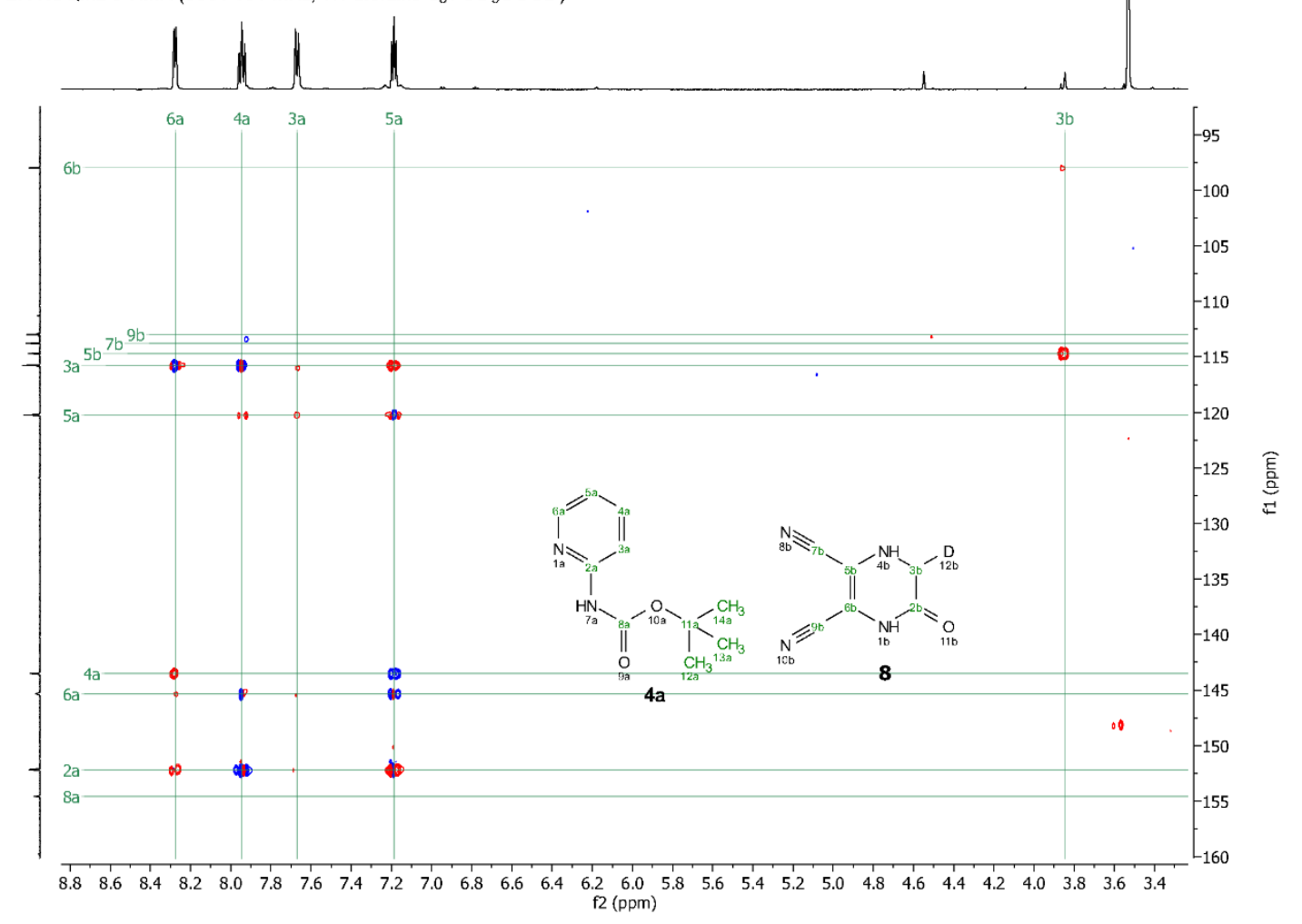

